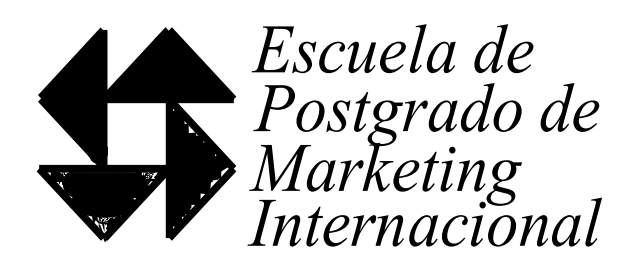

\title{
Evaluación de prefactibilidad de exportación compartida entre PyMES productoras de arándano orgánico, de los países de Argentina y Chile, hacia el mercado hortofrutícola de Hong Kong, China.
}

Trabajo Científico libre para la obtención del grado de Magister en Marketing Internacional de la Escuela de Postgrado de Marketing Internacional -Facultad de Ciencias Económicas

- Universidad Nacional de La Plata -

Profesor Director de Tesis: Mg. Aimara Gisela Caringi
Presentado por: Christopher Vivanco Barra Calle 64, numero 820 La Plata, Argentina.

Fecha de entrega: 15-11-2018 
En especial a mis padres Genoveva Barra y Marco Vivanco, a mis hermanos Marco y Pietro, a toda mi familia.

Quiero agradecer a la Escuela de Posgrado en Marketing Internacional (EPMI) de la Facultad de Ciencias Económicas de la Universidad Nacional de La Plata por el apoyo brindado, siendo sus miembros el Dr. Rogelio Simonato (director EPMI), Cra. Liesel Bischoff cruciales para el desarrollo de mis estudios. A la directora del presente trabajo la Lic. Mg Aimara Gisela Caringi, por su compromiso, guía y consejo.

En Argentina, a mis compañeros de Maestría, en especial a Ellien Rico y Diego Ribba, a mis profesores, al Gobierno de Argentina en especial al Ministerio de Agroindustria, al Servicio Nacional de Sanidad y Calidad Agroalimentaria (SENASA), al Instituto Nacional de Tecnología Agropecuaria (INTA) y a la Cámara de Comercio Argentina para Asia y el Pacífico; al Ing. Agr. Juan Carlos Ramírez Coordinador de producciones Ecológicas SENASA y al Ing. Agr. Pedro Landa Director Técnico de la Organización Internacional Agropecuaria (OIA) y Presidente del Movimiento Argentino para la Producción Orgánica (MAPO).

En Chile, a Cristian Hormazábal, Karin Ramírez y Aldo Pereira, por su constante apoyo, cariño y amistad, al Gobierno de Chile en especial al Ministerio de Agricultura, al Servicio Agrícola Ganadero (SAG), al Ministerio de Relaciones Exteriores, a la Oficina de Estudios y Políticas Agrarias (ODEPA) y al Departamento de Análisis de Mercado y Política Sectorial (DAMPS); al Ing. Agr. Claudio Cárdenas Catalá Jefe Subdepto Agricultura Orgánica SAG-División Protección Recursos Naturales Renovables y a la Ing. Agr. M Sc. Pilar Eguillor Recabarren Encargada Agricultura Orgánica ODEPA.

Y a todas las demás personas que contribuyeron de una forma u otra en la realización del presente trabajo. 
INDICE DE CONTENIDO

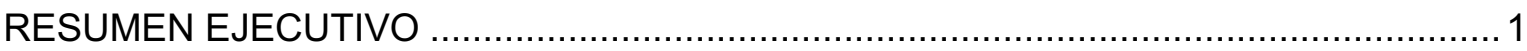

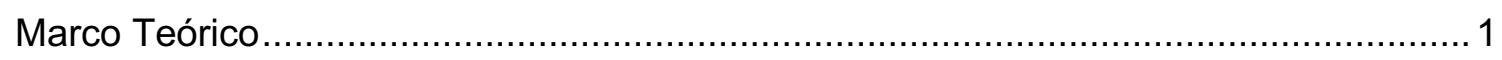

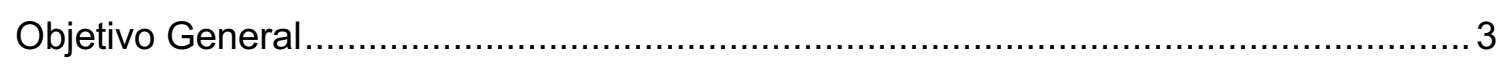

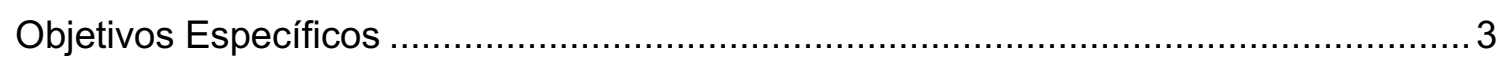

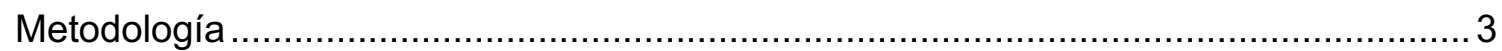

1 CAPITULO I: INTRODUCCIÓN AL ARÁNDANO ORGÁNICO ................................ 5

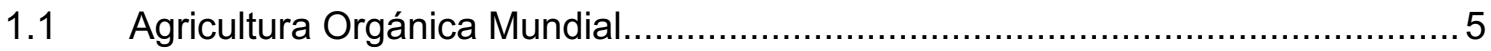

1.1.1 Escenario de la Agricultura Orgánica Mundial ............................................. 5

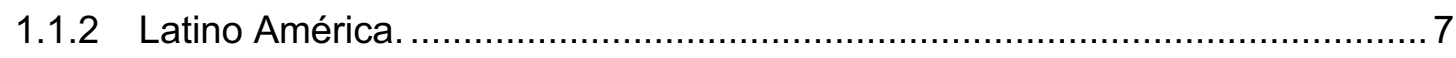

1.1.3 Principales Demandantes Mundiales..................................................... 8

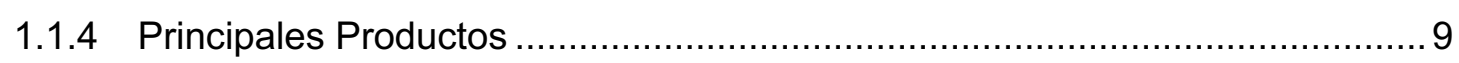

1.2 Introducción al Producto Arándano. ........................................................ 11

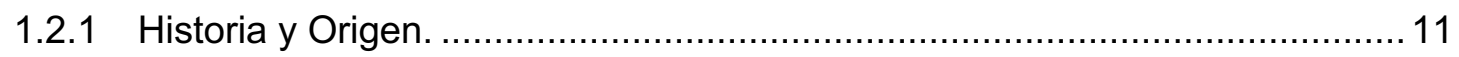

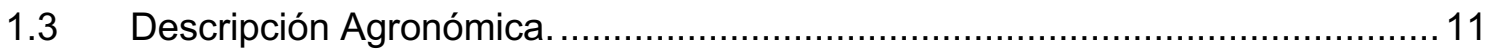

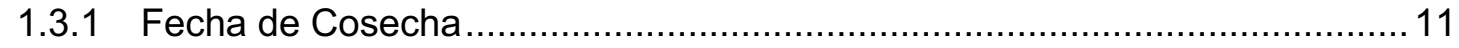

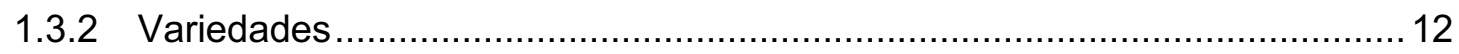

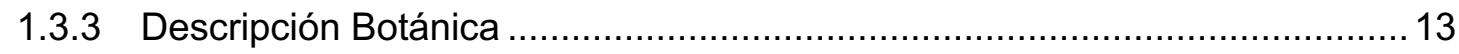

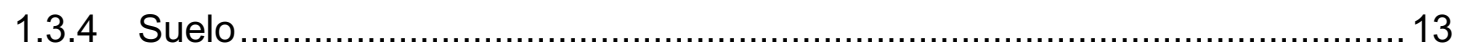

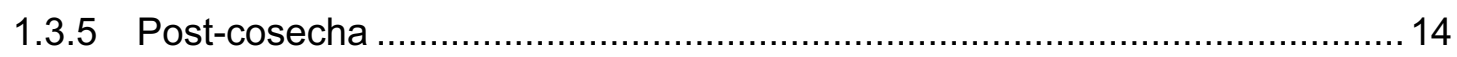

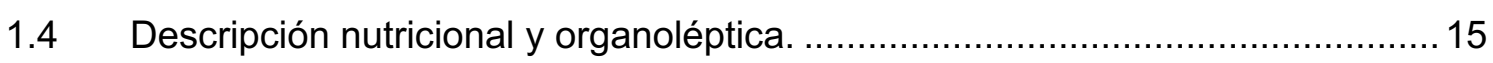

1.5 Certificación Producción Orgánica............................................................... 16

2 CAPITULO II: SITUACIÓN DE LA AGRICULTURA ORGÁNICA EN ARGENTINA Y CHILE CON SESGO EN ARÁNDANO ORGÁNICO DE CONSUMO FRESCO EN EL MERCADO EXPORTACIÓN HORTOFRUTÍCOLA; Y LA SITUACIÓN DE DEMANDA EN LA REGIÓN ADMINISTRATIVA ESPECIAL DE HONG KONG, DE LA REPÚBLICA

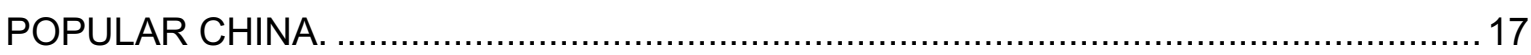

2.1 Situación de Argentina en la Producción Orgánica nacional y específica del arándano de consumo fresco de exportación. ............................................................. 17

2.1.1 Situación Argentina, Productos Orgánicos. ............................................... 17

2.1.2 Producción de Arándano Orgánico para exportación...................................19

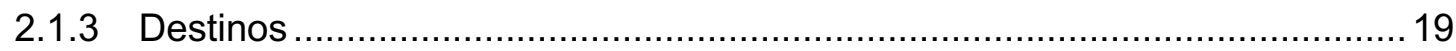

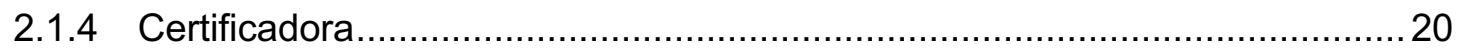

2.2 Situación de Chile en la Producción Orgánica nacional y específica del arándano de consumo fresco de exportación. ........................................................... 20

2.2.1 Situación Chile, Productos Orgánicos. .................................................... 20 
2.2.2 Producción de Arándano Orgánico para exportación...................................22

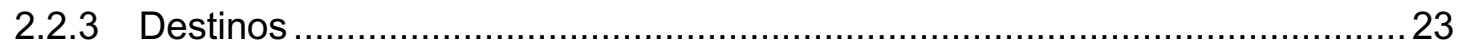

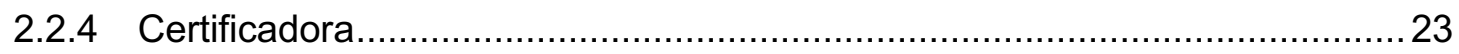

2.3 Mercado demandante de la región administrativa especial de Hong Kong, de la República Popular China.................................................................................... 24

2.3.1 Situación de escenario Orgánico en China 2015......................................2 24

2.3.2 Producción interna de arándano chino ...................................................... 24

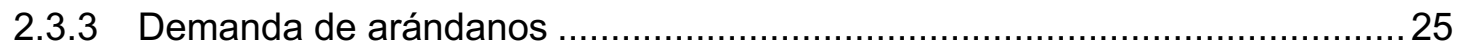

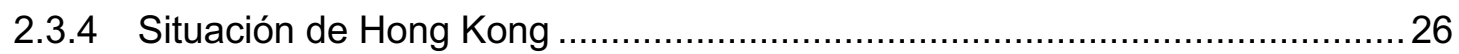

3 CAPITULO III: SITUACIÓN DEL ESCENARIO EXTERNO DEL MERCADO HORTOFRUTÍCOLA EN ARGENTINA, CHILE Y EN LA REGIÓN ADMINISTRATIVA ESPECIAL HONG KONG, DE LA REPÚBLICA POPULAR CHINA .............................. 28

3.1 Escenario Externo Mercado Hortofrutícola en Argentina ................................. 28

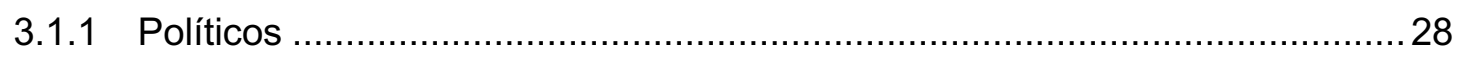

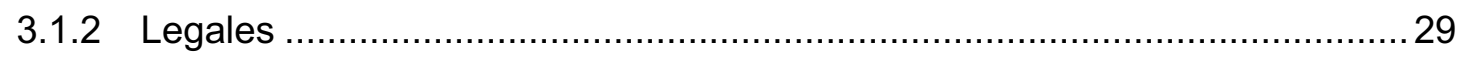

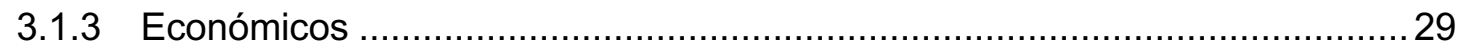

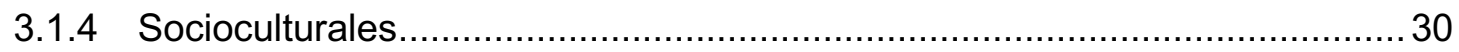

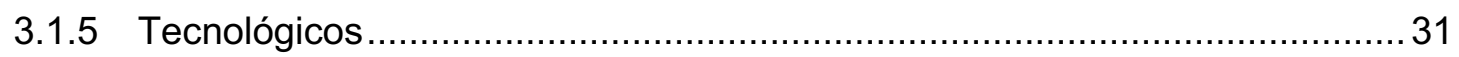

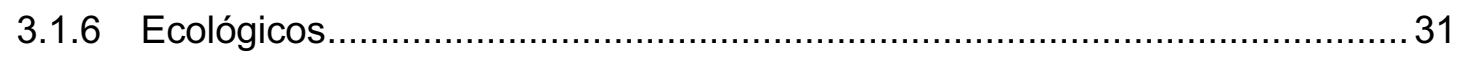

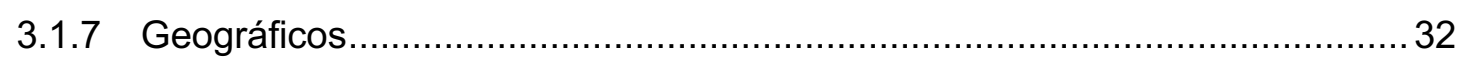

3.2 Escenario Externo Mercado Hortofrutícola en Chile.......................................... 32

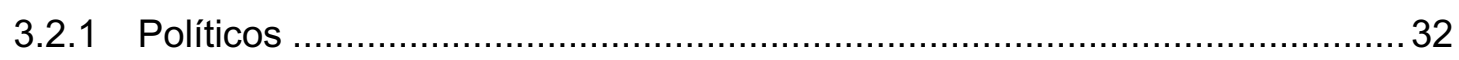

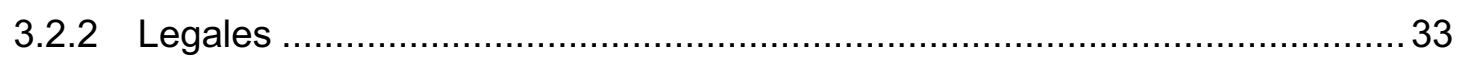

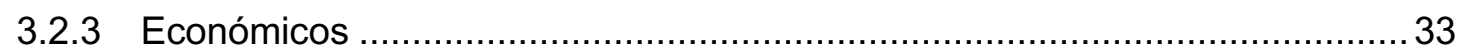

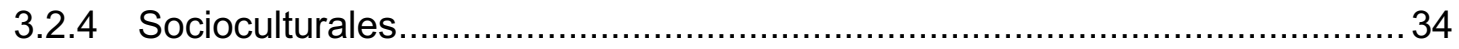

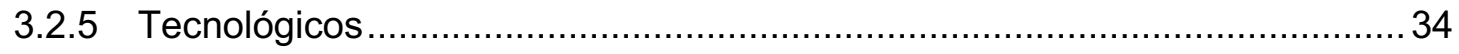

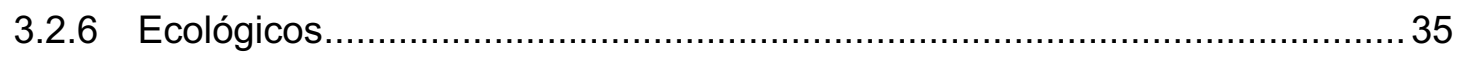

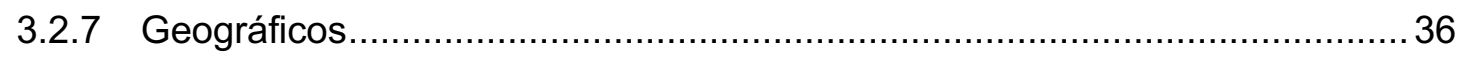

3.3 Escenario Externo Mercado Hortofrutícola en Hong Kong, China ..................... 36

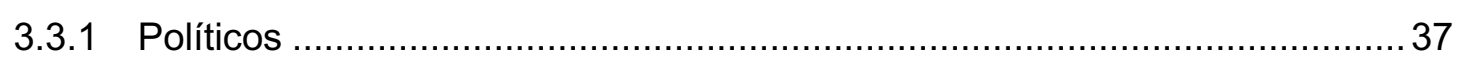

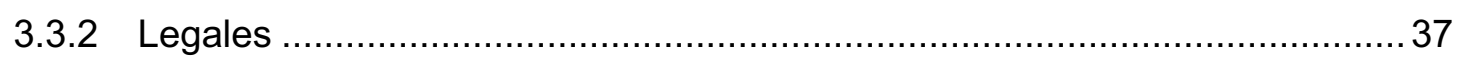

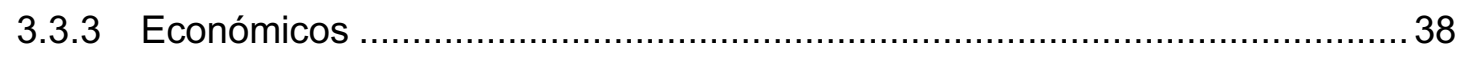

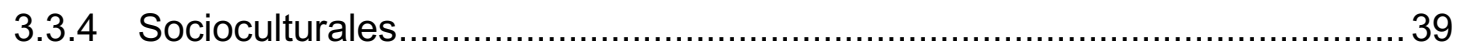

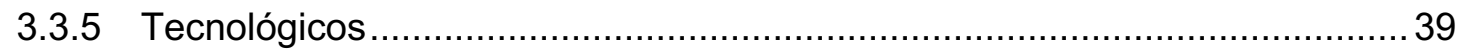

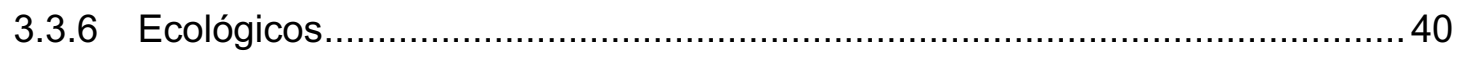

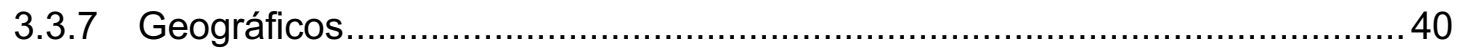


4 CAPITULO IV: SITUACIÓN DE RELACIONES COMERCIALES DEL MERCADO HORTOFRUTÍCOLA ORGÁNICO ENTRE ARGENTINA-CHILE, ARGENTINA-HONG KONG, CHINA Y CHILE-HONG KONG, CHINA.

4.1 Relaciones Comerciales del Mercado Hortofrutícola Orgánico entre Argentina y Chile

4.1.1 Relación bilateral Argentina-Chile .................................................. 41

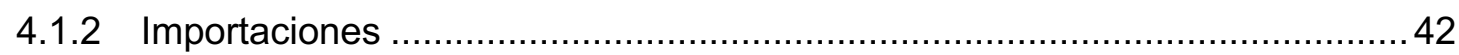

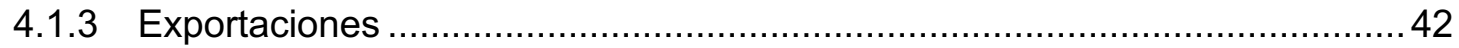

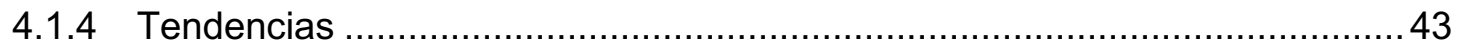

4.2 Relaciones Comerciales del Mercado Hortofrutícola Orgánico entre Argentina y la región administrativa especial de Hong Kong, de la República Popular China .........43

4.2.1 Relación bilateral Argentina-Hong Kong.................................................43

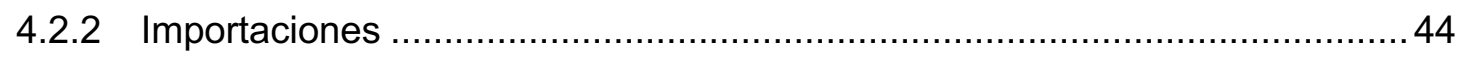

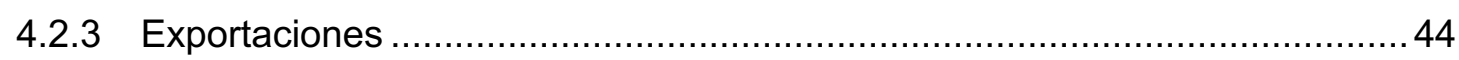

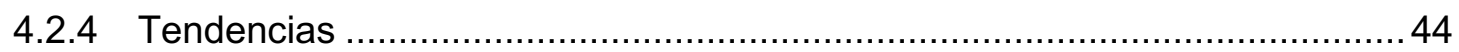

4.3 Relaciones Comerciales del Mercado Hortofrutícola Orgánico entre Chile y la Región Administrativa Especial de Hong Kong, de la República Popular China ..........45

4.3.1 Relación bilateral Chile-Hong Kong ...................................................... 45

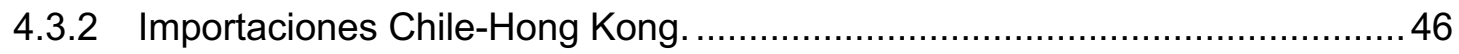

4.3.3 Exportaciones Chile-Hong Kong........................................................... 46

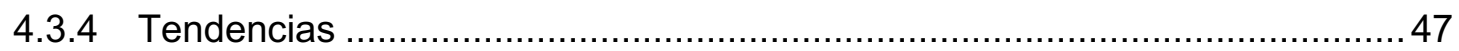

4.4 Requerimientos para exportar arándanos orgánicos a Hong Kong, China .......47

4.4.1 Código Sistema Armonizado de Hong Kong (HKHS) .................................47

4.4.2 Aranceles de internación para producto y otras barreras .............................47

4.4.3 Regulaciones y normativas de importación ............................................. 48

4.4.4 Certificaciones orgánicas: legislación y requerimientos locales ....................48

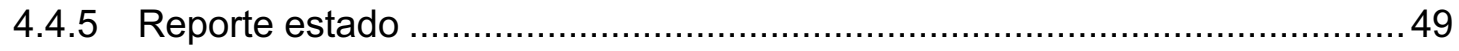

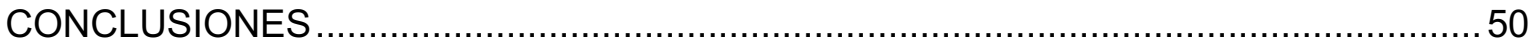

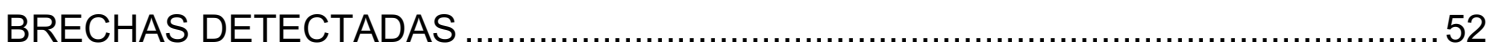

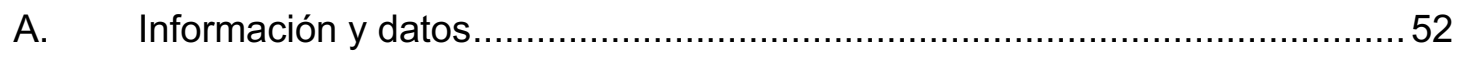

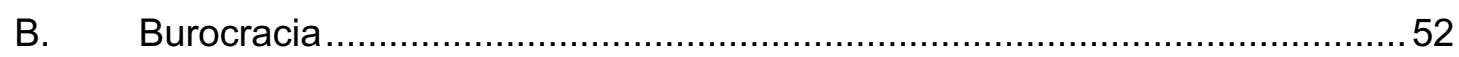

C. Capacidad de exportación de las Pymes.................................................52

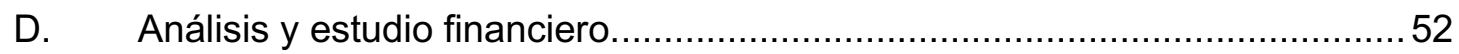

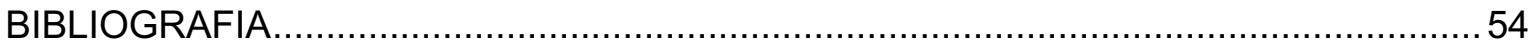

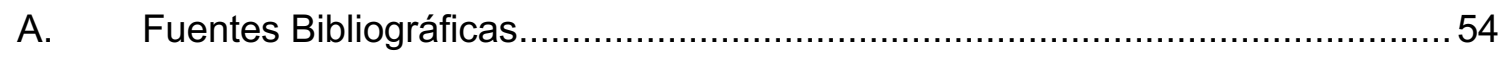

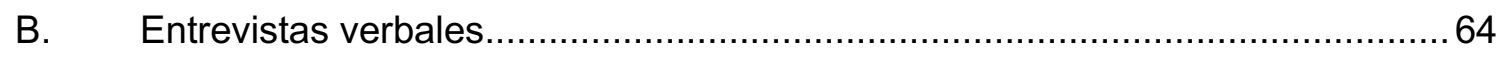

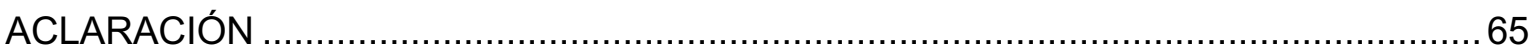


INDICE DE GRÁFICOS

Gráfico 1: Crecimiento de terrenos destinados a la Agricultura Orgánica Mundial desde el 1999 hasta el 2013.

Gráfico 2: Distribución de las tierras destinadas a la agricultura orgánica por regiones en el 2013.

Gráfico 3: Distribución de las categorías de uso de suelo orgánico a nivel mundial año 2014 9

Gráfico 4: Hectáreas de uso Orgánico en La Argentina 2010-1014 18

Gráfico 5: Hectáreas de uso Orgánico en Chile 2011-2015

\section{INDICE DE TABLAS}

Tabla 1: Países líderes en Mercado Orgánico Mundial en Mil Millones de Euro (MM de $€$ ) y Mil Millones de Dólares (MM de US\$)

Tabla 2: Desarrollo de tierras destinadas a cultivos permanentes y cultivos arables, desde el 2004 al 2013 10

Tabla 3: Nombre Científico y común de variedades de Arándanos. 12

Tabla 4: Información nutricional de 100 gramos de Arándano fresco. 15

Tabla 5: Productos Orgánicos (kg) Argentinos, de Origen Vegetal Certificados con destino a la exportación, durante el año 2014. 19

Tabla 6 Detalle de países destinos de Arándano Orgánico Argentino certificado, durante el año 2014

Tabla 7: Superficie destinada en Chile de los principales productos organicos 2014-2015

Tabla 8: Detalle de volúmenes exportados y Principales países destinos de Arándano Orgánico Chile certificado, durante el año 2015 23 
RESUMEN EJECUTIVO

\section{Marco Teórico}

La producción agrícola afecta, directa e indirectamente, al medio ambiente ${ }^{1}$ y a la misma producción de forma negativa ${ }^{2}$. Este impacto a nivel mundial está tomando mayor importancia, generando conciencia y legislaciones, esto se ve reflejado en los requisitos y estándares de importaciones que exigen los principales mercados internacionales, como en los planes de organizaciones gubernamentales e intergubernamentales ${ }^{3}$.

La producción agrícola ya no solamente tiene que generar alimentos, sino proveer de alimentos saludables ${ }^{4}$, de producción sostenibles en el tiempo y constar con prácticas agrarias responsables con el ecosistema ${ }^{5}$.

La producción agrícola orgánica es una respuesta positiva ante esta necesidad, de producción de alimentos saludables y ecológicos; ya que buscar una alimentación segura e inocua para la salud en personas, promoviendo el cuidado del medio ambiente y uso eficiente de recursos; conteniendo también un enfoque social, ligado a toda la cadena de producción y comercialización ${ }^{6}$.

La situación mundial de la producción orgánica ha presentado un crecimiento importante de superficie y de países que promueven, adoptan y reglamentan oficialmente este tipo de manejo ${ }^{7}$; existiendo más de 37 millones de hectáreas certificadas como orgánicas, la mayoría de estas en Oceanía $(32,7 \%)$, Europa $(27,1 \%)$ y América Latina $(22,7 \%)$; siendo cultivadas, principalmente, por pequeños y medianos productores rurales.

En Asia, a su vez, existen 2,8 millones de hectáreas certificada, 7,6\% de la participación mundial, dato que contrasta fuertemente con el número de sus habitantes,

\footnotetext{
1 Oesterbheld, M. (2008). Impacto de la agricultura sobre los ecosistemas [PDF]. Ecología Austral(18), 337-346. Obtenido de http://www.scielo.org.ar/pdf/ecoaus/v18n3/v18n3a07.pdf. Recuperado: 25 de mayo del 2015

2 Schmidt-Hebbel, H. (1986). Toxicos quimicos en alimentos [PDF] (Fundación Chile ed.). Santiago: Universitaria. Obtenido de http://mazinger.sisib.uchile.cl/repositorio/lb/ciencias quimicas_y farmaceuticas/schmidth09/schmidth09.pdf. Recuperado: 25 de mayo del 2015

3 Souza Brito, P. (2014). Exitosas políticas públicas reducen el impacto de la agricultura sobre el medio ambiente. Obtenido de http://www.fao.org/americas/noticias/ver/es/c/230491/. Recuperado: 25 de mayo del 2015

4 U.S. Food and Drug Administration [FDA]. (2013). COMUNICADO DE PRENSA DE LA FDA. Obtenido de La FDA propone nuevas normas de seguridad alimentaria para la prevención de enfermedades transmitidas por alimentos y la inocuidad de los productos agrícolas: http://www.fda.gov/newsevents/newsroom/pressannouncements/ucm334188.htm. Recuperado: 28 de mayo del 2015

5 Food and Agriculture Organization of the United Nations [FAO]. (2007). COMITÉ DE AGRICULTURA. Obtenido de EL MEDIO AMBIENTE Y LA AGRICULTURA [PDF]: ftp://ftp.fao.org/docrep/fao/meeting/011/j9289s.pdf. Recuperado:18 de mayo del 2015.

6 Rearch Institute of Organic Agriculture. (2014). Sustainability and quality of organic food [PDF]. Obtenido de https://www.fibl.org/fileadmin/documents/shop/1413-organic-products.pdf. Recuperado: 25 de mayo del 2015

7 Food and Agriculture Organization of the United Nations [FAO]. (2014). POLÍTICAS AGROAMBIENTALES [PDF]. Obtenido de http://www.fao.org/docrep/019/i3523s/i3523s.pdf. Recuperado:14 de septiembre del 2018.
} 
los cuales son más del $60 \%$ de la población global. Según ProChile $(2013)^{8}$, el consumo de productos orgánicos es incipiente en Asia, pero dado a la tendencia, se observa que se comienza a desarrollar rápidamente, constituyéndose en un segmento de producto con gran potencial, especialmente en China e India.

La situación orgánica de Argentina indica que los principales destinos de los productos son EEUU y la Unión Europea; observando un crecimiento constante desde hace más de 4 años ${ }^{9}$. En Chile, figura también como principal país destino EEUU, destacando las exportaciones de fruta frescas y vinos; así como también el estable y sólido crecimiento económico ${ }^{10}$.

Dentro de las principales frutas orgánicas de consumo fresco de exportación se encuentra el arándano (Vaccinium sp), ocupando el segundo lugar en Chile, en el año 2013 con 5.320 toneladas; y en Argentina ocupa el tercer lugar, en el año 2014 con 223 toneladas de exportación.

Chile, a partir de su apertura comercial de más de 30 años $^{11}$, ha firmado acuerdos estratégicos de libre comercio con diferentes países, regiones y bloques destinos. En el año 2012, firmó el acuerdo "TLC: Chile-Hong Kong, China ${ }^{12 ", ~ e l ~ c u a l ~ e s t i m u l a ~}$ directamente al mercado hortofrutícola oferente chileno de fruta fresca ${ }^{13}$. Por su parte, Argentina no cuenta con una apertura comercial tan extensa, lo que se observa por su política comercial internacional y puntualmente por no poseer exportaciones de arándano orgánico de consumo fresco a ningún mercado oferente hortofrutícola en Asia.

Esta investigación buscó analizar y establecer si existe viabilidad de exportaciones compartida de arándanos orgánicos, de pequeños y medianos productores-exportadores rurales de los países de Argentina y Chile, hacia el mercado de exportación hortofrutícola de Hong Kong, China.

8 Gobierno de Chile, Oficina Comercial de ProChile en R.P. China - Beijing. (2013). Tendencias del Mercado: Alimentos Orgánicos en la R. P. China. Obtenido de http://www.prochile.gob.cl/wpcontent/blogs.dir/1/files_mf/1367963128China_Tendencias_Organicos_2013_Beijing.pdf. Recuperado: 25 de mayo del 2015

9 Gobierno de Argentina, Dirección Nacional de Inocuidad y Calidad Agroalimentaria. (2016). Coordinación de productos Ecológicos. Situación de la Producción Orgánica en la Argentina durante el Año 2015. Obtenido de http://www.senasa.gob.ar/sites/default/files/ARBOL_SENASA/INFORMACION/PROD_ORGANICA/517informe_estadstico_2015.pdf. Recuperado: 6 de enero del 2016

10 Gobierno de Chile, Ministerio de Agricultura. (2013). Agricultura Orgánica Nacional: Bases Técnicas y Situación Actual [PDF]. Obtenido de http://www.sag.cl/sites/default/files/agricultura_org._nacional_bases_tecnicas_y_situacion_actual_2013.pdf. Recuperado: 25 de mayo del 2015

11 Gobierno de Chile, Dirección General de Relaciones Económicas Internacionales. (2009). Chile: 20 Años de Negociaciones Comerciales. Obtenido de http://www.direcon.gob.cl/wp-content/uploads/2013/09/Chile-20a\%C3\%B1os-de-negociaciones-comerciales1.pdf. Recuperado: 25 de mayo del 2015.

12 Gobierno de Chile, Servicio Nacional de Adunas. (2012). Tratado de Libre Comercio Chile - Hong Kong. Obtenido de https://www.aduana.cl/aduana/site/artic/20141204/asocfile/20141204120610/o_c_n__358_28_11_14_instr_tlc chile hong kong.pdf. Recuperado: 25 de mayo del 2015

13 Gobierño de Chile, Dirección General de Relaciones Económicas Internacionales. (2014). Chile-Hong Kong SAR. Obtenido de http://www.direcon.gob.cl/wp-content/uploads/2014/12/Hong-Kong-SARoctubre2014.pdf. Recuperado: 25 de mayo del 2015 
Objetivo General

Estimar viabilidad de exportación compartida, de pequeñas y medianas empresas productoras-exportadoras rurales de arándanos orgánicos asentadas en los países de Argentina y Chile, hacia el mercado hortofrutícola de la región administrativa especial de Hong Kong, de la República Popular China.

\section{Objetivos Específicos}

A. Analizar la situación del arándano orgánico de consumo fresco en el mercado de exportación hortofrutícola de Argentina y Chile; y la situación de mercado de demanda hortofrutícola en Hong Kong, China.

B. Determinar la situación de escenario externo del mercado del hortofrutícola en Argentina, Chile y en la región administrativa especial Hong Kong, China; con énfasis en el arándano orgánico de consumo fresco.

C. Describir la situación de relaciones comerciales del mercado hortofrutícola de arándano orgánico de consumo fresco entre Argentina-Chile, Argentina-Hong Kong, China y de Chile-Hong Kong, China.

\section{Metodología}

Para realizar esta investigación de carácter exploratorio, se utilizaron fuentes primarias y secundarias. Las fuentes primarias fueron adquiridas por medio de entrevistas personales con expertos; y las fuentes secundarias fueron obtenidas desde sitios web gubernamentales, intergubernamentales y web de organizaciones que aborden los temas principales de esta investigación.

Las entrevistas fueron realizadas principalmente en forma presencial y otras realizadas por Skype, dado que por gestión, tiempo o distancia no se podrían coordinar personalmente. La búsqueda de los expertos estuvo organizada bajo la siguiente clasificación: expertos que trabajen en organismos gubernamentales de control y de investigación en la producción orgánica, seguido por docentes universitarios y otros expertos vinculados a los temas de esta investigación, terminando con productoresexportadores de arándano orgánico; en donde se contactó con pares homólogos argentinos y chilenos.

Por medio de análisis y relaciones de las fuentes ya nombradas se determino la viabilidad de exportación compartida entre PyMES productoras de arándanos orgánico, de los países de Argentina y Chile, hacia el mercado hortofrutícola de Hong Kong, China. 
La inclusión de las entrevistas con expertos busco obtener de primera fuente la situación, en la cuales diferentes gobiernos, instituciones y productores; trabajan, abordan, controlan y estudian los temas ejes de esta investigación. La elección se basó en un análisis multinivel, en donde el orden se estableció desde lo macro (instituciones de gobierno) a lo micro (el productor de arándano orgánico); considerando también expertos académicos y de la industria privada.

Para Argentina se entrevistó al/a la: Ingeniero Agrónomo Juan Carlos Ramírez, Coordinador de producciones Ecológicas del Servicio Nacional de Sanidad y Calidad Agroalimentaria (SENASA); Licenciado Martin M. Lo coco, Director Executivo de la Cámara de comercio Argentina para el Asia y el Pacifico; Ingeniero Agrónomo Guillermo Hang, Director del Departamento de Desarrollo Rural de la Facultad de Ciencias Agrarias y Forestales, Universidad Nacional de La Plata; Ingeniera Agrónoma Gabriela Morelli, profesora experta en frutales no tradicionales y producciones orgánicas de la Facultad de Ciencias Agrarias y Forestales, Universidad Nacional de La Plata; Ingeniero Agrónomo Pedro Landa, Director técnico de la Organización Internacional Agropecuaria (OIA) y Presidente del Movimiento Argentino para la Producción Orgánica (MAPO); Ingeniera Laura Montenegro, Directora de ARGENCERT; y a los Agricultores y exportadores Alexander Bacco y Laura Montes.

Para Chile se entrevistó al/a la: Ingeniero Agrónomo Claudio Cárdenas Catalán, Jefe Subdepto. Agricultura Orgánica SAG-División Protección Recursos Naturales Renovables; Ingeniera Agrónoma M Sc. Pilar Eguillor Recabarren, Encargada Agricultura Orgánica y Denominaciones de Origen/Indicaciones Geográficas - BPAs del Departamento de Análisis de Mercado y Política Sectorial; Ingeniera Agrónoma M Sc. Susana Ursina Fischer Ganzoni, Director Departamento Producción Vegetal de la Facultad de Agronomía, Universidad de Concepción; Ingeniero Agrónomo Humberto Serri, Docente especialista en Berry, Facultad de Agronomía, Universidad de Concepción; Ingeniera Agrónoma Sigrid Vargas Schuldes, Coordinadora oficina Pemehue del Instituto Nacional de Investigación Agropecuaria (INIA); y a la Agricultora y exportadora María Ferrera 


\section{CAPITULO I: INTRODUCCIÓN AL ARÁNDANO ORGÁNICO}

Este capítulo entrega una introducción sobre el arándano orgánico, el cual es eje de esta investigación, para tal efecto se describen las principales áreas que este producto vincula. Una de las aristas más importantes tiene relación con la agricultura orgánica en aspectos mundiales (desarrollo, descripción y estado actual), así mismo el desarrollo de la historia de este producto de origen vegetal y sus tendencias de consumo.

Además, en este capítulo se entrega toda la descripción básica agronómica, nutricional y organoléptica; para integrar y otorgar un panorama general completo.

\subsection{Agricultura Orgánica Mundial.}

Los productos orgánicos siempre han existido en la alimentación humana, fue durante la "revolución verde", entre los años 1940-1970, que estos dejaron de ser consumidos de forma habitual, siendo reemplazados por productos cultivados de forma intensiva e industrial, los cuales tenían mejores rendimientos -productivos y económicos-, apoyados por la genética seleccionada, en el riego, en el uso de altas dosis de fertilizantes, hormonas vegetales y pesticidas.

Durante los siguientes 20 años posteriores de la "revolución verde", el consumo de productos orgánicos fue decreciendo exponencialmente; durante este periodo también se realizaron diversos estudios que comenzaron a vincular la toxicidad de pesticidas a la salud humana ${ }^{14}$, en especial con la fertilidad y desarrollo embrionario de los fetos en las poblaciones rurales carenciales.

En el año 1999, la Organización de las Naciones para la Alimentación y Agricultura (FAO), ante los antecedentes recopilados, crea un programa de largo plazo, con tres pilares fundamentales: Seguridad Alimentaria, Desarrollo Rural e Integridad del Medio Ambiente ${ }^{15} ; \mathrm{y}$ es desde este entonces que la agricultura orgánica comienza a renacer como tal.

\subsubsection{Escenario de la Agricultura Orgánica Mundial}

\footnotetext{
14 Leke I, R. J., Oduma, J. A., Bassol-Mayagoitia, S., \& Bacha, A. M. (1993). Regional and Geographical Variations in and Socioeconomic Factors and Socioeconomic Factors. Environmental Health Perspectives Supplements, 101 (Suppl. 2), 73-80. Obtenido de http://www.ncbi.nlm.nih.gov/pmc/articles/PMC1519926/pdf/envhper003790077.pdf. Recuperado: 15 de octubre del 2015

15 Food and Agriculture Organization of the United Nations [FAO]. (2015). Organic Agriculture. Obtenido de http://www.fao.org/organicag/oa-home/en/. Recuperado:18 de mayo del 2016.
} 
La mayoría de los registros sobre la agricultura orgánica, en el momento de esta investigación (año 2015), nacen a partir del año 1999, encontrando la mayoría de los informes técnicos actualizados al 2013; obteniendo información de fuente directa en Argentina (SENASA) del año $2014^{16}$ y de Chile (SAG) para el $2015^{17}$.

Según los registros mundiales al 2013, ya son 170 países los cuales adoptan políticas y legislaciones sobre la producción orgánica, seis más que el año anterior. No solamente se incrementaron los países que se inclina hacia esta propuesta de producción sino también hay un aumento en las hectáreas (há) producidas, las cuales son más de 43,1 millones; si se considera desde el inicio de los registros oficiales de la FAO en el año 1999, ha presentado un aumento de $291,81 \%$, de los iniciales 11 millones de hectáreas ${ }^{18}$. Información que contrasta fuertemente con la porción total de las tierras destinadas a la agricultura orgánica que es del $0,98 \%$ en relación al total de tierras cultivadas mundialmente ${ }^{19}$.

Gráfico 1: Crecimiento de terrenos destinados a la Agricultura Orgánica Mundial desde el 1999 hasta el 2013.

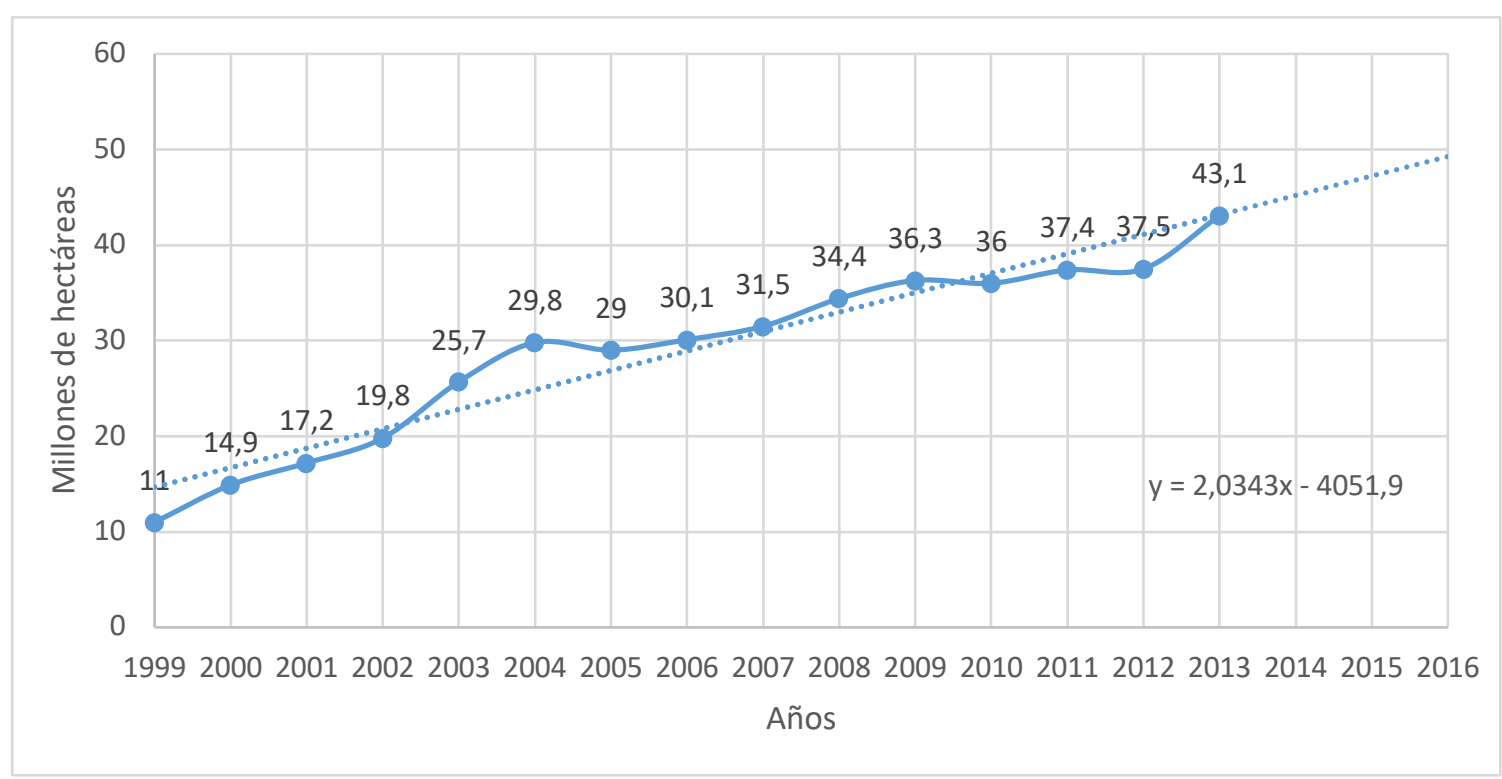

Nota. Elaboración propia en base a datos obtenidos en FiBL \& IFOAM ${ }^{20} 2015$.

16 Ramírez, J. C. (17 de julio de 2015). Situación de la Agricultura Orgánica en la Argentina, visión desde SENASA. (C. Vivanco, Entrevistador)

17 Catalán, C. C. (10 de agosto de 2015). Situación de la Agricultura Orgánica en Chile, visión desde SAG. (C. Vivanco, Entrevistador)

18 Willer, H., \& Lernoud, J. (2015). The World of Organic Agriculture 2015: Summary. En FiBL \& IFOAM, The World of Organic Agriculture Statistics \& Emerging Trends 2015 (págs. 24-31). Switzerland: FiBL \& IFOAM.

19 Willer, H., \& Lernoud, J. (2015). Current Statistics on Organic Agriculture Worldwide: Organic Area, Producer, Markets and Selected Crops. En FiBL \& IFOAM, The World of Organic Agriculture Stadistics \& Emerging Trends 2015 (págs. 32-118). Switzerland: FiBL \& IFOAM.

20 Willer, H., \& Lernoud, J. (2015). Current Statistics on Organic Agriculture Worldwide: Organic Area, Producer, Markets and Selected Crops. En FiBL \& IFOAM, The World of Organic Agriculture Stadistics \& Emerging Trends 2015 (págs. 32-118). Switzerland: FiBL \& IFOAM. 
En el gráfico 1, se observan los terrenos destinados a la agricultura orgánica mundial, desde el año 1999 hasta el 2013, teniendo una clara tendencia al crecimiento, con una línea de proyección lineal para el 2016 de casi 50 millones de hectárea.

Los países que lideran por superficie destinada a la producción orgánica son Australia con 17,2 millones de hectáreas, seguido por Argentina con 3,2 millones y en tercer lugar esta Estados Unidos con 2,2 millones de hectáreas (Chile ocupa el puesto 68 con 0,023 millones de hectáreas) ${ }^{21}$.

El número de productores para el año 2011 fueron de 1.8 millones, al 2013 esta cifra aumento a más de 2 millones; siendo un mercado que mueve más de 72 billones de dólares, incremento del $373,7 \%$ con su inicial de 15,2 billones de dólares en $1999^{22}$.

\subsubsection{Latino América.}

Al 2013, en Latino América existían más de 300.000 productores repartidos en 6,6 millones de hectáreas en tierra destinadas a la agricultura o en proceso de conversión orgánica, abarcando el $15 \%$ de la agricultura orgánica a nivel mundial; con un claro perfil a la exportación ${ }^{23}$.

Gráfico 2: Distribución de las tierras destinadas a la agricultura orgánica por regiones en el 2013.

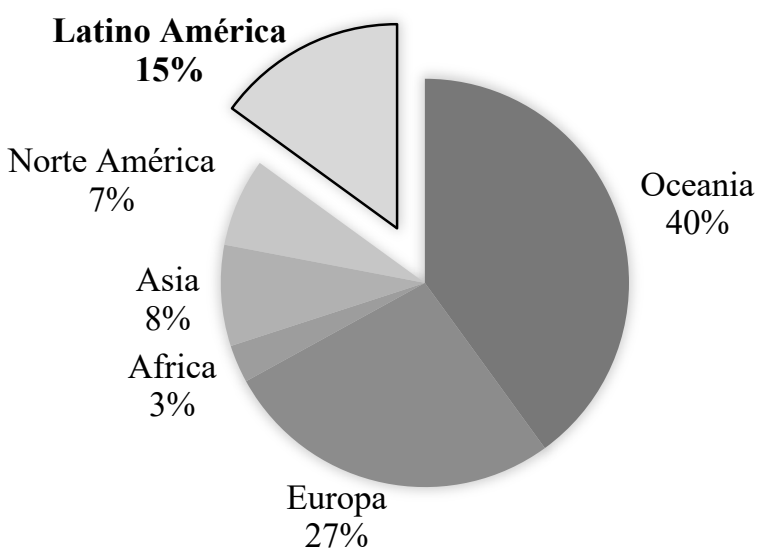

Nota. Elaboración propia en base a datos obtenidos en FiBL \& IFOAM ${ }^{24} 2015$.

21 Willer, H., \& Lernoud, J. (2015). Current Statistics on Organic Agriculture Worldwide: Organic Area, Producer, Markets and Selected Crops. En FiBL \& IFOAM, The World of Organic Agriculture Stadistics \& Emerging Trends 2015 (págs. 32-118). Switzerland: FiBL \& IFOAM.

22 Willer, H., \& Lernoud, J. (2015). Current Statistics on Organic Agriculture Worldwide: Organic Area, Producer, Markets and Selected Crops. En FiBL \& IFOAM, The World of Organic Agriculture Stadistics \& Emerging Trends 2015 (págs. 32-118). Switzerland: FiBL \& IFOAM.

23 Willer, H., \& Lernoud, J. (2015). Current Statistics on Organic Agriculture Worldwide: Organic Area, Producer, Markets and Selected Crops. En FiBL \& IFOAM, The World of Organic Agriculture Stadistics \& Emerging Trends 2015 (págs. 32-118). Switzerland: FiBL \& IFOAM.

24 Willer, H., \& Lernoud, J. (2015). Current Statistics on Organic Agriculture Worldwide: Organic Area, Producer, Markets and Selected Crops. En FiBL \& IFOAM, The World of Organic Agriculture Stadistics \& Emerging Trends 2015 (págs. 32-118). Switzerland: FiBL \& IFOAM. 
Argentina lidera con los terrenos destinados a este tipo de agricultura con un total de más de 3,2 millones de hectáreas, seguidos por Uruguay con 0,9 millones de hectáreas y Brasil 0,7 millones de hectáreas. Siendo Perú destacado en la zona por un alto incremento de hectáreas de conversión y de destino a la producción orgánica, con más de 200.000 hectáreas.

El mercado doméstico de Latino América se desarrolla de forma especializada, encontrando tiendas que venden exclusivamente este tipo de productos, así también empresas de deliveries y restoranes, no siendo un mercado relevante; los principales productos que se comercializan son café, frutas de la estación, vegetales y carnes ${ }^{25}$.

Los gobiernos de Argentina, Brasil, Chile, Perú y México han promovido al sector orgánico nacional con una serie de programas los cuales incluyen beneficios arancelarios, capacitaciones y promociones a la producción; incluyendo una política integradora agendada en sus planes de gobierno ${ }^{26}$.

\subsubsection{Principales Demandantes Mundiales.}

Los países que presentan mercados más importantes sobre la demanda de productos orgánicos son Estados Unidos con 24,3 millones de euros, seguido de Alemania con 7,6 mil millones de euros, Francia con 4,4 mil millones de euros y China con 2,4 mil millones de euros.

Tabla 1: Países líderes en Mercado Orgánico Mundial en Mil Millones de Euros (MM de $€$ ) y Mil Millones de Dólares (MM de US\$)

$\begin{array}{lll}\text { País } & \text { MM de } € & \text { MM de US } \mathbf{\$}^{27} \\ \text { Estados Unidos } & 24,3 & 26,84 \\ \text { Alemania } & 7,6 & 8,39 \\ \text { Francia } & 4,4 & 4,86 \\ \text { China } & 2,4 & 2,65\end{array}$

Nota: Elaboración propia en base a datos obtenidos en FiBL \& IFOAM ${ }^{28} 2015$.

25 Willer, H., \& Lernoud, J. (2015). Current Statistics on Organic Agriculture Worldwide: Organic Area, Producer, Markets and Selected Crops. En FiBL \& IFOAM, The World of Organic Agriculture Stadistics \& Emerging Trends 2015 (págs. 32-118). Switzerland: FiBL \& IFOAM.

26 Hang, G. (17 de junio de 2015). Desarrollo rural de los productos orgánicos en Argentina. (C. Vivanco, Entrevistador) 27 Cambio 1 euro $=1,103485$ dólares estadounidenses 28/07/2015

28 Willer, H., \& Lernoud, J. (2015). Current Statistics on Organic Agriculture Worldwide: Organic Area, Producer, Markets and Selected Crops. En FiBL \& IFOAM, The World of Organic Agriculture Stadistics \& Emerging Trends 2015 (págs. 32-118). Switzerland: FiBL \& IFOAM. 


\subsubsection{Principales Productos}

La $\mathrm{FAO}^{29}$ definió los usos de las tierras destinadas a la producción orgánica en cinco clasificaciones, las cuales están contenidas en los informes internacionales con algunas salvedades para algunos productos.

Las cinco clasificaciones son: agricultural land, no details (tierras de uso de agricultura, sin detalles); arable crops (tierra de uso en cultivos arables); cropland, no details (tierras de cultivo, sin detalle); other agricultural land (otras tierras de agricultura); permanent crops (tierras de cultivos permanentes) y permanent grassland (tierras de pastos permanentes) ${ }^{30}$.

Gráfico 3: Distribución de las categorías de uso de suelo orgánico a nivel mundial año 2014

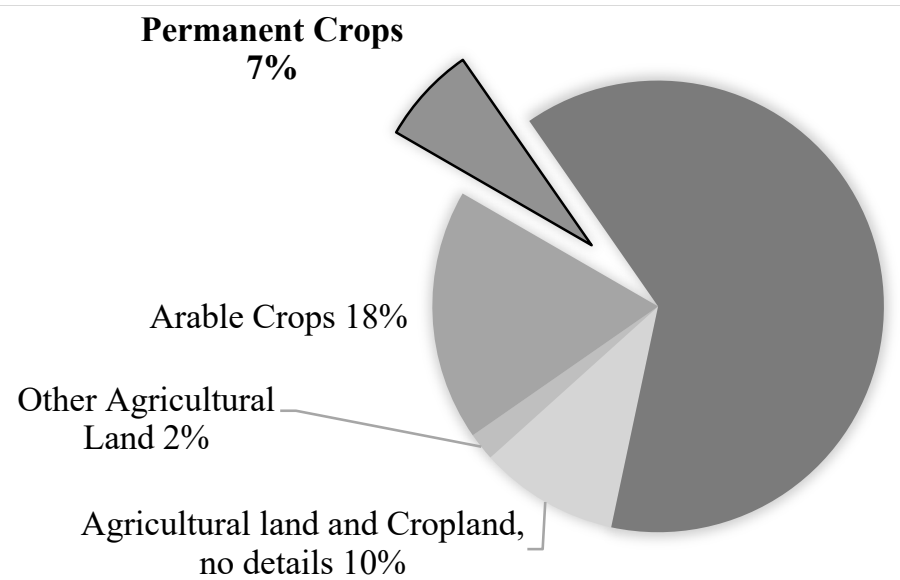

Permanent

Grassland 63\%

Nota: Elaboración propia en base a datos obtenidos en FiBL \& IFOAM ${ }^{31}$; FAO FA $^{32} 2015$.

En el gráfico 3, se observa la distribución en porcentaje de las tierras destinadas por categoría al uso orgánico, el cual presenta el panorama de los principales productos orgánicos. Apartando los pastos permanentes y las tierras sin detalles, las cuales están vinculadas con producciones cárnicas y a manejos integrales de permacultura, temas que no aborda esta investigación; nos encontramos principalmente con cultivos arables (18\%) y con cultivos permanentes $(7 \%)$.

\footnotetext{
29 Food and Agriculture Organization of the United Nations [FAO]. (s.f.). Obtenido de Glossary: http://faostat.fao.org/site/379/DesktopDefault.aspx?PagelD=379. Recuperado:18 de junio del 2015. 30 Food and Agriculture Organization of the United Nations [FAO]. (s.f.). Obtenido de Glossary: http://faostat.fao.org/site/379/DesktopDefault.aspx?PagelD=379. Recuperado:18 de junio del 2015.

31 Willer, H., \& Lernoud, J. (2015). Current Statistics on Organic Agriculture Worldwide: Organic Area, Producer, Markets and Selected Crops. En FiBL \& IFOAM, The World of Organic Agriculture Stadistics \& Emerging Trends 2015 (págs. 32-118). Switzerland: FiBL \& IFOAM.

32 Food and Agriculture Organization of the United Nations [FAO]. (2015). Organic Agriculture. Obtenido de http://www.fao.org/organicag/oa-home/en/. Recuperado:18 de mayo del 2016.
} 
Dentro de los cultivos arables destacan los cereales 3,31 millones de hectáreas, seguidos por forrajes verdes 2,38 millones de hectáreas y en tercer lugar semillas oleaginosas 0,78 millones de hectáreas.

Dentro de los cultivos permanentes destacan el café con 0,73 millones de hectáreas, seguido de los olivos con 0,61 millones de hectáreas y en tercer lugar con nueces con 0,32 millones de hectáreas.

Tabla 2: Desarrollo de tierras destinadas a cultivos permanentes y cultivos arables, desde el 2004 al 2013

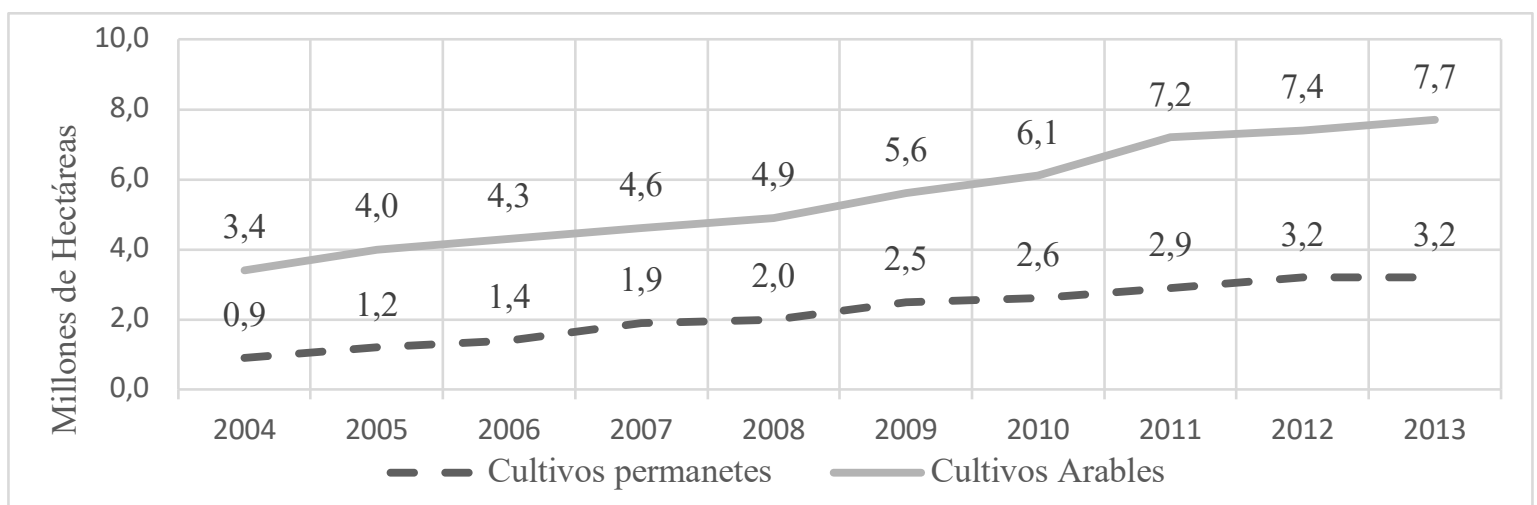

Nota: Elaboración propia en base a datos obtenidos en FiBL \& IFOAM ${ }^{33} 2015$.

La tabla 2, expone el crecimiento de las tierras destinadas a la producción de cultivos permanentes y cultivos arables, ambos presentan una tendencia positiva y constante en el tiempo. Los cultivos permanentes han mostrado una tendencia positiva de menor intensidad que la de los cultivos permanentes, manteniéndose en los dos últimos periodo.

Los cultivos permanentes ocupan más de 3,2 millones de hectáreas, en donde las zonas geográficas que tiene más participación son Europa 1,3 millones de hectáreas, seguido por América Latina 0,8 millones de hectáreas y África 0,6 millones de hectáreas; los cultivos más importantes son café 0,7 millones de hectáreas, seguido por olivos 0,6 millones de hectáreas, nueces 0,32 millones de hectáreas, uva 0,31 millones de hectáreas y en cuarto lugar cacao 0,2 millones de hectáreas.

El arándano es un producto vegetal clasificado como cultivo permanente (permanent crops), el cual está especificado dentro de la familia de los Berries. Los berries, dentro de los cultivos permanentes orgánicos mundiales ocupan 42,6 mil 
hectáreas teniendo una participación $1,3 \%$ y el puesto número 12, en relación al total de productos orgánicos de cultivo permanente mundial al 2013.

\subsection{Introducción al Producto Arándano.}

1.2.1 Historia y Origen.

El arándano es conocido en español como arándano azul o mora azul, en inglés como blueberry ${ }^{34}$ y en chino simplificado como 蓝莓 (pinyin =Lánméi). Es una planta que pertenece al género Vaccinium de la familia Ericaceae, se caracteriza por tener frutas (bayas) de pequeño tamaño muy ricos en antioxidantes, vitaminas y acido benzoico ${ }^{35}$; el color de la fruta va desde negro azulado a violáceo dependiendo la variedad de cual se cultiva.

Es una planta arbustiva, originaria de Hemisferio Norte, perenne y de producción estacional, considerada domesticada recientemente por medio de selección silvestre, siendo referente el botánico Frederick Coville, el cual a partir de 1911, mejoró notablemente la calidad a través de cruzamientos y mejoramiento genético ${ }^{36}$.

Consumida de forma habitual por todo el Hemisferio Norte, en especial por Estados Unidos, Rusia y la región de Escandinavia (Noruega, Dinamarca y Suecia) siendo parte de tradiciones y comidas típicas. Principalmente se consume fresco o congelado, aunque actualmente se puede encontrar deshidratado, en preparaciones de té, en polvo, concentrado, salsas, mermeladas y jugos ${ }^{37}$.

\subsection{Descripción Agronómica.}

Dentro de la descripción agronómica se revisaron conceptos claves para el entendimiento del producto como: morfología básica, variedades, requerimientos, fechas de cosecha y poscosecha ${ }^{38}$.

\subsubsection{Fecha de Cosecha}

34 Food and Agriculture Organization of the United Nations [FAO]. (1999). Depósito de Documentos de la FAO: Glosario. Obtenido de www.fao.org/docrep/006/y4893s/y4893s0c.htm. Recuperado:21 de septiembre del 2015

35 Jiménez Bonilla, V.; Abdelnour Esquivel, A. (2011). Identificación y Valor nutricional de algunas especies nativas de arándano (Vaccinium spp)., de Doctoral dissertation, Instituto Tecnológico de Costa Rica. Vicerrectoría de Investigación y Extensión. Obtenido de http://bibliodigital.itcr.ac.cr/handle/2238/2944. Recuperado: 10 de marzo de 2015

36 San Martín, J. (2010). SITUACIÓN VARIETAL EN ARÁNDANO. Obtenido de http://biblioteca.inia.cl/medios/biblioteca/boletines/NR39095.pdf. Recuperado: 10 de junio del 2016

37 Ministerio de Agricultura de Chile. (2013). Mercado y Proyecciones del Cultivo del Arándano. Obtenido de http://www.minagri.gob.cl/wp-content/uploads/2013/08/Mercado-y-proyecciones-del-cultivo-dear\%C3\%A1ndanos.pdf. Recuperado: 25 de mayo del 2015

38 Gobierno de Argentina, Instituto Nacional de Tecnología Agropecuaria [INTA]. (2011). Guía práctica para el cultivo de Arándanos en la zona norte de la provincia de Buenos. Obtenido de http://inta.gob.ar/documentos/guia-practicapara-el-cultivo-de-arandanos-en-la-zona-norte-de-la-provincia-de-buenosaires/at_multi_download/file/mg_0801.pdf. Recuperado: 22 de junio del 2015. 
La fecha de cosecha del arándano está relacionada con varias variables, las más importantes son fenología del cultivo ${ }^{39}$ (clima), la variedad, suelo y el manejo agronómico. La fenología estudia la relación que existe entre el clima y los ciclos de los seres vivos; esta es una de las relaciones más importantes que dicta los ciclos biológicos vegetales de crecimiento, floración, cuaja, fructificación maduración y reposo ${ }^{40}$.

Tanto las zonas de mayor producción de arándano de Argentina y Chile comparten similitudes macro-climáticas, de manejo y de suelo para el desarrollo del cultivo, en aspectos generales las cosechas son durante finales de octubre hasta la segunda semana de abril; esta ventana de producción se debe a las diferentes variedades de arándanos cultivados, siendo algunos más tempraneros y otros tardíos ${ }^{41}$.

En Chile, por ejemplo, nos encontramos las regiones IV, V y RM como tempraneras, las cuales dan inicio de cosecha durante finales de octubre hasta finales de diciembre; las regiones VI, VII y VIII tienen cosechas desde finales de noviembre hasta inicios de febrero; las regiones IX y X son tardías, desde mediados de diciembre hasta mediados de abril (fechas estimativas teniendo excepciones) ${ }^{42}$.

\subsubsection{Variedades}

Las variedades más cultivadas son Vaccinium anustifolium, Vaccinium corymbosum y Vacinium ashei; también existiendo otros cultivares no tradicionales en ambos países ${ }^{43}$.

Tabla 3: Nombre Científico y común de variedades de Arándanos.

Nombre Científico
Vaccinium corymbosum
Vaccinium ashei
Vaccinium macrocarpon
Vaccinium vitis-idea
Vaccinium myrtillus

Nota: Elaboración propia en base a registros SENASA ${ }^{44} 2014$ y SAG SA $^{45} 2015$.

\author{
Nombre Común \\ Arándano alto (Highbush) \\ Arándano ojo de conejo \\ Arandano (cramberry) \\ Arándano europeo (Ligonberry) \\ Arándano eurpero (Bilberry)
}

\footnotetext{
-

$39 \mathrm{El}$ arándano es una planta que requiere un periodo de reposo o invernación para la próxima temporada de producción. 40 Serri, H. (8 de diciembre de 2015). Arándano orgánico en Chille, plagas y enfermedades. (C. Vivanco, Entrevistador) 41 Rivadeneira, M. F. (2001). Instituto Nacional de Tecnología Agropecuaria [INTA]. Obtenido de Comportamiento Fenológico de variedades tradicionales y nuevas de arándano: http://inta.gob.ar/documentos/comportamientofenologico-de-variedades-tradicionales-y-nuevas-dearandano/at_multi_download/file/fenolog\%C3\%ADa\%20nuevas\%20y\%20tradicionales\%20arandanos.pdf. Recuperado: 25 de mayo del 2015

42 Vargas, S. (23 de junio de 2016). El arándano orgánico en Chile, avances en tecnología, producción y calidad. (C. Vivanco, Entrevistador)

43 Morelli, G. (20 de marzo de 2015). Mirada desde la academia del potencial del arándano orgánico de la Argentina. (C Vivanco, Entrevistador)

44 Ramírez, J. C. (17 de julio de 2015). Situación de la Agricultura Orgánica en la Argentina, visión desde SENASA. (C. Vivanco, Entrevistador)

45 Catalán, C. C. (10 de agosto de 2015). Situación de la Agricultura Orgánica en Chile, visión desde SAG. (C. Vivanco, Entrevistador)
} 


\subsubsection{Descripción Botánica}

Las partes más importantes para describir del arándano son sus raíces, tallos, hojas y flores y fruto.

Las raíces son de aspecto fibroso, poco profundas las cuales suelen poseer simbiosis con micorrizas específicas. Dado que, al sistema radicular poco profundo, es un cultivo que requiere mayor número de riegos de corta duración; con el fin de mantener la humedad en la capa superficial de la tierra ${ }^{46}$.

Los tallos de color café a marrón anaranjado (depende de la variedad) de crecimiento arbustivo pequeño con abundantes ramificaciones, existiendo relación directa entre grosor del tallo y edad del mismo. Los tallos se encuentran las yemas vegetativas, las que contienen los primordios de tallos, hojas, flores de la siguiente temporada ${ }^{47}$.

Las hojas, son de carácter perenne, aunque se observa en algunas variedades un cambio de tonalidad en invierno a rojizo y caedizas, son de tamaño pequeño de verde intenso con peciolos $\operatorname{cortos}^{48}$.

Las flores tienen pétalos que van desde el blanco al rosado, juntas en racimos (axiales) ubicadas en las yemas terminales de la rama, activadas por el fotoperiodo de otoño.

El fruto es una baya esférica, de tamaño pequeño 0,7 a 1,5 centímetros de diámetro, climatérica de color negro azulado a violáceo. Unas de las características del fruto es la presencia de una cubierta cerosa de pruibina. El arándano es un fruto simple carnoso y jugoso, así mismo como el tomate, las uvas y las grosellas ${ }^{49}$.

\subsubsection{Suelo}

El $80 \%$ del sistema radicular del arando se encuentra a no más de 50 centímetros de profundidad del suelo, en la primera capa; el sistema se caracteriza por tener raíces finas y fibrosas, la mayoría sin pelos radiculares con muy baja capacidad de absorción ${ }^{50}$.

\footnotetext{
46 Undurraga, P., \& Vargas, S. (2013). Boletín INIA N²63. Obtenido de Manual del Arándano: http://biblioteca.inia.cl/medios/biblioteca/boletines/NR39094.pdf. Recuperado: 10 de junio del 2016 47 Rivadeneira, M. F. (2001). Instituto Nacional de Tecnología Agropecuaria [INTA]. Obtenido de Comportamiento Fenológico de variedades tradicionales y nuevas de arándano: http://inta.gob.ar/documentos/comportamientofenologico-de-variedades-tradicionales-y-nuevas-dearandano/at_multi_download/file/fenolog\%C3\%ADa\%20nuevas\%20y\%20tradicionales\%20arandanos.pdf. Recuperado: 25 de mayo del 2015

48 Rivadeneira, M. F. (2001). Instituto Nacional de Tecnología Agropecuaria [INTA]. Obtenido de Comportamiento Fenológico de variedades tradicionales y nuevas de arándano: http://inta.gob.ar/documentos/comportamientofenologico-de-variedades-tradicionales-y-nuevas-dearandano/at multidownload/file/fenolog\%C3\%ADa\%20nuevas\%20y\%20tradicionales\%20arandanos.pdf. Recuperado: 25 de mayo del 2015

49 Undurraga, P., \& Vargas, S. (2013). Boletín INIA №263. Obtenido de Manual del Arándano: http://biblioteca.inia.cl/medios/biblioteca/boletines/NR39094.pdf. Recuperado: 10 de junio del

50 Morelli, G. (20 de marzo de 2015). Mirada desde la academia del potencial del arándano orgánico de la Argentina. (C. Vivanco, Entrevistador)
} 
Las raíces no poseen la capacidad de penetrar suelos compactos, se recomienda el cultivo en suelos con una alta porosidad -macro y micro-, además de excelente drenaje; por estos requerimientos se observa que las plantaciones son realizadas sobre camellones, con un porcentaje alto de materia orgánica $(3-8 \%)^{51}$.

Los arándanos crecen bien en suelos con pH entre 4,4 y 5,5 ; siendo clasificados como suelos ácidos ${ }^{52}$.

\subsubsection{Post-cosecha ${ }^{53}$}

La post-cosecha dentro de la cadena de producción del arándano es una de las partes más importantes ${ }^{54}$, sino la característica-manejo inherente para poder exportar a los mercados demandantes extranjeros, siendo un punto clave para llegar al consumidor con un producto fresco de calidad. Un aspecto técnico a considerar es la clasificación del metabolismo de la fruta después de cortada ${ }^{55}$.

Dentro de los aspectos físicos-químicos y organolépticos, todas la frutas se clasifican en dos grandes grupos, el primero corresponde a frutos no climatéricos, son todos los frutos que después de ser cortados (cosechados) su estado de madurez se detiene en ese momento, una vez cortados sus características organolépticas no mejoran (cerezas, naranjas, uva, piña, fresa, aceituno, pomelo); el segundo corresponde a frutos climatéricos, que son todos los frutos que después de ser cortado su estado de madurez puede seguir, aumentan sus características organolépticas (manzana, pera, palta, melón, ciruela, sandia, kiwi, arándano $)^{56}$.

Dado que el arándano es climatérico, su metabolismo y respiración después de ser cortado sigue funcionando (madurando, respirando) produciendo etileno, siendo este gas una fuerte señal fitohormonal para acelerar la madurez el cual provoca una alta susceptibilidad a pudriciones ${ }^{57}$.

Entre las principales causas de deterioro en arándano están: pudriciones, deshidratación, pérdida de firmeza, pérdida de apariencia, desarrollo de desórdenes y calidad sensorial. Es importante considerar que las variedades pueden presentar distintos

51 Undurraga, P., \& Vargas, S. (2013). Boletín INIA N²63. Obtenido de Manual del Arándano: http://biblioteca.inia.cl/medios/biblioteca/boletines/NR39094.pdf. Recuperado: 10 de junio del 52 Undurraga, P., \& Vargas, S. (2013). Boletín INIA N²63. Obtenido de Manual del Arándano: http://biblioteca.inia.cl/medios/biblioteca/boletines/NR39094.pdf. Recuperado: 10 de junio del 2016

53 Defilippi, B., Robledo, P., \& Becerra, C. (2013). Manejo de cosecha y Poscosecha en Arándano. En C. R. Quilamapu, Manual del Arándano (págs. 107-125). Chillán, Chile: Instituto de Investigaciones Agropecuarias. Obtenido de http://biblioteca.inia.cl/medios/biblioteca/boletines/NR39094.pdf. Recuperado:1 de octubre del 2015.

54 Bacco, A. (23 de julio de 2015). Mirada de la exportación desde Argentina de Productos orgánicos. (C. Vivanco, Entrevistador)

55 Vargas, S. (23 de junio de 2016). El arándano orgánico en Chile, avances en tecnología, producción y calidad. (C. Vivanco, Entrevistador)

56 Martínez, M., Balois, R., \& Alia, I. (2013). Postharvest fruits: maturation and biochemical changes. Obtenido de http://www.redalyc.org/pdf/2631/263153823018.pdf. Recuperado: 10 de junio del 2016

57 Fischer, S. (15 de octubre de 2015). Producciones orgánicas en Chile, potencial e importancia mirada desde la academia. (C. Vivanco, Entrevistador) 
niveles de respiración. Además, la tasa respiratoria está influenciada, como en otros productos frescos, por la temperatura ${ }^{58}$.

\subsection{Descripción nutricional y organoléptica.}

Nutricionalmente el arándano ha sido reconocido como una fruta que posee altos contenidos de antioxidantes, vitaminas y minerales ${ }^{59}$. Actualmente hay diversos estudios que relacionan los beneficios de consumir esta fruta en la prevención de problemas metabólicos ${ }^{60}$, además de estar frecuentemente ingresada en planes de dietas y de alimentación saludable ${ }^{61}$.

Tabla 4: Información nutricional de 100 gramos de Arándano fresco.

Información Nutricional, 100 gramos.

$\begin{array}{llllll}\text { Agua } & (\mathrm{g}) & 87,4 & \text { Ácido pantoténico } & (\mathrm{mg}) & 12 \\ \text { Proteínas } & (\mathrm{g}) & 0,3 & \text { Sodio } & (\mathrm{mg}) & 2 \\ \text { Fibras } & (\mathrm{g}) & 1,7 & \text { Potasio } & (\mathrm{mg}) & 72 \\ \text { Calorías } & (\mathrm{kcal}) & 42 & \text { Calcio } & (\mathrm{mg}) & 14 \\ \text { Vitamina A } & (\mathrm{Ul}) & 30 & \text { Magnesio } & (\mathrm{mg}) & 6 \\ \text { Vitamina B1 } & (\mathrm{mg}) & 0,014 & \text { Manganeso } & (\mathrm{mg}) & 0,5 \\ \text { Vitamina B2 } & (\mathrm{mg}) & 0,0024 & \text { Hierro } & (\mathrm{mg}) & 0,5 \\ \text { Vitamina B6 } & (\mathrm{mg}) & 0,012 & \text { Cobre } & (\mathrm{mg}) & 0,26 \\ \text { Vitamina C } & (\mathrm{mg}) & 12 & \text { Fósforo } & (\mathrm{mg}) & 10 \\ \text { Ácido nicotínico } & (\mathrm{mg}) & 0,2 & \text { Cloro } & (\mathrm{mg}) & 4\end{array}$

Nota. Adaptación de datos de tesis Doctoral. Jiménez Bonilla, V.; Abdelnour Esquivel, A $(2011)^{62}$.

La calidad está definida por una serie de factores, dentro los más importantes son: color, firmeza, ausencia de daños, balance dulzor/acidez y aroma ${ }^{63}$.

58 Vargas, S. (23 de junio de 2016). El arándano orgánico en Chile, avances en tecnología, producción y calidad. (C. Vivanco, Entrevistador)

59 Jiménez Bonilla, V.; Abdelnour Esquivel, A. (2011). Identificación y Valor nutricional de algunas especies nativas de arándano (Vaccinium spp)., de Doctoral dissertation, Instituto Tecnológico de Costa Rica. Vicerrectoría de Investigación y Extensión. Obtenido de http://bibliodigital.itcr.ac.cr/handle/2238/2944. Recuperado: 10 de marzo de 2015

60 Cranberries, O. S., \& EUA, I. L. (2005). Constituyentes fitoquímicos del arándano americano (Vaccinium macrocarpon) y sus beneficios para la salud. Revista de fitoterapia. Revista de fitoterapia, 5(1), 5-16

61 Morelli, G. (20 de marzo de 2015). Mirada desde la academia del potencial del arándano orgánico de la Argentina. (C. Vivanco, Entrevistador)

62 Jiménez Bonilla, V.; Abdelnour Esquivel, A. (2011). Identificación y Valor nutricional de algunas especies nativas de arándano (Vaccinium spp)., de Doctoral dissertation, Instituto Tecnológico de Costa Rica. Vicerrectoría de Investigación y Extensión. Obtenido de http://bibliodigital.itcr.ac.cr/handle/2238/2944. Recuperado: 10 de marzo de 2015

63 Silvia Nuñez, E. M. (2015). Actividad antioxidante del arándano (vaccinium corymbosum I.) Y sus propiedades para prevenir enfermedades neurodegenerativas. Obtenido de http://152.74.96.159:8080/jspui/handle/123456789/295 Recuperado: 25 de noviembre del 2015 
Organolépticamente se espera que las bayas sean turgentes y crocantes, jugosas, de sabor equilibrado entre dulce y acido; se busca bayas de colores intensos, brillantes y parejos. Paleta aromática sutil nasal y retronasal, vinculada a mermeladas de frutos azules con trazas de cítrico.

\subsection{Certificación Producción Orgánica}

La certificación es una herramienta de credibilidad entre los productores para los consumidores finales, la cual entrega valor y diferenciación de producto; actualmente está contenida en los marcos normativos y de sanidad de los principales países productores y compradores, siendo constantemente revisada, actualizada y normada ${ }^{64}$.

El pilar fundamental de la certificación es la inocuidad de los alimentos con bases en la sustentabilidad del sistema, con un alto respeto -conciencia- al medio ambiente y social $^{65}$.

En aspectos generales, es el país del mercado destino el que impone el pool normativo y requerimientos para la certificación orgánica que tienen que cumplir el producto, los productores y la cadena de comercialización. Encontrando normas comunes por bloques económicos como es la Unión Europea y USA-Canadá66.

64 Fischer, S. (15 de octubre de 2015). Producciones orgánicas en Chile, potencial e importancia mirada desde la academia. (C. Vivanco, Entrevistador)

65 Seghezzo, L. (2013). Ensayo IX.1 Recursos Naturales y sustentabilidad. En L. Malacalza, \& L. Malacalza (Ed.), Ecología y Ambiente. Buenos Aires: LISEA.

66 Eguillor, P. (7 de septiembre de 2015). Mirada desde el Gobierno Chileno al potencial orgánico del arándano. (C. Vivanco, Entrevistador) 


\section{CAPITULO II: SITUACIÓN DE LA AGRICULTURA ORGÁNICA EN ARGENTINA Y CHILE CON SESGO EN ARÁNDANO ORGÁNICO DE CONSUMO FRESCO EN EL MERCADO EXPORTACIÓN HORTOFRUTÍCOLA; Y LA SITUACIÓN DE DEMANDA EN LA REGIÓN ADMINISTRATIVA ESPECIAL DE HONG KONG, DE LA REPÚBLICA POPULAR CHINA.}

Este capítulo entrega en detalle el estado de la agricultura orgánica en Argentina y en Chile; evolución, superficies, producciones y mercados destinos principales con sesgo en el arándano orgánico de consumo fresco. Se desglosa las certificadoras para cada país, según las normas actualizadas al 2015.

También se abordan la situación de China con respecto al Arándano y la demanda de Hong Kong con respecto a productos hortofrutícola con sesgo en el arándano orgánico, actualizadas al 2015.

2.1 Situación de Argentina en la Producción Orgánica nacional y específica del arándano de consumo fresco de exportación.

2.1.1 Situación Argentina, Productos Orgánicos.

La situación de la producción y exportación orgánica en Argentina durante el año 2014 indica, en aspectos generales, que la principal plaza de los productos orgánicos argentinos sigue siendo liderada por Estados Unidos. Estados Unidos registra una participación del 53,2\% del total de destinos de productos orgánicos exportados, presentando un crecimiento de $29 \%$ en consideración al año 2013; después se encuentra la Unión Europea 28,99\%; Suiza 1,1\%; Japón con un 0,4\% y otros países destinos de $16,3 \%{ }^{67}$.

Destaca las producciones de cereales, oleaginosas y productos industrializados; teniendo en total un crecimiento positivo de 14\% en comparación al año anterior. Las oleaginosas presentaron un crecimiento de un $66 \%$, siendo uno de los cultivos más destacados $^{68}$.

\footnotetext{
67 Gobierno de Argentina, Dirección Nacional de Inocuidad y Calidad Agroalimentaria. (2016). Coordinación de productos Ecológicos. Situación de la Producción Orgánica en la Argentina durante el Año 2015. Obtenido de http://www.senasa.gob.ar/sites/default/files/ARBOL_SENASA/INFORMACION/PROD_ORGANICA/517informe_estadstico_2015.pdf. Recuperado: 6 de enero del 2016

68 Gobierno de Argentina, Dirección Nacional de Inocuidad y Calidad Agroalimentaria. (2016). Coordinación de productos Ecológicos. Situación de la Producción Orgánica en la Argentina durante el Año 2015. Obtenido de http://www.senasa.gob.ar/sites/default/files/ARBOL_SENASA/INFORMACION/PROD_ORGANICA/517informe_estadstico_2015.pdf. Recuperado: 6 de enero del 2016
} 
Las provincias de Buenos Aires y Salta fueron las que mayores aumentos obtuvieron, bajo el concepto de cosecha de superficie, las cuales aumentaron en un $13 \%$ para Buenos Aires y un $44 \%$ para Salta ${ }^{69}$.

La superficie orgánica en argentina durante el 2014 presentó una disminución del $7 \%$ en comparación al año anterior (3,1 millones de hectáreas), esta disminución se viene observando desde el año $2009^{70}$.

Gráfico 4: Hectáreas de uso Orgánico en La Argentina 2010-1014.

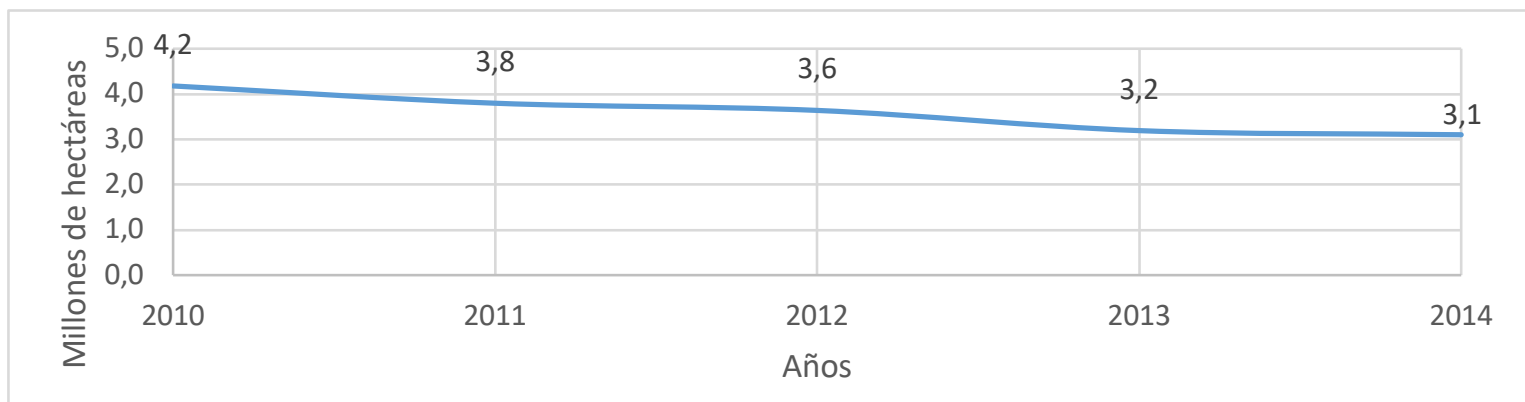

Nota. Elaboración propia en base a datos obtenidos en FiBL \& IFOAM ${ }^{71} 2015$; SENASA $^{72}$.

En el grafico 4, se observa una tendencia de disminución en las hectáreas destinadas a la producción orgánica durante los últimos 5 años, esta tendencia se puede explicar por: condiciones climatológicas adversas y por la retirada del sistema orgánico de productores de Formosa, Misiones, Mendoza, entre otros ${ }^{73}$.

El organismo Argentino responsable de garantizar y certificar la sanidad y calidad de la producción agropecuaria, pesquera y forestal es SENASA (Servicio Nacional de Sanidad y Calidad Agroalimentaria) el cual jerárquicamente posee un coordinador para las producciones ecologías, cargo ocupado por el Ingeniero Agrónomo Juan Carlos Ramírez ${ }^{74}$.

69 Gobierno de Argentina, Dirección Nacional de Inocuidad y Calidad Agroalimentaria. (2016). Coordinación de productos Ecológicos. Situación de la Producción Orgánica en la Argentina durante el Año 2015. Obtenido de http://www.senasa.gob.ar/sites/default/files/ARBOL SENASA/INFORMACION/PROD ORGANICA/517informe estadstico_2015.pdf. Recuperado: 6 de enero del 2016

70 Gobierno de Argentina, Dirección Nacional de Inocuidad y Calidad Agroalimentaria. (2016). Coordinación de productos Ecológicos. Situación de la Producción Orgánica en la Argentina durante el Año 2015. Obtenido de http://www.senasa.gob.ar/sites/default/files/ARBOL_SENASA/INFORMACION/PROD_ORGANICA/517informe_estadstico_2015.pdf. Recuperado: 6 de enero del 2016

71 Willer, H., \& Lernoud, J. (2015). Current Statistics on Organic Agriculture Worldwide: Organic Area, Producer, Markets and Selected Crops. En FiBL \& IFOAM, The World of Organic Agriculture Stadistics \& Emerging Trends 2015 (págs. 32-118). Switzerland: FiBL \& IFOAM.

72 Gobierno de Argentina, Dirección Nacional de Inocuidad y Calidad Agroalimentaria. (2016). Coordinación de productos Ecológicos. Situación de la Producción Orgánica en la Argentina durante el Año 2015. Obtenido de http://www.senasa.gob.ar/sites/default/files/ARBOL SENASA/INFORMACION/PROD ORGANICA/517informe_estadstico_2015.pdf. Recuperado: 6 de enero del 2016

73 Montes, L. (31 de julio de 2015). Realidad de Exportación de arándanos orgánicos en Argentina. (C. Vivanco, Entrevistador)

74 Ramírez, J. C. (17 de julio de 2015). Situación de la Agricultura Orgánica en la Argentina, visión desde SENASA. (C. Vivanco, Entrevistador) 
SENASA actualmente posee una excelente reputación internacional en su sistema de control, obteniendo una convalidación de normas a los estándares de la Unión Europea. Según, Ramírez 2015, la institución posee una estabilidad la cual fue formada durante varios años en un arduo trabajo de controlaría, velando por la seguridad de sus trabajadores, con proyecciones laborales, económicas y de recursos humanos; para un correcto y limpio desenvolviendo de todas las actividades de control $^{75}$.

\subsubsection{Producción de Arándano Orgánico para exportación.}

Al año 2014 Argentina Exportó 223.254 kilos de Arándanos Orgánicos, siendo la tercera fruta orgánica más exportada.

Tabla 5: Productos Orgánicos (kg) Argentinos, de Origen Vegetal Certificados con destino a la exportación, durante el año 2014.

$\begin{array}{lrrrrr}\text { Fruta } & \text { Unión Europea } & \text { Estados Unidos } & \text { Otros } & \text { Totales } & \text { Porcentaje } \\ \text { Pera } & 11.033 .589 & 13.877 .911 & 3.513 .909 & 28.425 .409 & 59,61 \% \\ \text { Manzana } & 9.196 .510 & 8.707 .258 & 825.055 & 18.728 .824 & 39,28 \% \\ \text { Arándanos } & 34.357 & 168.219 & \mathbf{2 0 . 6 7 8} & \mathbf{2 2 3 . 2 5 3} & \mathbf{0 , 4 7 \%} \\ \text { Ciruela } & 64.725 & 44.604 & 988 & 110.317 & 0,23 \% \\ \text { Kiwi } & 96.000 & & & 96.000 & 0,20 \% \\ \text { Uva } & 34.000 & & 22.800 & 56.800 & 0,12 \% \\ \text { Cereza } & 2.320 & 25.760 & 3.640 & 31.720 & 0,07 \% \\ \text { Nectarinas } & & 9.792 & & 9.792 & 0,02 \% \\ \text { Total } & 20.461 .501 & 22.833 .544 & 4.387 .070 & & \\ \text { Porcentaje } & 42,91 \% & 47,89 \% & 9,20 \% & 47.682 .115 & 100,00 \%\end{array}$

Nota: Elaboración propia en base a datos obtenidos de SENASA ${ }^{76} 2015$.

\subsubsection{Destinos}

Tabla 6 Detalle de países destinos de Arándano Orgánico Argentino certificado, durante el año 2014

$\begin{array}{lrr}\text { País } & \text { Kilogramos } & \text { Porcentaje } \\ \text { Canadá } & 20.678 & 9,26 \% \\ \text { Países Bajos } & 20.335 & 9,11 \% \\ \text { Reunió Unido } & 14.022 & 6,28 \% \\ \text { USA } & 168.219 & 75,35 \% \\ & 223.254 & 100,00 \%\end{array}$

Nota: Elaboración propia en base a datos obtenidos de SENASA 2015.

\footnotetext{
75 Ramírez, J. C. (17 de julio de 2015). Situación de la Agricultura Orgánica en la Argentina, visión desde SENASA. (C. Vivanco, Entrevistador)

76 Gobierno de Argentina, Dirección Nacional de Inocuidad y Calidad Agroalimentaria. (2016). Coordinación de productos Ecológicos. Situación de la Producción Orgánica en la Argentina durante el Año 2015. Obtenido de http://www.senasa.gob.ar/sites/default/files/ARBOL_SENASA/INFORMACION/PROD_ORGANICA/517informe_estadstico_2015.pdf. Recuperado: 6 de enero del 2016

77 Gobierno de Argentina, Dirección Nacional de Inocuidad y Calidad Agroalimentaria. (2016). Coordinación de productos Ecológicos. Situación de la Producción Orgánica en la Argentina durante el Año 2015. Obtenido de
} 
En la tabla 6, se observa el detalle de países destino del arándano orgánico, el cual mantiene la tendencia general de los productos orgánicos argentinos, teniendo como socio principal a Estados Unidos, siendo de mayor importancia dado que tiene una participación como país de destino de más de un $75 \%$, teniendo presencia en Canadá con 20.678 kilos exportados con una participación del 9,26\%, los países bajos con 20.335 kilos con el $9,11 \%$ y en último lugar Reino Unido con 14.022 con el $6,28 \%{ }^{78}$.

\subsubsection{Certificadora}

El listado de operadores orgánicos oficial de productos primarios orgánicos año 2014, creado por SENASA ${ }^{79}$, tiene como referencia directa a las cuatro certificadoras más importantes de la Argentina. Es este documento el que recopila a todos los productores oficiales y legales, habilitados para realizar comercio de productos orgánicos para el mercado interno y/o externo. Las certificadoras son Argencert S.R.L, OIA S.A, Letis S.A. y Food Safety S.A ${ }^{80}$.

2.2 Situación de Chile en la Producción Orgánica nacional y específica del arándano de consumo fresco de exportación.

\subsubsection{Situación Chile, Productos Orgánicos.}

La situación de la producción y exportación orgánica en Chile durante el año 2015 indica, en aspectos generales, que la principal plaza de los productos orgánicos chileno al igual que de Argentina- es Estados Unidos; encontrando una excepción al producto vino, que la plaza de mayor importancia es Inglaterra ${ }^{81}$. Estados Unidos lidera con un $43,8 \%$ seguido por la Unión Europea con 15,1\%; Perú con 10\% y Canadá con un 3\%, en al año $2013^{82}$.

Destacan las producciones de recolecciones silvestres, uva vinífera, frutales mayores (manzanas, olivos, kiwi) y menores los (arándanos, frambuesas, mora). Las

http://www.senasa.gob.ar/sites/default/files/ARBOL_SENASA/INFORMACION/PROD_ORGANICA/517informe_estadstico_2015.pdf. Recuperado: 6 de enero del 2016

78 Gobierno de Argentina, Dirección Nacional de Inocuidad y Calidad Agroalimentaria. (2016). Coordinación de productos Ecológicos. Situación de la Producción Orgánica en la Argentina durante el Año 2015. Obtenido de http://www.senasa.gob.ar/sites/default/files/ARBOL_SENASA/INFORMACION/PROD_ORGANICA/517informe estadstico 2015.pdf. Recuperado: 6 de enero del 2016

79 Ramírez, J. C. (17̄ de julio de 2015). Situación de la Agricultura Orgánica en la Argentina, visión desde SENASA. (C. Vivanco, Entrevistador)

80 Montenegro, L. (23 de noviembre de 2015). Certificaciones de arándanos orgánicos producidos en Argentina y en Chile. (C. Vivanco, Entrevistador)

81 Gobierno de Chile, Oficina de Estudio y Políticas Agrarias [ODEPA]. (2015). Producción orgánica nacional: Situación y Perspectivas. Obtenido de http://www.odepa.cl/wpcontent/files mf/1440087284AgriculturaOrg\%C3\%A1nica2015.pdf. Recuperado: 27 de mayo del 2015

82 Gobierno de Chile. ODEPA. (2014). Chile: comercio exterior de productos orgánicos. Obtenido de http://www.odepa.cl/wp-content/files_mf/1391441139ChileComercioExteriorProductosOrganicos.pdf. Recuperado:25 de mayo del 2015. Recuperado: 25 de mayo del 2015 
Regiones del Bío-Bío ${ }^{83}$, Maule y Valparaíso son las que concentran el mayor uso de tierras para ese destino de cultivo. Siendo Biobío la que posee más del $61,4 \%$ de terrenos certificados; de los cuales el 94,7\% corresponde a recolección silvestre.

El organismo chileno responsable de garantizar y certificar la sanidad y calidad de las producciones agropecuarias, y forestal es SAG (Servicio Agrícola Ganadero) el cual jerárquicamente posee un jefe de subdepartamento de Agricultura Orgánica cargo ocupado por el Ingeniero Agrónomo Claudio Cárdenas Catalán, División Protección Recursos Naturales Renovables; cuyo homólogo argentino es el Ingeniero Agrónomo Juan Carlos Ramírez ${ }^{84}$.

SAG, actualmente es un organismo dependiente del Ministerio de Agricultura que cumple un rol fiscalizador, trabajando en paralelo con Aduanas, Ministerio de Salud y otros.

En Chile, por decreto presidencial y ministerial, existe una comisión encargada de la información, transferencia e imagen de los productos Orgánicos. La Comisión Nacional de Agricultura Orgánica $(\mathrm{CNAO})^{85}$, tiene como objetivo facilitar el acceso a información relacionada con la agricultura orgánica, dar a conocer las actividades de la Comisión Nacional, de las Comisiones Regionales e informar sobre los distintos eventos relacionados con el sector. Trabajando bidireccionalmente y por región, hacia las necesidades internas chilenas y externas de los mercados demandantes ${ }^{86}$.

\footnotetext{
83 Por nueva administración para el 2017, la Región del Biobío, se dividirá en dos: Región del Biobío capital Concepción y Región del Ñuble capital Chillán.

84 Catalán, C. C. (10 de agosto de 2015). Situación de la Agricultura Orgánica en Chile, visión desde SAG. (C. Vivanco, Entrevistador)

85 Oficina de Estudios y Políticas Agrarias. (2016). Comisión Nacional de Agricultura Orgánica. Obtenido de https://www.odepa.gob.cl/coordinacion-publico-privada/comision-nacional-de-agricultura-organica. Recuperado: 15 de junio del 2016

86 Catalán, C. C. (10 de agosto de 2015). Situación de la Agricultura Orgánica en Chile, visión desde SAG. (C. Vivanco, Entrevistador)
} 
Gráfico 5: Hectáreas de uso Orgánico en Chile 2011-2015.

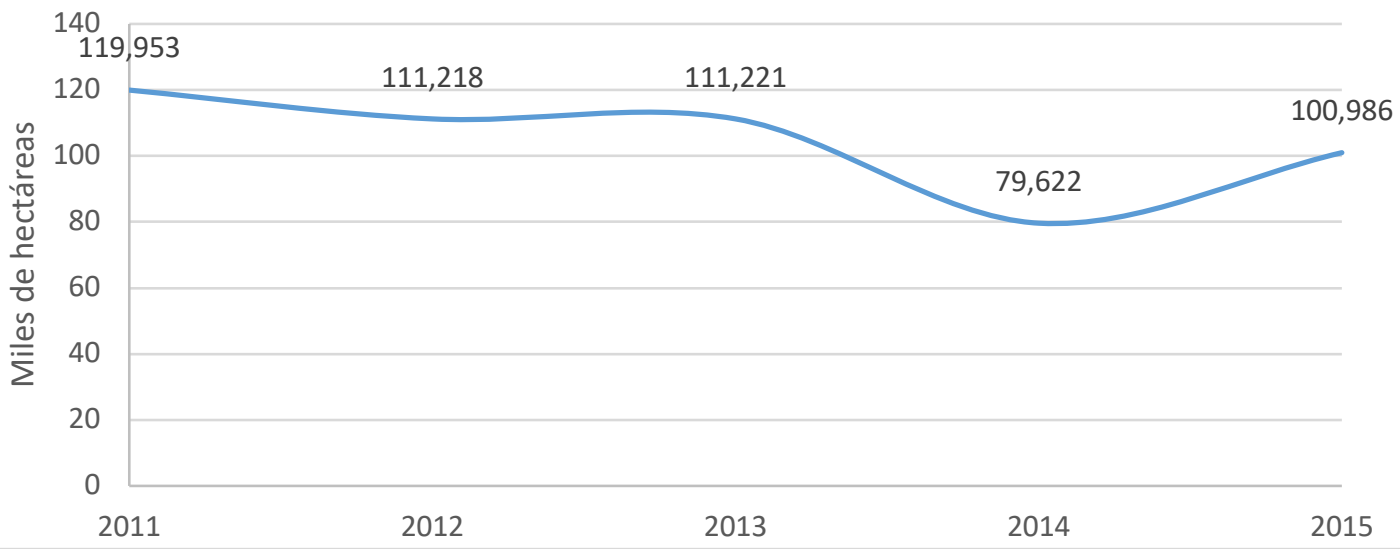

Nota. Elaboración propia en base a datos obtenidos en FiBL \& IFOAM ${ }^{87} ;$ SAG $^{88} 2015$.

En el grafico 5, se observa una tendencia de disminución en las hectáreas destinadas a la producción orgánica durante los últimos 5 años, esta tendencia se puede explicar en Chile por la fluctuación de cultivos silvestres que salen de la certificación, siendo principalmente el maqui, rosa mosqueta, los cuales por el destino de uso se transforman en terrenos forestales; observando un repunte en el 2015 dado a los fuertes incentivos de producción de los programas gubernamentales ${ }^{89}$.

\subsubsection{Producción de Arándano Orgánico para exportación.}

Tabla 7: Superficie destinada en Chile de los principales productos orgánicos 20142015

$\begin{array}{lrr}\text { Producto } & \text { Julio del } 2014 & \text { Julio del } 2015 \\ \text { Uva Vinífera } & 3.571 & 3.735 \\ \text { Arándano } & 1.528 & 2.173 \\ \text { Manzano } & 1.118 & 1.129 \\ \text { Frambuesa } & 564 & 804 \\ \text { Kiwi } & 328 & 292\end{array}$

Nota. Elaboración propia en base a datos obtenidos en ODEPA ${ }^{90} 2015$.

87 Willer, H., \& Lernoud, J. (2015). Current Statistics on Organic Agriculture Worldwide: Organic Area, Producer, Markets and Selected Crops. En FiBL \& IFOAM, The World of Organic Agriculture Stadistics \& Emerging Trends 2015 (págs. 32-118). Switzerland: FiBL \& IFOAM.

88 Catalán, C. C. (10 de agosto de 2015). Situación de la Agricultura Orgánica en Chile, visión desde SAG. (C. Vivanco, Entrevistador

89 Ferrera, M. (4 de diciembre de 2015). Realidad de exportación de Arándanos Orgánicos en Chile. (C. Vivanco, Entrevistador)

90 Gobierno de Chile, Oficina de Estudio y Políticas Agrarias [ODEPA]. (2015). Producción orgánica nacional: Situación y Perspectivas. Obtenido de http://www.odepa.cl/wpcontent/files_mf/1440087284AgriculturaOrg\%C3\%A1nica2015.pdf. Recuperado: 27 de mayo del 2015 
La superficie destinada de arándano en Chile ha registrado un aumento del $42 \%$ en el 2015, principalmente debido a su importancia económica ${ }^{91}$ y al cambio de rubro de cultivos anuales o de cultivos de arándano tradicional, a arándano orgánico ${ }^{92}$.

\subsubsection{Destinos}

Tabla 8: Detalle de volúmenes exportados y Principales países destinos de Arándano Orgánico Chile certificado, durante el año 2015

$\begin{array}{lll}\text { Estados Unidos } & 7663,1 & 76 \% \\ \text { Canadá } & 804,9 & 8 \% \\ \text { Holanda } & 394,9 & 4 \% \\ \text { Corea del Sur } & 338,2 & 3 \% \\ \text { Nueva Zelanda } & 329,4 & 3 \% \\ \text { Australia } & 240,5 & 2 \% \\ \text { Reino Unido } & 148 & 1 \% \\ \text { TONELADAS } & 10077 & 100 \%\end{array}$

Nota. Elaboración propia en base a datos obtenidos en ODEPA ${ }^{93} 2015$.

Chile ha aumentado los volúmenes de exportación de forma creciente, siendo Estados Unidos el principal cliente.

\subsubsection{Certificadora}

El marco regulatorio chileno para las certificaciones de productos orgánicos se rige bajo la ley №20.089, creando el sistema Nacional de Certificación de Productos Orgánicos. Esta ley opera en temas regulatorios muy parecida al sistema argentino, y es supervisada por el Servicio Agrícola y Ganadero (SAG) $)^{94}$.

Existen cuatro entidades certificadoras registradas: Institute for Marketecology Chile S.A, BCS ÖKO: GARANTIE GmbH, Argencert S.R.L y Ceres-Certification of Enviromental Standards $\mathrm{GmbH}^{95}$.

91 Eguillor, P. (7 de septiembre de 2015). Mirada desde el Gobierno Chileno al potencial orgánico del arándano. (C. Vivanco, Entrevistador)

92 Ferrera, M. (4 de diciembre de 2015). Realidad de exportación de Arándanos Orgánicos en Chile. (C. Vivanco, Entrevistador)

93 Gobierno de Chile, Oficina de Estudio y Políticas Agrarias [ODEPA]. (2015). Producción orgánica nacional: Situación y Perspectivas. Obtenido de http://www.odepa.cl/wpcontent/files_mf/1440087284AgriculturaOrg\%C3\%A1nica2015.pdf. Recuperado: 27 de mayo del 2015

94 Catalán, C. C. (10 de agosto de 2015). Situación de la Agricultura Orgánica en Chile, visión desde SAG. (C. Vivanco, Entrevistador)

95 Montenegro, L. (23 de noviembre de 2015). Certificaciones de arándanos orgánicos producidos en Argentina y en Chile. (C. Vivanco, Entrevistador) 
A diferencia del sistema argentino, la ley chilena permite tener otras entidades certificadoras, clasificadas en Organizaciones de Pequeños Agricultores Ecológicos, entregando a estos grupos las herramientas para auto certificar sus producciones y comercializarla al consumidor directo final en el mercado nacional. Permitiendo acceso al mercado interno, con una propuesta de valor certificada por el Gobierno de Chile ${ }^{96}$.

2.3 Mercado demandante de la región administrativa especial de Hong Kong, de la República Popular China.

\subsubsection{Situación de escenario Orgánico en China 2015}

El gobierno de China, a mediados de los años ochenta, dado a una fuerte conciencia ambientalista con una política preventiva de salud, da inicio al programa de productos orgánicos, el cual comenzó a tomar forma en el aspecto regulatorio y de supervisión a finales de los años noventas ${ }^{97}$. Ya en el 2005, el sistema regulatorio contaba con un sello orgánico de carácter único para los alimentos de producción interna y exigía que productos extranjeros homologaran sus sellos, por medios de las propias entidades China, el sello único chino (GB/T 19630-2005), política que se ha mantenido hasta la fecha ${ }^{98}$.

La demanda interna de alimentos saludables con sellos internacionales ha aumentado, a pesar de la legislación China, dado que, se han registrado casos polémicos sobre estándares de calidad, inocuidad y trasparencia en la producción; donde han reportado intoxicaciones y muertes de consumidores. Es donde los alimentos con sellos extranjeros de prestigiosas empresas internacionales y certificaciones europeas/estadounidense han penetrado ${ }^{99}$.

\subsubsection{Producción interna de arándano chino}

China en la década de los noventa, por medio de su estrategia gubernamental de alimentación, introdujo el arándano como cultivo experimental en la provincia de Jiangsu, supervisados por la Academia de las Ciencias de China (Chinnese Academy of Sciencie). Se investigó y experimentó durante los años 1983 al 2005, para finalmente en el 2009

\footnotetext{
96 Recabarren, P. E. (2015). Certificación de productos orgánicos. Obtenido de Ministerio de Agricultura: http://cnao.odepa.cl/wp-content/files_mf/1422966075Productos_org\%C3\%A1nicos_certificaci\%C3\%B3n.pdf. Recuperado: 20 de enero del 2016

97 Gobierno de Chile, Oficina Comercial de ProChile en R.P. China - Beijing. (2013). Tendencias del Mercado: Alimentos Orgánicos en la R. P. China. Obtenido de http://www.prochile.gob.cl/wpcontent/blogs.dir/1/files_mf/1367963128China_Tendencias_Organicos_2013_Beijing.pdf. Recuperado: 25 de mayo del 2015

98 Consulado General y Centro de Promoción Argentina En Shanghái. (2015). Perfil del mercado de arándano en China. Obtenido de Promoción Comercial: https://www.santanderrio.com.ar/banco/wcm/connect/171b0dda-dc43-4f1d9304-1f074ba0fc95/CSHAN+informe+de+mercado+de+arandano.pdf. Recuperado:18 de enero del 2016

99 Gobierno de Chile, Ministerio de Agricultura. (2013). Agricultura Orgánica Nacional: Bases Técnicas y Situación Actual [PDF]. Obtenido de http://www.sag.cl/sites/default/files/agricultura_org._nacional_bases_tecnicas_y_situacion_actual_2013.pdf. Recuperado: 25 de mayo del 2015
} 
constar con las primeras producciones comerciales en la China, las cuales eran extensivas y tecnificadas ${ }^{100}$.

En el 2015 el arándano es cultivado en veintisiete provincias de China, concentrado mas de la mitad en solo tres: Shangong 25\%, Liaoning $22 \%$ y Jilin $19 \%$, ubicadas en el norte de China ${ }^{101}$.

La producción interna temporada 2014-2015 fue de 27.077 toneladas, las cuales tuvieron una fuerte inversión por parte del gobierno chino, estimando alcanzar las 50.000 toneladas en la temporada $2015-2016^{102}$.

La temporada de cosecha se concentra durante cuatros meses, desde finales de marzo a inicios de agosto, siendo los meses de junio y julio los más productivos.

Destinada en la mayoría a consumo interno de carácter local ${ }^{103}$.

\subsubsection{Demanda de arándanos}

La situación económica que ha experimentado China en las últimas décadas ha generado una clase media con alto poder adquisitivo con ciudades altamente pobladas (como, por ejemplo: Beijin, Shanhái, Guangzhou y Shenzhen) las convierte en zonas que consumen 8 veces más alimento que el resto del país ${ }^{104}$.

La ingesta anual por persona de arándano en las ciudades súper pobladas se estima en 46 gramos, lo que equivale aproximadamente a 38 bayas o un tercio de una taza; para las ciudades menos pobladas -que son del tamaño de Buenos Aires- son de 6 bayas $^{105}$.

El mercado por menor, los precios de comercialización a cliente final del arándano importado varían entre 136 y 156 CNY por jin (un jin 斤, es una unidad de masa tradicional China, que es usada ampliamente en las tiendas y comercios para pesar alimentos, equivale a 604,78982 gramos en Hong Kong y en China Continental se aproxima a 500 gramos); aproximadamente $22-25$ USD $^{106}$ por medio kilogramos de

\footnotetext{
100 Consulado General y Centro de Promoción Argentina En Shanghái. (2015). Perfil del mercado de arándano en China. Obtenido de Promoción Comercial: https://www.santanderrio.com.ar/banco/wcm/connect/171b0dda-dc43-4f1d9304-1f074ba0fc95/CSHAN+informe+de+mercado+de+arandano.pdf. Recuperado:18 de enero del 2016

101 Consulado General y Centro de Promoción Argentina En Shanghái. (2015). Perfil del mercado de arándano en China. Obtenido de Promoción Comercial: https://www.santanderrio.com.ar/banco/wcm/connect/171b0dda-dc43-4f1d9304-1f074ba0fc95/CSHAN+informe+de+mercado+de+arandano.pdf. Recuperado:18 de enero del 2016

102 Consulado General y Centro de Promoción Argentina En Shanghái. (2015). Perfil del mercado de arándano en China. Obtenido de Promoción Comercial: https://www.santanderrio.com.ar/banco/wcm/connect/171b0dda-dc43-4f1d9304-1f074ba0fc95/CSHAN+informe+de+mercado+de+arandano.pdf. Recuperado:18 de enero del 2016

103 Eguillor, P. (7 de septiembre de 2015). Mirada desde el Gobierno Chileno al potencial orgánico del arándano. (C. Vivanco, Entrevistador)

104 Lo Coco, M. (21 de agosto de 2015). Importancia de los productos orgánicos en Hong Kong y en Asia. (C. Vivanco, Entrevistador)

105 Consulado General y Centro de Promoción Argentina En Shanghái. (2015). Perfil del mercado de arándano en China. Obtenido de Promoción Comercial: https://www.santanderrio.com.ar/banco/wcm/connect/171b0dda-dc43-4f1d9304-1 f074baOfc95/CSHAN+informe+de+mercado+de+arandano.pdf. Recuperado:18 de enero del 2016

106 Cambio a enero del 2015: 1CNY=0.1611 USD
} 
arándano importado. Además del consumo como fruta fresca se puede encontrar en confituras, pastelería, dulces, jugos, productos lácteos, vinos, gelatinas y snack ${ }^{107}$.

Los principales países exportadores de arándano a China son: Canadá 31\%, Chile $24 \%$ y Estados Unidos 19\%; siendo Chile un actor principal dado que actualmente se ha convertido en uno de los principales proveedores de fruta fresca en toda Asia, debido a dos factores: el primero tiene relación con la oferta complementaria de contra estación de producción y la segunda a un tratado comercial el cual establece un tratamiento arancelario e impuesto de $0^{108}$.

China para el 2025, se estima, que la demanda de arándano será cercana a un millón de toneladas, siendo un desafío mundial poder atender a esta necesidad futura ${ }^{109}$.

\subsubsection{Situación de Hong Kong}

Dado que Hong Kong ha sido y es, el puente de China con el mundo occidental en aspectos de comercio exterior es considerado un mercado más maduro con respecto al de China Continental ${ }^{110}$. Las producciones internas de alimento son muy escasas o inexistentes, principalmente por condiciones climáticas y por cambio del uso de suelo ${ }^{111}$.

Con respecto al mercado hortofrutícola, se utiliza una reexportación desde Hong Kong, hacia el mercado de China Continental y hacia el mercado japonés; siendo las cerezas, uvas y naranjas las más importantes ${ }^{112}$.

Las preferencias del consumidor de fruta fresca en Hong Kong, destacan las compras en góndola de supermercados, compra fruta de forma frecuente y en pocas cantidades -más que unidad buscan la porción-, con privilegio a productos orgánicos y bio-saludables con una preocupación en la seguridad alimentaria y nutricional; con gran disposición al gasto en alimentación ${ }^{113}$.

107 Consulado General y Centro de Promoción Argentina En Shanghái. (2015). Perfil del mercado de arándano en China. Obtenido de Promoción Comercial: https://www.santanderrio.com.ar/banco/wcm/connect/171b0dda-dc43-4f1d9304-1f074ba0fc95/CSHAN+informe+de+mercado+de+arandano.pdf. Recuperado:18 de enero del 2016

108 Ministerio de Agricultura de Chile. (2013). Mercado y Proyecciones del Cultivo del Arándano. Obtenido de http://www.minagri.gob.cl/wp-content/uploads/2013/08/Mercado-y-proyecciones-del-cultivo-dear\%C3\%A1ndanos.pdf. Recuperado: 25 de mayo del 2015

109 Consulado General y Centro de Promoción Argentina En Shanghái. (2015). Perfil del mercado de arándano en China. Obtenido de Promoción Comercial: https://www.santanderrio.com.ar/banco/wcm/connect/171b0dda-dc43-4f1d9304-1f074ba0fc95/CSHAN+informe+de+mercado+de+arandano.pdf. Recuperado:18 de enero del 2016

110 Export Entreprises SA. (2016). HONG KONG: POLÍTICA Y ECONOMÍA. Obtenido de Santander Trade: https://es.portal.santandertrade.com/analizar-mercados/hong-kong/politica-y-economia. Recuperado: 11 de octubre del 2016

111 Zheng, P. (2006). Geografía China. Shanghái: China Intercotineal Press.

112 Consulado General y Centro de Promoción Argentina En Shanghái. (2015). Perfil del mercado de arándano en China. Obtenido de Promoción Comercial: https://www.santanderrio.com.ar/banco/wcm/connect/171b0dda-dc43-4f1d9304-1f074ba0fc95/CSHAN+informe+de+mercado+de+arandano.pdf. Recuperado:18 de enero del 2016.

113 Gobierno de Chile, Servicio Agricola Ganadero [SAG]. (2014). Centros de documentación SAG. Obtenido de LINEAMIENTOS PARA EXPORTACIÓN DE ARÁNDANOS A CHINA: http://www.sag.cl/sites/default/files/lineamientos_exportacion_arandanos_a_china.pdf. Recuperado: 25 de mayo del 2015 
El arándano es un producto relativamente nuevo en el mercado interno de Hong

Kong, el cual complementa la rica dieta en frutas y verduras que se consumen de forma tradicional $^{114}$. 


\section{CAPITULO III: SITUACIÓN DEL ESCENARIO EXTERNO DEL MERCADO HORTOFRUTÍCOLA EN ARGENTINA, CHILE Y EN LA REGIÓN ADMINISTRATIVA ESPECIAL HONG KONG, DE LA REPÚBLICA POPULAR CHINA}

En este capítulo, revisaremos los escenarios externos de Argentina, Chile y de Hong Kong, abordando para cada uno siete aspectos a desarrollar: políticos, legales, económicos, socioculturales, tecnológicos, ecológicos y geográficos; con sesgo en el mercado hortofrutícola.

\subsection{Escenario Externo Mercado Hortofrutícola en Argentina}

Argentina posee un mercado hortofrutícola interno muy importante, además de un aumento paulatino en el mundo; en el 2013, se observó un alza de exportaciones de peras, limones y manzanas; pero también se observo disminución en las exportaciones de uva y frutas de carozo ${ }^{115}$.

Según los registros, se observa una disminución en los volúmenes netos totales de exportación del mercado de frutas, sin embargo, en términos monetarios, esta disminución es menos significativa, dado que se exportan frutas que se comercializan a mayor precio $^{116}$.

\subsubsection{Políticos}

Argentina posee una democracia Representativa, Republicana y Federal; con un Gobierno de carácter Nacional y 23 Gobernaciones Provinciales, más la Ciudad Autónoma de Buenos Aires ${ }^{117}$.

El Poder Legislativo es bicameral y es representado en el Congreso Nacional; compuesto por el Senado de la Nación con 73 senadores, presidida por el Vicepresidente de la Nación; y la Cámara de diputados compuesta por 257 miembros ${ }^{118}$.

115 Brendecke, U. (2014). El mercado frutihortícola argentino y su comercialización. Obtenido de Info Campo: www.infocampo.com.ar/el-mercado-frutihorticola-argentino-y-su-comercializacion/. Recuperado:15 de Octubre del 2015

116 Brendecke, U. (2014). El mercado frutihortícola argentino y su comercialización. Obtenido de Info Campo:

www.infocampo.com.ar/el-mercado-frutihorticola-argentino-y-su-comercializacion/. Recuperado:15 de Octubre del 2015

117 Gobierno de Argentina, Presidencia de la Nación. (2016). Los Tres Poderes. Obtenido de Casa Rosada, Nuestro País: https://www.casarosada.gob.ar/nuestro-pais/organizacion?id=2722. Recuperado: 12 de septiembre del 2016

118 Gobierno de Argentina, Presidencia de la Nación. (2016). Los Tres Poderes. Obtenido de Casa Rosada, Nuestro País: https://www.casarosada.gob.ar/nuestro-pais/organizacion?id=2722. Recuperado: 12 de septiembre del 2017 
El Poder Ejecutivo Nacional es de carácter unipersonal y de elección popular, obteniendo el titulo de Presidente de la Nación Argentina; siendo Jefe de Estado, de la Administración Publica Nacional y Comandante en Jefe de las Fuerzas Armadas ${ }^{119}$.

En aspecto de la corrupción, Argentina fue clasificada por la ONG de Transparencia Internacional 2016, con 36 puntos de una escala de 100, siendo 0 altamente corrupto y 100 muy poco corrupto; ocupando el puesto relativo mundial $95^{120}$.

\subsubsection{Legales}

La Constitución adoptada por Argentina fue iniciada en 1853 , el $1^{\circ}$ de mayo en Santa Fe, por el Congreso General Constituyente de la Confederación Argentina, siendo objeto de reformas en 1860, incorporando la Provincia de Buenos Aires. En el año 1949, se remplazaron los textos, pero fueron dejados sin efecto por el Gobierno Provisorio en 1956, el cual recuperó los anteriores. Ya en el año 1994, la Convención Nacional Constituyente aprobó reformas a la Constitución Nacional, siendo esta ultima la vigente actualmente. Todas las autoridades del Gobierno Federal tienen sede en la Ciudad Autónoma de Buenos Aires ${ }^{121}$.

El poder Judicial está organizado por jueces federales y por jueces con diferentes jurisdicciones, todos encabezados por la Corte Suprema de Justicia. La Corte Suprema esta compuesta por un presidente, un vicepresidente y tres ministros, todos seleccionados directamente por el presidente, ratificados por el Senado y el Congreso de la Nación ${ }^{122}$.

Por Constitución, en Argentina existe un Ministerio Público que funciona como órgano independiente con autonomía funcional y financiera, teniendo como objetivo el promover las gestiones en temas de justicia, considerándose como un cuarto poder o un órgano extra poder del sistema ${ }^{123}$

\subsubsection{Económicos}

Argentina posee una de las economías más importantes de América Latina, con un Producto Interno Bruto (PIB) de más de US\$600 mil millones; encontrándose en una

\footnotetext{
119 Organización de los Estados Americanos. (2007). Sistema de administración de justicia Argentino. Obtenido de http://www.oas.org/juridico/MLA/sp/arg/sp_arg-int-description.html. Recuperado: 20 de mayo del 2015 120 Transparency International. (2017). CORRUPTION PERCEPTIONS INDEX 2016. Obtenido de https://www.transparency.org/news/feature/corruption_perceptions_index_2016. Recuperado: 10 de enero del 2018

121 Organización de los Estados Americanos. (2007). Sistema de administración de justicia Argentino. Obtenido de http://www.oas.org/juridico/MLA/sp/arg/sp_arg-int-description.html. Recuperado: 20 de mayo del 2015 122 Organización de los Estados Americanos. (2007). Sistema de administración de justicia Argentino. Obtenido de http://www.oas.org/juridico/MLA/sp/arg/sp_arg-int-description.html. Recuperado: 20 de mayo del 2015 123 Procuración General de la Nación. (2016). Ministerio Público Fiscal. Obtenido de Qué es el MPF: https://www.mpf.gob.ar/que-es-el-mpf/ Recuperado: 15 de octubre del 2017
} 
constante transformación, teniendo como eje promover el desarrollo económico sostenible con inclusión social e inserción en la economía global ${ }^{124}$.

La moneda es el Peso Argentino (símbolo: \$, ISO 4217: $032 \mathrm{AR}^{125}$ ), registrando una inflación en el 2015 de casi un 30\%, la segunda más alta del bloque, siendo superada por Venezuela con $160 \%$, provocando una constante desvalorización del peso $\operatorname{argentino~}^{126}$, junto con políticas económicas regulatorias estrictas; ya a finales del 2015 el sistema regulatorio comienza a flexibilizar y a normalizar el libre mercado cambiario argentino ${ }^{127}$.

Dado que posee abundantes recursos naturales, teniendo tierras muy fértiles, convierte a Argentina en una potencia en producción de alimento, con industrias de gran escala en los sectores de agricultura (cultivos anuales) y ganadería (bovinos) ${ }^{128}$.

En la microeconómica de la población argentina, se observa una brecha económica muy significativa, según la Organización para la Cooperación y el Desarrollo económico $(\mathrm{OCDE})^{129}$ el 10\% de la población más rica recibió ingresos promedio 23 veces más altos que el $10 \%$ más pobre; con un coeficiente de GINI $0,424^{130}$.

\subsubsection{Socioculturales}

Argentina posee geográficamente un gran tamaño, con diferentes climas y de grandes contrastes, siendo reflejado esto en su cultura y sociedad, sumado a la gran corriente de inmigraciones durante los siglos diecinueve y veinte de diversos países europeos (Italia, Alemania, España e Irlanda entre otros), además del actual crecimiento constante de inmigraciones de Latino América y Asia (China, Japón y Corea); todos estos factores han estimulado y favorecido de forma muy positiva la música, el teatro, la danza y la cultura en general. Los museos, los teatros, las galerías de arte, el cine argentino, el baile, la música y la arquitectura -por nombrar algunas- tienen fama y prestigio a nivel ISO 4217: https://www.iso.org/iso-4217-currency-codes.html. Recuperado: 23 de octubre del 2016

126 Infobae. (2017). IPC Congreso: la inflación superó el 40\% en 2016 y fue la más alta en 14 años. Obtenido de https://www.infobae.com/economia/2017/01/10/ipc-congreso-la-inflacion-supero-el-40-en-2016-y-fue-la-mas-altaen-14-anos/. Recuperado: 22 de mayo del 2017

127 Thomson Reuters. (2015). DATOS-¿Qué es el "cepo" cambiario de Argentina? Obtenido de https://ar.reuters.com/article/topNews/idARL1N1451XY20151216. Recuperado: 10 de enero del 2016

128 Banco Mundial. (2016). Argentina: panorama general. Obtenido de http://www.bancomundial.org/es/country/argentina/overview. Recuperado: 10 de octubre del 2016

129 Rivas, F. (2017). Argentina profundiza la desigualdad social. Obtenido de El Pais: https://elpais.com/economia/2017/01/06/actualidad/1483732167_789124.html. Recuperado: 20 de enero del 2018

130 Centro de Economía y Política Argentina. (2016). Desigualdad Un cambio con ganadores y perdedores. Obtenido de http://eppa.com.ar/wp-content/uploads/2016/11/Desigualdad-Octubre-2016.pdf. Recuperado:14 de enero del 2017 
mundial con importantes referentes muy apreciados; el folclore, el deporte y la gastronomía esta en la impronta de todo argentino ${ }^{131}$.

La población de argentina es estimada al 2015 aproximadamente en 43 millones, su capital es Buenos Aires; su religión oficial es el Catolicismo Romano; el idioma oficial es el español, con una expresión fonética particular ${ }^{132}$.

\subsubsection{Tecnológicos}

Dentro del bloque, los avances tecnológicos están rezagados, a pesar de su rezago, existen registros de avances importantes en agricultura específicamente en la generación de agroquímicos (fertilizantes y plaguicidas); también en la introducción de maquinaria y al uso de la biotecnología como herramienta para aumentar la productividad, siendo liderados éstos, por el Instituto Nacional de Tecnología Agropecuaria (INTA), según información, con presupuestos reducidos en I+D (Investigación y Desarrollo) $)^{133}$.

La agricultura de precisión, se abre paso como canal de penetración de tecnología en la industria privada, siendo el foco los cultivos de grano extensivos y frutales de mayor retorno monetario, como el arándano y la vid ${ }^{134}$.

\subsubsection{Ecológicos}

Argentina es rica en recursos naturales, posee una gran variedad de ecosistemas y de macrozonas climáticas. El clima predominante corresponde al árido y semiárido, siendo el recurso hídrico muy escaso, clima que contrasta fuertemente con la Mesopotamia y la Pampa húmeda Argentina ${ }^{135}$.

Argentina posee un Ministerio de Ambiente y Desarrollo Sustentable, creado a finales del 2015, el cual asiste directamente al Presidente de la Nación y todos los ministerios en temas medioambientales ${ }^{136}$.

131 Dos Manos Travel Agency. (2009). Argentina - Cultura y Sociedad. Obtenido de http://www.dosmanosargentina.com/travelargentina/spanish/cultura-y-sociedad.php. Recuperado: 10 de mayo del 2015

132 Instituto Nacional de Estadística y Censos. (2016). Proyecciones nacionales. Obtenido de Estimaciones y proyecciones de población. Total del país 2010-2040:

https://www.indec.gob.ar/nivel4_default.asp?id_tema_1=2\&id_tema_2=24\&id_tema_3=84. Recuperado: 10 de septiembre del 2017

133 García, S. I. (2016). Obtenido de GUÍA DE USO RESPONSABLE DE AGROQUÍMICOS: https://www.toxicologia.org.ar/wp-content/uploads/2016/03/guia_de_uso_de_agroquimicos.pdf. Recuperado:10 de enero del 2017

134 Maroni, J. (2010). Las nuevas Tecnologías y su impacto sobre la producción Agrícola. Obtenido de Facultad de Ciencias Agrarias, Universidad Nacional de Rosario: http://www.fcagr.unr.edu.ar/Extension/Agromensajes/14/3AM14.htm. Recuperado: 20 de mayo del 2015

135 Instituto Nacional de Tecnología Agropecuaria [INTA]. (2010). ATLAS CLIMÁTICO DIGITAL DE LA REPÚBLICA ARGENTINA. Obtenido de https://inta.gob.ar/sites/default/files/script-tmptexto_atlas_climtico_digital_de_la_argentina_110610_2.pdf. Recuperado: 20 de mayo del 2015

136 Ministerio de Ambiente y Desarrollo Sustentable. (2016). Institucional. Obtenido de www.abiente.gov.ar/institucional. Recuperado: 10 de junio del 2016 


\subsubsection{Geográficos}

Argentina esta situada en el extremo sur de América Latina y ubicada hacia el océano Atlántico. Limita al norte con Bolivia y Paraguay, al nordeste con Brasil, al oeste y sur con Chile y al este con Uruguay y el Océano Atlántico; tiene una extensión de $2.780 .400 \mathrm{~km}^{2}$. Argentina mantiene reclamaciones de soberanía sobre las islas Malvinas, Georgias del Sur, Sandwich del Sur y Aurora, administradas Actualmente por el Reino Unido $^{137}$.

\subsection{Escenario Externo Mercado Hortofrutícola en Chile.}

Chile se ha convertido en un líder regional latinoamericano; dentro de los principales factores destaca su estabilidad política, estrategia comercial orientada a la exportación, imagen país y producciones altamente tecnificadas, liderando en el bloque las exportaciones hortofrutícolas con valor agregado, introducción temprana de frutales exóticos y tratados comerciales con aranceles $0^{138}$.

\subsubsection{Políticos}

Chile posee una democracia Representativa y Republicana, con un Gobierno de carácter Nacional, con 15 regiones a lo largo y estrecho del territorio ${ }^{139}$.

El Poder Legislativo es bicameral y es representado en el Congreso Nacional, que se ubicada en el puerto de la ciudad de Valparaíso, compuesto por 38 senadores y 120 diputados $^{140}$.

El Poder Ejecutivo Nacional es de carácter unipersonal y de elección popular, obteniendo el titulo de presidente de Chile; siendo Jefe de Estado, de la Administración Publica y Comandante en Jefe de las Fuerzas Armadas; con mandato de 4 año, sin derecho a reelección ${ }^{141}$.

137 Aparicio, G., \& Gómez, C. (2005). Geografía Argentina - Polimodal. Obtenido de http://bdigital.uncu.edu.ar/objetos_digitales/1385/geografiaapoli.pdf. Recuperado: 22 de mayo del 2015 138 Gobierno de Chile, Dirección General de Relaciones Económicas Internacionales. (2009). Chile: 20 Años de Negociaciones Comerciales. Obtenido de http://www.direcon.gob.cl/wp-content/uploads/2013/09/Chile-20a\%C3\%B1os-de-negociaciones-comerciales1.pdf. Recuperado: 25 de mayo del 2015.

139 Gaete Coddou, G. (2006). MANUAL DE GEOGRAFIA DE CHILE. Obtenido de https://es.scribd.com/doc/286956087/Manual-Geografia-de-Chile. Recuperado: 10 de diciembre del 2016

140 Ministerio de Relaciones Exteriores. (2017). Chile en el Exterior Embajadas, Consulados y Misiones Multilaterales de Chile. Obtenido de Sistema político: https://chile.gob.cl/chile/sistema-politico. Recuperado: 15 de septiembre del 2017

141 Ministerio de Relaciones Exteriores. (2017). Chile en el Exterior Embajadas, Consulados y Misiones Multilaterales de Chile. Obtenido de Sistema político: https://chile.gob.cl/chile/sistema-politico. Recuperado: 15 de septiembre del 2017 
En aspecto de la corrupción, Chile, fue clasificada por la ONG de Transparencia Internacional 2016, con 66 puntos de una escala de 100, siendo 0 altamente corrupto y 100 muy poco corrupto; ocupando el puesto relativo mundial $24^{142}$.

\subsubsection{Legales}

El sistema legal de Chile esta basado en el código de 1857, el cual es derivado del derecho español e influenciados por el derecho francés y austriaco. La constitución actual vigente es del año 1980, la cual fue generada durante la dictadura militar, teniendo más de 18 reformas después que volvió la democracia $(1990)^{143}$.

El poder Judicial es un órgano independiente y autónomo; la Corte Suprema es integrada por 21 miembros, de los cuales uno es escogido por el presidente cada tres años. El sistema procesal chileno ha estado en una constante iteración y reformulación, siendo considerado dentro del bloque como moderno y ágil en la resolución de procesos ${ }^{144}$.

\subsubsection{Económicos}

Chile posee una de las economías más solidas de América Latina, con un Producto Interno Bruto (PIB) de más de US $\$ 250$ mil millones ${ }^{145}$.

La moneda es el Peso chileno (símbolo: \$, ISO 4217: 152 CLP $^{146}$ ), registrando una inflación en el 2015 de un 4,36\%, la tercera más baja del bloque y muy estable considerando la del año pasado ${ }^{147}$.

Chile no posee muchas tierras fértiles, pero si altos rendimiento acompañados con calidad, apoyados por el uso de tecnología y agricultura de precisión, siendo líder del bloque. Como ejemplo, se han registrado rendimientos sobre las 100 toneladas en remolacha por hectárea, un $40 \%$ más productivas que las remolachas cultivadas en países vecinos ${ }^{148}$.

\footnotetext{
142 Transparency International. (2017). CORRUPTION PERCEPTIONS INDEX 2016. Obtenido de https://www.transparency.org/news/feature/corruption_perceptions_index_2016. Recuperado: 10 de enero del 2018

143 Export Entreprises SA. (2017). CHILE: ENTORNO LEGAL. Obtenido de https://es.portal.santandertrade.com/establecerse-extranjero/chile/entorno-legal. Recuperado: 12 de diciembre del 2017

144 Export Entreprises SA. (2017). CHILE: ENTORNO LEGAL. Obtenido de https://es.portal.santandertrade.com/establecerse-extranjero/chile/entorno-legal. Recuperado: 12 de diciembre del 2017

145 Unidad Editorial Información Económica S.L. (2016). Chile: EI PIB ascendió un 2,3\%. Obtenido de https://datosmacro.expansion.com/pib/chile?anio=2015. Recuperado: 10 de junio del 2016

146 International Organization for Standardization. (2016). Códigos de monedas ISO 4217 . Obtenido de Currency codes ISO 4217: https://www.iso.org/iso-4217-currency-codes.html. Recuperado: 23 de octubre del 2016

147 Editorial Ecoprensa S.A. (2016). La inflación en Chile cierra el año 2015 en un 4,4\%, bajo las proyecciones. Obtenido de https://www.eleconomistaamerica.cl/economia-eAm-chile/noticias/7265204/01/16/La-inflacion-en-Chile-cierrael-ano-2015-en-un-44-por-ciento.html. Recuperado: 15 de junio del 2016

148 Olfos, M. J. (2013). Obtenido de Proyecciones del mercado internacional del azúcar y cultivo nacional de remolacha: https://www.odepa.gob.cl/odepaweb/publicaciones/doc/9033.pdf. Recuperado: 25 de mayo del 2015
} 
En la microeconomía de la población chilena, se observa una brecha económica muy significativa según la Organización para la Cooperación y el Desarrollo económico (OCDE) el $10 \%$ de la población más rica recibió ingresos promedio 26,5 veces más altos que el $10 \%$ más pobre; con un coeficiente de GINI $0,477^{149}$.

\subsubsection{Socioculturales}

Etnográficamente la población chilena proviene principalmente de la mezcla de los pueblos españoles, precolombinos y mapuches, no teniendo influencias significativas de otras culturas; el aislamiento natural de la cordillera de los Andes, el océano pacifico y el desierto más árido del mundo, han ayudado a generar una cultura más reservada y conservadora ${ }^{150}$.

El vino y el pisco son parte de la cultura chilena, siendo consumidos en forma regular en cenas y celebraciones. La gastronomía es rica en uso de verduras, siendo la papa base en la alimentación, y con mayor frecuencia al sur; en el consumo de carnes destaca el vacuno, el pollo y el cerdo, así como también el consumo frecuente de pescados y frutos del mar ${ }^{151}$.

La población de Chile es estimada al 2016 aproximadamente en 17,6 millones de habitantes, su capital es Santiago; en temas religiosos posee libertad de culto, con una clara separación de la iglesia católica y el estado -siendo el Catolicismo Romano, la religión predominante-, el idioma oficial es el español ${ }^{152}$.

\subsubsection{Tecnológicos}

Chile es líder tecnológico dentro del bloque, destacan avances tecnológicos en diferentes industrias, siendo las más importantes: Minería, Industrias Creativas, Alimentos Saludables, Smart City (ciudades inteligentes) y Internet of Think loT (internet de las cosas) ${ }^{153}$; todos apoyados por una política gubernamental fuerte y constante entre los diferentes gobiernos ${ }^{154}$.

\footnotetext{
149 Programa de las Naciones Unidas Para el Desarrollo. (2017). Orígenes, cambios y desafíos de la brecha social en Chile. Obtenido de http://www.cl.undp.org/content/dam/chile/docs/pobreza/undp_cl_pobreza-Libro-DESIGUALESfinal.pdf. Recuperado: 20 de septiembre del 2017

150 Fundación Universia. (2016). CULTURA Y TRADICIONES. Obtenido de http://www.universia.es/estudiarextranjero/chile/vivir/cultura-tradiciones/3194. Recuperado: 10 de diciembre del 2016

151 Fundación Universia. (2016). CULTURA Y TRADICIONES. Obtenido de http://www.universia.es/estudiarextranjero/chile/vivir/cultura-tradiciones/3194. Recuperado: 10 de diciembre del 2016

152 Instituto Nacional de Estadísticas. (2016). DEMOGRÁFICAS Y VITALES. Obtenido de http://www.ine.cl/estadisticas/demograficas-y-vitales. Recuperado: 10 de septiembre del 2017

153 Araneda, C. (2017). National Innovation System: Reflections and analysis of the Chilean case. Obtenido de https://scielo.conicyt.cl/pdf/idesia/v35n4/0718-3429-idesia-35-04-00111.pdf. Recuperado:10 de enero del 2018

154 Gattavara, F. (2017). Chile: Avances tecnológicos cambiarán los empleos, pero no los harán desaparecer. Obtenido de https://www.america-retail.com/chile/chile-avances-tecnologicos-cambiaran-los-empleos-pero-no-los-harandesaparecer/. Recuperado: 20 de noviembre del 2017
} 
Destaca StartUp-Chile aceleradora de negocios, la cual esta clasificada dentro de las 10 mejores del mundo, cuyo objetivo es atraer capital humano internacional altamente capacitado para realizar innovación y emprendimiento en Chile ${ }^{155}$.

El beneficio tributario y subsidio de carácter directo en I+D+i (Investigación, Desarrollo e implementación); junto con la política de trabajo colaborativo académico, público y privado; y acuerdos internacionales de desarrollo tecnológico, son las herramientas que sostiene el crecimiento tecnológico en Chile ${ }^{156}$.

En agricultura destacan los avances en: la creación de nuevas variedades de frutales, patentamiento de agroquímicos, usos de agricultura de precisión y control entomopatogeno ${ }^{157}$ de plagas; todos liderados por el Instituto Nacional de Investigación Agropecuaria (INIA) ${ }^{158}$.

La Corporación de Fomento de la Producción (CORFO) del ministerio de Economía y la Fundación para la Innovación Agraria (FIA) del ministerio de Agricultura, son las intuiciones nacionales que, lideran, soporta y subsidian, potenciando la experimentación y disminuyendo los riesgos vinculados a la introducción de nuevas tecnologías ${ }^{159}$.

\subsubsection{Ecológicos}

El clima mediterráneo es el más extendido en Chile, con cuatro estaciones bien marcadas, aunque también posee zonas de altos contrastes, como el clima árido del norte, el tropical de las islas polinésicas y glaciales del extremo sur; con una flora y fauna muy diversa ${ }^{160}$.

El Ministerio de Medio Ambiente, es un órgano del estado chileno que colabora con el presidente de la Nación, para el diseño y aplicación de políticas para la protección y conservación de la diversidad biológica y sustentabilidad de los recursos renovables ${ }^{161}$.

155 Ministerio de Economía, Fomento y Turismo. (2016). EVALUACIÓN DE IMPACTO DEL PROGRAMA START-UP CHILE DE CORFO. Obtenido de http://www.economia.gob.cl/wp-content/uploads/2016/08/Resumen-EjecutivoStart-Up-Chile-Abril-2016.pdf. Recuperado: 10 de septiembre del 2017

156 Araneda, C. (2017). National Innovation System: Reflections and analysis of the Chilean case. Obtenido de https://scielo.conicyt.cl/pdf/idesia/v35n4/0718-3429-idesia-35-04-00111.pdf. Recuperado:10 de enero del 2018 157 Serri, H. (8 de diciembre de 2015). Arándano orgánico en Chille, plagas y enfermedades. (C. Vivanco, Entrevistador) 158 Vargas, S. (23 de junio de 2016). El arándano orgánico en Chile, avances en tecnología, producción y calidad. (C. Vivanco, Entrevistador)

159 Eguillor, P. (7 de septiembre de 2015). Mirada desde el Gobierno Chileno al potencial orgánico del arándano. (C. Vivanco, Entrevistador)

160 Gaete Coddou, G. (2006). MANUAL DE GEOGRAFIA DE CHILE. Obtenido de https://es.scribd.com/doc/286956087/Manual-Geografia-de-Chile. Recuperado: 10 de diciembre del 2016 161 Ministerio del Medio Ambiente. (2016). http://portal.mma.gob.cl/estructura/. Obtenido de http://portal.mma.gob.cl/estructura/. Recuperado: 10 de noviembre del 2016 


\subsubsection{Geográficos}

Chile está situado en el extremo sur de América Latina, cuyo territorio se extiende por el oeste y suroeste de Sudamérica; limita al norte con Perú, al este con Bolivia y Argentina, y al sur y al oeste con el océano Pacífico; tiene una extensión aproximada de $756.626 \mathrm{~km}^{2}$, mantiene una soberanía histórica en la Antártica, entre los $53^{\circ}$ y los $90^{\circ} \mathrm{de}$ longitud Oeste ${ }^{162}$.

Chile además cuenta con una serie de archipiélagos comenzando desde la isla de Chiloé hasta las islas Diego Ramírez; también posee las islas de Juan Fernández, la isla de Pascua, la de Sala y Gómez y la de San Félix y San Ambrosio, todas ellas en el Pacífico Sur ${ }^{163}$.

\subsection{Escenario Externo Mercado Hortofrutícola en Hong Kong, China}

Hong Kong es una zona geográfica estratégica tanto comercial como militar, como puente a China continental ${ }^{164}$. En la Guerra del Opio (1839-1842) fue tomada como colonia británica, después en la segunda guerra mundial fue ocupada por Japón, tomando el control británico nuevamente en el año 1942; en 1984 se llegó a un acuerdo entre Reino Unido y China para retornar los territorios a China Central volviendo a tener soberanía por parte de China en 1997 hasta la actualidad ${ }^{165}$. Todos estos eventos han marcado y diferenciado en los aspectos externos con respectos a los de China Continental, estando en una transición siendo comúnmente llamado "un país, dos sistemas"; dado que lentamente del sistema británico se esta transitando al sistema Chino central ${ }^{166}$.

A nivel internacional, Hong Kong es muy interesante para el mercado de exportación hortofrutícola; durante el 2016 se importaron más de US\$4.340 millones en fruta y más de US\$658 millones en hortalizas, de las cuales solamente en fruta fresca registran un valor cercano a los US\$2.600 millones destacando las uvas, duraznos naranjas, manzanas y ciruelas ${ }^{167}$.

\footnotetext{
162 Gaete Coddou, G. (2006). MANUAL DE GEOGRAFIA DE CHILE. Obtenido de https://es.scribd.com/doc/286956087/Manual-Geografia-de-Chile. Recuperado: 10 de diciembre del 2016 163 Gaete Coddou, G. (2006). MANUAL DE GEOGRAFIA DE CHILE. Obtenido de https://es.scribd.com/doc/286956087/Manual-Geografia-de-Chile. Recuperado: 10 de diciembre del 2016 164 Garcia, T. (2005). Hong Kong, Puente de encuentro del Oriente y Occidente. Obtenido de http://catarina.udlap.mx/u_dl_a/tales/documentos//ri/garcia_t_g/capitulo1.pdf. Recuperado: 10 de julio del 2017 165 Lo Coco, M. (21 de agosto de $201 \overline{5}$ ). Importancia de los productos orgánicos en Hong Kong y en Asia. (C. Vivanco, Entrevistador)

166 Export Entreprises SA. (2016). HONG KONG: POLÍTICA Y ECONOMÍA. Obtenido de Santander Trade: https://es.portal.santandertrade.com/analizar-mercados/hong-kong/politica-y-economia. Recuperado: 11 de octubre del 2016

167 Lo Coco, M. (21 de agosto de 2015). Importancia de los productos orgánicos en Hong Kong y en Asia. (C. Vivanco, Entrevistador)
} 


\subsubsection{Políticos}

Hong Kong es una Región Administrativa Especial (RAS) de la República Popular de China, pertenece a China, pero la administración política, económica y legal es separada; actualmente posee un jefe del Poder Ejecutivo, considerado el Presidente de Consejo Ejecutivo de Hong Kong y del Gobierno de la Región Administrativa Especial de Hong Kong , elegido cada 5 años por un comité electoral de 1.200 miembros, en las cuales están incluidos parlamentarios, personalidades importantes y representantes de los sectores profesionales ${ }^{168}$.

Junto con el Jefe del Poder Ejecutivo existe un Consejo Ejecutivo, el cual esta integrados por 17 ministros del gobierno más 15 miembros no oficiales, que son nombrados por el Jefe del Poder Ejecutivo, estos son empresarios y personas civiles sin cargos públicos; es en este sistema, donde se elabora la política del gobierno ${ }^{169}$.

Hong Kong posee un nivel alto de autonomía política con respecto a China, pero ésta no es completa; China impone que dentro del sistema político existan partidos de interés de China central, siendo de carácter obligatorio, con voz y voto; los partidos políticos actúan bajo la forma de empresas o corporaciones ${ }^{170}$.

En aspecto de la corrupción, Hong Kong, fue clasificada por la ONG de Transparencia Internacional 2016, con 77 puntos de una escala de 100, siendo 0 altamente corrupto y 100 muy poco corrupto; ocupando el puesto relativo mundial $15^{171}$.

\subsubsection{Legales}

El sistema legal de Hong Kong, está contenido en la "Ley Fundamental" que dispone en términos generales que Hong Kong coexistirá con China como "un país, dos sistemas" durante 50 años después del retorno a China por parte de Reino Unido; esta ley expira en el año 2047; existe una constante tensión y fuerza de poder por parte China, declarando que legalmente posee jurisdicción absoluta, cosa que se contrapone a los derechos y libertades de los residentes de Hong Kong ${ }^{172}$.

La ley fundamental es homologada como una constitución la cual fue aceptada por el Gobierno Popular Chino en el año 1990, como parte del tratado con Reino Unido.

\footnotetext{
168 Export Entreprises SA. (2016). HONG KONG: POLÍTICA Y ECONOMÍA. Obtenido de Santander Trade: https://es.portal.santandertrade.com/analizar-mercados/hong-kong/politica-y-economia. Recuperado: $11 \mathrm{de}$ octubre del 2016

169 Lopez, M. (2011). El estatuto jurídico-político de Hong Kong en la República Popular de China. Obtenido de https://revistas.um.es/analesderecho/article/view/118071/111611/. Recuperado: 10 de noviembre del 2016

170 Export Entreprises SA. (2016). HONG KONG: POLÍTICA Y ECONOMÍA. Obtenido de Santander Trade: https://es.portal.santandertrade.com/analizar-mercados/hong-kong/politica-y-economia. Recuperado: 11 de octubre del 2016

171 Transparency International. (2017). CORRUPTION PERCEPTIONS INDEX 2016. Obtenido de https://www.transparency.org/news/feature/corruption_perceptions_index_2016. Recuperado: 10 de enero del 2018

172 López, M. (2011). El estatuto jurídico-político de Hong Kong en la República Popular de China. Obtenido de https://revistas.um.es/analesderecho/article/view/118071/111611/. Recuperado: 10 de noviembre del 2016
} 
El poder legislativo, es monocamaral liderado por el Consejo Legislativo ${ }^{173}$, es éste consejo el encargado de presentar propuestas legales, examinar y aprobar presupuestos, también toma decisiones impositivas y es encargado de nombrar al presidente del Tribunal Supremo; otra función que posee este consejo es monitorear y supervisar la conducta del jefe del Poder Ejecutivo y que el gobierno en su totalidad aplique la política de forma correcta ${ }^{174}$.

\subsubsection{Económicos}

Hong Kong es considerada la décima potencia económica y la tercera plaza financiera más importante en el mundo, un modelo del liberalismo económico, con un Producto Interno Bruto sobre los US $\$ 320$ miles de millones ${ }^{175}$.

La moneda es el Dólar de Hong Kong (símbolo: \$, ISO 4217: 344 es HKD ${ }^{176}$ ), registrando una inflación en el 2015 de un 3\%, siendo esta moneda una de las 10 más transadas en el mundo ${ }^{177}$.

La estabilidad y crecimiento económico se basan en la orientación histórica que tiene la bahía de Hong Kong como uno de los puertos principales del mundo ${ }^{178}$, una región orientada a los servicios y como puente de reexportación ${ }^{179}$.

En la microeconomía de la población en Hong Kong, se observa una brecha económica muy significativa, según la Organización para la cooperación y el desarrollo económico $(\mathrm{OCDE})^{180}$ el 10\% de la población más rica recibió ingresos promedio 32 veces más altos que el $10 \%$ más pobre, con un coeficiente de GINI de $0,537^{181}$.

173 López, M. (2011). El estatuto jurídico-político de Hong Kong en la República Popular de China. Obtenido de https://revistas.um.es/analesderecho/article/view/118071/111611/. Recuperado: 10 de noviembre del 2016 174 Export Entreprises SA. (2016). HONG KONG: POLÍTICA Y ECONOMÍA. Obtenido de Santander Trade: https://es.portal.santandertrade.com/analizar-mercados/hong-kong/politica-y-economia. Recuperado: 11 de octubre del 2016

175 Export Entreprises SA. (2016). HONG KONG: POLÍTICA Y ECONOMÍA. Obtenido de Santander Trade: https://es.portal.santandertrade.com/analizar-mercados/hong-kong/politica-y-economia. Recuperado: 11 de octubre del 2016

176 International Organization for Standardization. (2016). Códigos de monedas ISO 4217 . Obtenido de Currency codes ISO 4217: https://www.iso.org/iso-4217-currency-codes.html. Recuperado: 23 de octubre del 2016

177 Export Entreprises SA. (2016). HONG KONG: POLÍTICA Y ECONOMÍA. Obtenido de Santander Trade: https://es.portal.santandertrade.com/analizar-mercados/hong-kong/politica-y-economia. Recuperado: $11 \mathrm{de}$ octubre del 2016

178 Garcia, T. (2005). Hong Kong, Puente de encuentro del Oriente y Occidente. Obtenido de http://catarina.udlap.mx/u_dl_a/tales/documentos//ri/garcia_t_g/capitulo1.pdf. Recuperado: 10 de julio del 2017

179 Export Entreprises SA. (2016). HONG KONG: POLÍTICA Y ECONOMÍA. Obtenido de Santander Trade: https://es.portal.santandertrade.com/analizar-mercados/hong-kong/politica-y-economia. Recuperado: 11 de octubre del 2016

180 Dirección General de Relaciones Económicas Internacionales. (2016). ¿Qué es OCDE?. Obtenido de https://www.direcon.gob.cl/ocde/. Recuperado: 10 de noviembre del 2016

181 Organisation for Economic Co-operation and Development. (2016). Hong Kong, China. Obtenido de http://www.oecd.org/countries/hongkongchina/. Recuperado: 10 de noviembre del 2016 


\subsubsection{Socioculturales}

La población en Hong Kong posee una historia y un vínculo milenario con China Continental, pero que ha sido mezclada a la fuerza con otras culturas, principalmente con los más de 150 años del dominio bajo colonia y terreno de ultramar británico, y la ocupación japonesa, durante la segunda guerra mundial ${ }^{182}$.

El comunismo imperial convive junto con el sistema capitalista, entregando una impronta en el pueblo y una complejidad no completamente entendida por occidente; el pueblo se caracteriza por ser longevo y saludable, con un respeto inherente a la gente de edad; la alimentación es muy variada en verduras, carne y productos del $\operatorname{mar}^{183}$.

La población de Hong Kong es estimada al 2016 en 7,4 millones de habitantes, la capital es Ciudad Victoria ${ }^{184}$; en temas religiosos, posee libertad de culto coexistiendo de forma natural y dinámicamente tres líneas espirituales: budismo, taoísmo y confucionismo -una persona puede transitar por cualquiera de estas líneas durante su vida, no siendo una opuesta a la otra, como en el caso Latinoamericano-, el idioma oficial es el chino cantonés y el ingles, siendo introducido por china central el mandarín como idioma en los colegios $^{185}$.

\subsubsection{Tecnológicos}

La constante política interna ha convertido a Hong Kong, en un polo de desarrollo tecnológico, como una vitrina del oriente para el mundo. El gobierno ha destinado recursos de I+D+i, para el desarrollo de centros tecnológicos públicos creando Silicon Harbour, siendo el homólogo del Sillcon Vally en USA, centros que concentran universidades, entidades públicas y privadas; en un ecosistema de innovación y emprendimiento, al sostén de las nuevas tecnologías ${ }^{186}$.

Destacan el uso de la tecnología con servicios vinculados al mercado financiero internacional, análisis de grandes bases de datos y algoritmos matemáticos; hay usos en tecnologías en medioambiente y aplicaciones de energías renovables, también avances importantes en el mercado de flores ${ }^{187}$.

\footnotetext{
182 Garcia, T. (2005). Hong Kong, Puente de encuentro del Oriente y Occidente. Obtenido de http://catarina.udlap.mx/u_dl_a/tales/documentos//ri/garcia_t_g/capitulo1.pdf. Recuperado: 10 de julio del 2017 183 Fundación Universia. (2016). ESTUUDIAR EN HONG KONG . Obtenido de CULTURA Y TRADICIONES: http://www.universia.es/estudiar-extranjero/hong-kong/vivir/cultura-tradiciones/4640. Recuperado: 15 de junio del 2016

184 Datos Macros. (2017). Hong Kong - Población. Obtenido de https://datosmacro.expansion.com/demografia/poblacion/hong-kong Recuperado: 16 de enero del 2017 185 Fundación Universia. (2016). ESTUDIAR EN HONG KONG . Obtenido de CULTURA Y TRADICIONES : http://www.universia.es/estudiar-extranjero/hong-kong/vivir/cultura-tradiciones/4640. Recuperado: 15 de junio del 2016

186 Jolias, L. (2016). Hong Kong, nueva expresión del desafío de las ciudades inteligentes. Obtenido de https://politicacomunicada.com/cgi-sys/suspendedpage.cgi. Recuperado: 14 de julio del 2017

187 Revill, G. (2015). El mercado de servicios financieros en Hong Kong. Obtenido de https://www.icex.es/icex/es/navegacion-principal/todos-nuestros-servicios/informacion-de-
} 
Otro aspecto de interés son las ferias internacionales, "Asia Fruit Logistica" 2015 destacaron los usos de tecnologías en la trazabilidad, usos de códigos QR informativos, químicos que aumentan la poscosecha y usos de packaging sustentables ${ }^{188}$.

\subsubsection{Ecológicos}

El clima en Hong Kong es subtropical, se considera un clima muy agradable durante todo el año, es muy común las nubes bajas y las nieblas espesas; se distinguen claramente dos estaciones una húmeda y otra seca; dado a su posición geográfica los riesgos de tifones son frecuentes ${ }^{189}$.

Lamentablemente, dado al crecimiento de la ciudad y uso discriminado de químicos, se registran contaminaciones importantes en las napas subterráneas de deposito de agua dulce, así como contaminaciones por conceptos de basura ${ }^{190}$.

\subsubsection{Geográficos}

Hong Kong se encuentra al sureste de la Republica Popular de China, frente al mar de China meridional, se componen de tres territorios principalmente: Isla de Hong Kong, la península de Kowloon y los Nuevos Territorios. Tiene una extensión aproximada de $2.754 \mathrm{~km}^{2}$, considerado como uno de los puertos marítimos natural más profundo del mundo, cuenta con mas 260 islas y su península está inserta en el mar del Sur de China ${ }^{191}$.

mercados/paises/navegacion-principal/el-mercado/estudios-informes/DOC2015600286.html?idPais=HK. Recuperado: 11 de septiembre del 2016

188 Siekman, D. (2015). Fresh Fruits. Obtenido de Asia Fruit Logistica 2015: https://www.producereport.com/article/photosasia-fruit-logistica-2015. Recuperado: 10 de diciembre del 2016 189 Zheng, P. (2006). Geografía China. Shanghái: China Intercotineal Press. 190 Heifetz, J. (2017). Hong Kong se ha quedado casi sin espacio para la basura. Obtenido de https://www.vice.com/es_latam/article/bjz8x3/hong-kong-sin-espacio-para-basura. Recuperado: 15 de octubre del 2017

191 Zheng, P. (2006). Geografía China. Shanghái: China Intercotineal Press. 


\section{CAPITULO IV: SITUACIÓN DE RELACIONES COMERCIALES DEL MERCADO HORTOFRUTÍCOLA ORGÁNICO ENTRE ARGENTINA-CHILE, ARGENTINA-HONG KONG, CHINA Y CHILE-HONG KONG, CHINA.}

En este capitulo se revisarán las relaciones comerciales bilaterales entre Argentina-Chile, Argentina-Hong Kong y Chile-Hong Kong, con sesgo al mercado hortofrutícola orgánico. Revisando la histórica del inicio de las relaciones, además de revisión de los productos más importados, exportados y sus tendencias país en el mercado.

Además de los requerimientos actuales para exportar arándano orgánico a Hong Kong, China.

\subsection{Relaciones Comerciales del Mercado Hortofrutícola Orgánico entre Argentina y Chile}

\subsubsection{Relación bilateral Argentina-Chile}

Las relaciones bilaterales entre los países de Argentina y Chile datan desde los inicios de los mismos, hace más de 200 años cuando ambos países se emanciparon de la corona española por medio de una estrategia en conjunta tanto militar, económica y social, dando inicio en año 1810, regulándose y consolidándose en el año 1856 en el "Tratado de paz, amistad, comercio y navegación entre la República de Chile y la Confederación Argentina ${ }^{192}$.

El marco actual de las relaciones comerciales esta sostenido inicialmente en el Acuerdo Comercial Preferencial firmado en el año 1990, siendo actualizado con el Acuerdo de Complementación Económica entre Chile y el Mercado Común del Sur MERCOSUR (integrado por Argentina, Paraguay, Brasil y Uruguay) ${ }^{193}$, firmado 1996, el cual estableció a Chile como país asociado con el objetivo de: establecer un marco normativo para construir un espacio económico favorable, la liberación comercial de mercaderías, la gradualidad de liberación del comercio de servicios, la promoción de las inversiones, y de facilitar el desarrollo y utilización de la infraestructura física y de las

192 Embajada de Chile en Argentina. (2016). Relación bilateral. Obtenido de https://chile.gob.cl/argentina/relacion-bilateral. Recuperado: 11 de septiembre del 2016 
interconexiones bioceánicas; existen además, otros acuerdos y tratados entre ArgentinaChile $^{194}$ :

- "Tratado entre la República de Chile y la República de Argentina sobre Promoción y Protección Recíproca de Inversiones"

- "Tratado entre la República de Chile y la República Argentina sobre Integración y Complementación Minera"

- "Convenio de Pagos y Créditos Recíprocos de la ALADI".

- "Tratado de Integración de Maipú".

Para Argentina, el inicio de la regulación comercial de productos orgánicos comenzó en el año $1992^{195}$, para Chile en el $2006^{196}$; levantado estándar en ambos países durante el 2010-2012 donde se reglamentaron la identificación de productos, el etiquetado, sellos de origen y los protocolos de certificación, todo con una clara intención de nivelar estándares internacionales para la exportación ${ }^{197}$.

\subsubsection{Importaciones}

Argentina en el 2016 importo desde Chile principalmente cátodos y secciones de cátodos de cobre refinado, gas natural, salmones del atlántico enteros fresco 0 refrigerado, cajas de cambio y sus partes para vehículos de la partida 87.03 , y pulpas de tomate procesadas; moviendo un total aproximado de 742 millones USD ${ }^{198}$.

Además de ser el principal abastecedor de cobre en la Argentina, Chile juega un papel importante frutícola dado que es uno de los proveedores más relevantes de paltas, kiwis, pomelos, frutos secos y pulpas de frutas ${ }^{199}$.

\subsubsection{Exportaciones}

Argentina en el 2016 exportó hacia Chile principalmente: cereales y preparaciones con cereales, carne de bovinos deshuesada fresca o refrigerada, camionetas con capacidad de carga útil superior a 500 kilos, y los demás aceites de soya (soja) y sus

\footnotetext{
194 Dirección General de Relaciones Económicas Internacionales. (2016). 20 años del Acuerdo Mercosur. Obtenido de https://www.direcon.gob.cl/wp-content/uploads/2017/05/20-a\%C3\%B1os-del-Acuerdo-Chile-Mercosur.pdf. Recuperado: 10 de enero del 2017

195 Ramírez, J. C. (17 de julio de 2015). Situación de la Agricultura Orgánica en la Argentina, visión desde SENASA. (C. Vivanco, Entrevistador)

196 Catalán, C. C. (10 de agosto de 2015). Situación de la Agricultura Orgánica en Chile, visión desde SAG. (C. Vivanco, Entrevistador)

197 Montenegro, L. (23 de noviembre de 2015). Certificaciones de arándanos orgánicos producidos en Argentina y en Chile. (C. Vivanco, Entrevistador)

198 Embajada de Chile en Argentina. (2016). Relación bilateral. Obtenido de https://chile.gob.cl/argentina/relacion-bilateral. Recuperado: 11 de septiembre del 2016

199 Ministerios de Relaciones Exteriores. (2016). Exportaciones/importaciones. Obtenido de https://chile.gob.cl/argentina/asuntos-comerciales/oficina-comercial/exportaciones-importaciones. Recuperado: 10 de enero del 2017
} 
fracciones, incluso refinado, pero sin modificación química; moviendo un total aproximado de 2.770 millones USD ${ }^{200}$.

Argentina es el tercer proveedor más importante de Chile en productos orgánicos, destacando los cereales, las frutas y la carne bovina ${ }^{201}$.

\subsubsection{Tendencias}

Argentina y Chile son países que han generado entre ellos comercio de forma natural, dado a su cercanía, historia y política, pero con estrategias económicas distintas, Argentina se apegó completamente a un proceso integrador a través del Mercado Común del Sur (Mercosur), Chile, por su parte, se dispuso a importar materia prima y se ha vinculado en Tratados de Libre Comercio con grandes potencias como Estados Unidos, China, Unión Europea y Corea del Sur, y es miembro activo además, en el Foro de Cooperación Económica Asia-Pacífico (APEC) y de la Alianza del Pacifico (Chile, Colombia, México y Perú) $)^{202}$.

Argentina posee una mirada comercial interna, la cual en los últimos años recién ha retomado una apertura hacia nuevos y exóticos mercados; mientras tanto Chile se ha enfocado en la penetración, expansión y consolidación de mercados exteriores con una política fuerte y sostenida en el tiempo por más de 30 años.

La tendencia para Argentina y Chile es avanzar en los mercados exteriores con una mirada a productos y servicios con mayor valor agregado.

\subsection{Relaciones Comerciales del Mercado Hortofrutícola Orgánico entre Argentina y la} región administrativa especial de Hong Kong, de la República Popular China

\subsubsection{Relación bilateral Argentina-Hong Kong}

Las relaciones bilaterales entre Argentina y Hong Kong fueron débiles e irregulares en el tiempo, dado que Argentina priorizo su contacto con China Continental y con lo países limítrofes, más que con la colonia británica de Hong Kong ${ }^{203}$; en el año 1974 existen registros oficiales, pero estos pierden consistencia en año 1976 dado al inicio de la dictadura argentina, afectando sensiblemente las relaciones comerciales. El

\footnotetext{
200 Ministerios de Relaciones Exteriores. (2016). Exportaciones/importaciones. Obtenido de https://chile.gob.cl/argentina/asuntos-comerciales/oficina-comercial/exportaciones-importaciones. Recuperado: 10 de enero del 2017

201 Ministerios de Relaciones Exteriores. (2016). Exportaciones/importaciones. Obtenido de https://chile.gob.cl/argentina/asuntos-comerciales/oficina-comercial/exportaciones-importaciones. Recuperado: 10 de enero del 2017

202 Ministerio de Relaciones Exteriores. (2016). Acuerdos y Tratados Bilaterales. Obtenido de https://chile.gob.cl/argentina/relacion-bilateral/acuerdos-y-tratados-bilaterales. Recuperado: 11 de septiembre del 2016

203 Oviedo, E. (2015). El ascenso de China y sus efectos en la relación con Argentina. Obtenido de https://scielo.conicyt.cl/pdf/rei/v47n180/art04.pdf. Recuperado: 10 de enero del 2017
} 
principal producto exportado por argentina inicialmente fue el algodón, el cual fue rápidamente reemplazado por la carne bovina y sus derivados, teniendo un crecimiento a partir del año $1985^{204}$.

Las importaciones desde Hong Kong por parte de Argentina son igualmente irregulares, registrando tres picos los cuales se generaron durante los años 2004-2006, 2010-2012 y 2014-2016, todos productos relacionados con tecnología, ropa y calzado ${ }^{205}$.

Actualmente Argentina posee un consulado en Hong Kong, el cual apoya y promociona la cultura, turismo y el comercio ${ }^{206}$,

\subsubsection{Importaciones}

Argentina importa de Hong Kong principalmente circuitos electrónicos integrados, circuitos electrónicos sin montar y aparatos de recepción, convención, emisión y transmisión o generación de voz, imagen u otro dato ${ }^{207}$.

En detalle importan partes y piezas electrónicas para armado nacional de celulares, computadores y electrodomésticos en general; también destacan importaciones de partes y piezas de calzado ${ }^{208}$.

\subsubsection{Exportaciones}

Las exportaciones argentinas hacia Hong Kong son principalmente cueros recurtidos y engrasados, menudencias bovinas congeladas y cuero de bovino dividido.

Argentina, actualmente no es un socio clave en términos monetarios, mueve aproximadamente USD 240 millones en el 2016, correspondiente solamente al 0,03\% de las importaciones totales de Hong-Kong, casi la mitad de todas las exportaciones son concentradas desde la provincia de Buenos Aires ${ }^{209}$.

Argentina, a mediados de noviembre del 2018 realizo la primera exportación de arándano frescos a China ${ }^{210}$.

\subsubsection{Tendencias}

\footnotetext{
204 Cámara de Comercio Argentina. (2015). RELACIONES BILATERALES Argentina y Hong Kong - China . Obtenido de http://www.argentinahk.com/relaciones-bilaterales/. Recuperado: 10 de enero del 2017

205 Datos Macro. (2016). Comparar economía países: Argentina vs Hong Kong. Obtenido de https://datosmacro.expansion.com/paises/comparar/argentina/hong-kong. Recuperado: 10 de enero del 2017 206 Ministerio de Relaciones Exteriores y Culto. (2016). Consulado General de la Republica Argentina en Hong Kong. Obtenido de http://www.chong.mrecic.gov.ar/es/content/consulado-general-de-la-republica-argentina-en-hongkong. Recuperado: 10 de enero del 2017

207 The Observatory of Economic Complexit. (2016). Hong Kong. Obtenido de https://atlas.media.mit.edu/en/profile/country/hkg/. Recuperado: 10 de enero del 2017 208 The Observatory of Economic Complexit. (2016). Hong Kong. Obtenido de https://atlas.media.mit.edu/en/profile/country/hkg/. Recuperado: 10 de enero del 2017 209 The Observatory of Economic Complexit. (2016). Hong Kong. Obtenido de https://atlas.media.mit.edu/en/profile/country/hkg/. Recuperado: 10 de enero del 2017

210 Reinke, M. (2018). Realizan la primera exportación de arándanos a China. Obtenido de Diario la Nación https://www.lanacion.com.ar/2193498-arandanos-china-parte-primer-embarque. Recuperado: 20 de noviembre del 2018
} 
Argentina es una potencia en temas agroindustriales ${ }^{211}$, posee extensiones de tierras fértiles donde sus cultivos aun no han llegado a sus máximos potenciales de rendimientos.

La tendencia posiciona a Argentina como un actor clave en las relaciones comerciales con Asia, más aún con sus vínculos con China Continental, aumentando las exportaciones de granos y carnes, pero con un camino por recorrer en temas de acuerdos internacionales, estabilidad política-económica e imagen país.

\subsection{Relaciones Comerciales del Mercado Hortofrutícola Orgánico entre Chile y la} Región Administrativa Especial de Hong Kong, de la República Popular China

\subsubsection{Relación bilateral Chile-Hong Kong}

Las relaciones comerciales entre Chile y Región Administrativa Especial de Hong Kong, de la República Popular China, nacen en el año 1840, en donde se abre la primera Oficina de Asuntos Comerciales y Culturales, con un fin de velar el derecho comercial de Chile, teniendo un rol activo de supervisión; ya en el 1844 se establece el Consulado Chileno ${ }^{212}$.

Los primeros bienes exportados por Chile correspondieron a trigo y cobre, los cuales viajaban por más de 80 días, desde el puerto de Valparaíso hacia el Puerto de Hong Kong; e importados desde Hong Kong: finas sedas, madera lacada, biombos, especies, arroz y azúcar ${ }^{213}$.

Actualmente dado a este vínculo fructífero han nacido diferentes acuerdos, tratados, convenios, de los cuales destacan ${ }^{214}$.

- Memorando de Entendimiento sobre Cooperación vitivinícolas.

- Extensión de doble tributación en materia naviera.

- Acuerdo de cooperación entre comité de inversiones extranjeras de Chile e InvestHK.

- Tratado de libre Comercio TLC.

211 Landa, P. (28 de julio de 2015). La importancia de los productos orgánicos en Argentina y el mundo. Certificaciones y procesos. (C. Vivanco, Entrevistador)

212 Biblioteca del Congreso Nacional. (2012). Relaciones bilaterales Chile-Hong Kong y aspectos relevantes para la firma de un TLC. Obtenido de

Relacioneshttps://www.bcn.cl/obtienearchivo?id=repositorio/10221/14579/3/201252311628389_20125239173288 2_201252217476609_201252217313603_GRID_22_05_2012_SA_CF_JJ_HONG\%20KONG_.pdfbilaterales Chile-Hong Kong y aspectos relevantes para la firma de un TLC. Recuperado: 21 de octubre del 2016

213 Instituto de Relaciones Internacionales. (2017). El retorno de Hong Kong a China por parte del Reino Unido. Obtenido de http://www.iri.edu.ar/wp-content/uploads/2017/07/Efemerides_julio_espinoza.pdf. Recuperado: 10 de septiembre del 2017

214 Biblioteca del Congreso Nacional. (2012). Relaciones bilaterales Chile-Hong Kong y aspectos relevantes para la firma de un TLC. Obtenido de

Relacioneshttps://www.bcn.cl/obtienearchivo?id=repositorio/10221/14579/3/201252311628389_20125239173288 2_201252217476609_201252217313603_GRID_22_05_2012_SA_CF_JJ_HONG\%20KONG_.pdfbilaterales Chile-Hong Kong y aspectos relevantes para la firma de un TLC. Recuperado: 21 de octubre del 2016 
Sobre el TLC, el cual fue firmado el 7 de septiembre de 2012, en el marco de la cumbre de Líderes de El Foro de Cooperación Económica de Asia Pacífico (APEC) celebrada en Vladivostok, Federación de Rusia; destaca el arancel 0 para los productos orgánicos y blindaje ante cambios de políticas arancelarias futuras ${ }^{215}$.

Desde la mirada estratégica de ambos países se han desarrollado agendas complementarias de trabajo para impulsar cuatro áreas de interés común: Transporte Aéreo, Sector Alimentario; Educación, cultura y turismo; y Ciencia y tecnología.

\subsubsection{Importaciones Chile-Hong Kong.}

Chile importa de Hong Kong principalmente tecnología de toda Asia; el programa geoestratégico chino Belt \& Road establece a Hong Kong como centro comercial y Hub conector de mercados de la zona. Destacan las importaciones en equipos y componentes electrónicos de telecomunicaciones, computadores y calzado ${ }^{216}$.

La inversión de capitales en Chile desde Hong Kong, es una estrategia económica la cual esta promocionada y protegida en el acuerdo TLC, siendo uno de los ejes de las negociaciones, dado que la inversión de Hong Kong en el mundo es la segunda más importante para los países en desarrollo ${ }^{217}$.

\subsubsection{Exportaciones Chile-Hong Kong.}

Las exportaciones chilenas hacia Hong Kong son principalmente: frutas, frutos secos, bebidas alcohólicas y pescados; todos productos contenidos en el TLC del $2012^{218}$.

Chile, actualmente no es un socio clave en términos monetarios, mueve aproximadamente 1.434 millones USD en el 2016, correspondiente solamente al 0,2\% de las importaciones totales de Hong-Kong, pero si posee un gran prestigio en frutas de calidad organoléptica e inocuidad, como, las cerezas, ciruelas, duraznos, arándanos y uva de mesa, siendo uno de los principales proveedores internacionales teniendo un $65 \%$ de participación en el mercado de arándano, el $82 \%$ de participación en el mercado de

\footnotetext{
215 Servicio Nacional de Aduana de Chile. (2016). Tratado de Libre Comercio Chile - Hong Kong. Obtenido de https://www.aduana.cl/tratado-de-libre-comercio-chile-hong-kong/aduana/2014-12-04/120610.html. Recuperado: 20 de octubre del 2016

216 San Martín, D. (2017). LA INICIATIVA “ONE BELT, ONE ROAD” Y SU IMPACTO EN CHILE. Obtenido de http://centroestudiosinternacionales.uc.cl/images/noticias/One_belt_one_road_y_su_relaci\%C3\%B3n_con_Chile. pdf. Recuperado: 13 de noviembre del 2017

217 Ministerio de Relaciones Exteriores. (2017). Chile y Hong Kong destacan los 5 años del TLC bilateral. Obtenido de https://www.prochile.gob.cl/noticia/chile-y-hong-kong-destacan-los-5-anos-del-tlc-bilateral/. Recuperado: 13 de noviembre del 2017

218 Dirección General de Relaciones Económicas Internacionales. (2016). Tratado de Libre Comercio Chile - Hong Kong SAR. Obtenido de https://www.direcon.gob.cl/2017/06/tratado-de-libre-comercio-chile-hong-kong-sar/. Recuperado: 13 de noviembre del 2017
} 
cerezas, el $48 \%$ de participación en el mercado palta y un 38\% de participación en el mercado de uva de mesa ${ }^{219}$.

Las frutas chilenas comúnmente se reexportan a China Continental, según un estudio de ProChile 2015-2016 estima este movimiento en más $77 \%$ del total exportado por este ítem ${ }^{220}$.

Para los productos hortofrutícolas orgánicos exportados chilenos poseen un nicho altamente demandante en Hong Kong, siendo más fuertemente demandante cuando se exportan frutas frescas 221 .

Del total de las exportaciones el $91 \%$ corresponde a fruta fresca y fruta seca, el $2,4 \%$ corresponde a bebidas alcohólicas siendo el vino y el pisco los referentes; Chile exporta con una clara tendencia a los productos agropecuarios ${ }^{222}$.

\subsubsection{Tendencias}

La tendencia de Chile en aspecto de comercio exterior es mantener su nivel de calidad y prestigio en temas agroalimentarios, junto con la expansión y consolidación de mercados, con un portafolio más amplio y profundo para Hong Kong y toda Asia ${ }^{223}$.

\subsection{Requerimientos para exportar arándanos orgánicos a Hong Kong, China}

\subsubsection{Código Sistema Armonizado de Hong Kong (HKHS)}

El código armonizado de Hong Kong, China para el arándano orgánico corresponde a la partida 08.10, con código 0810.4011 Arándanos rojos, mirtilos y demás frutos del género Vaccinium Orgánico; y para la variedad azul Código 0810.4021 Arándanos azules o blueberry Orgánico 224 .

\subsubsection{Aranceles de internación para producto y otras barreras}

219 The Observatory of Economic Complexit. (2016). Hong Kong. Obtenido de https://atlas.media.mit.edu/en/profile/country/hkg/. Recuperado: 10 de enero del 2017

220 Gobierno de Chile, Fundación ProChile. (2015). Estadísticas de Comercio Exterior. Obtenido de Resultado de Búsqueda de Estadísticas de Exportaciones Chilenas: Arándano Orgánico: http://www.prochile.gob.cl/inicio/estadisticas-de-comercioexterior/?buscarpor=producto\&nombre codigo=ARANDANOS\%20AZULES\%200\%20BLUEBERRY\%20ORGANI COS $\% 20 F R E S C O S$. \&pais $=0 \&$ anio $=2016$ \&idproducto $=8104021$

221 Ministerio de Relaciones Exteriores. (2017). Chile y Hong Kong destacan los 5 años del TLC bilateral. Obtenido de https://www.prochile.gob.cl/noticia/chile-y-hong-kong-destacan-los-5-anos-del-tlc-bilateral/. Recuperado: 13 de noviembre del 2017

222 The Observatory of Economic Complexit. (2016). Hong Kong. Obtenido de https://atlas.media.mit.edu/en/profile/country/hkg/. Recuperado: 10 de enero del 2017

223 Morales, P. (2017). El estado de las relaciones de chile con Asia pacífico: obstáculos y desafíos para una estrategia a futuro. Obtenido de https://www.bcn.cl/obtienearchivo?id=documentos/10221.1/67263/6/Estado_relacionesChile_AsiaPacificojulio2017-1. Recuperado: 13 de noviembre del 2017

224 Dirección General de Relaciones Económicas Internacionales. (2017). Sistema Armonizado de Designación y Codificación de Mercancías . Obtenido de https://www.direcon.gob.cl/certificacion-de-origen/nomenclatura/. Recuperado: 13 de noviembre del 2017 
Para Chile no existen impuestos a internalización para las importaciones de arándanos orgánicos, ni otros impuestos o barreras arancelarias o no arancelarias, dado que Hong Kong corresponde a puerto franco contenido en el $\mathrm{TLC}^{225}$, caso que no comparte Argentina dado que el total de aranceles es del $30 \%{ }^{226}$.

\subsubsection{Regulaciones y normativas de importación}

La normativa y regulaciones son muy homólogas al sistema argentino y chileno, existiendo un ente regulador de todo el mercado en Hong Kong en temas de alimentación que supervisan y controlan, corresponde al "Centro de Seguridad Alimentaria", en términos generales, que todo alimento que se comercializa tiene que ser apto para el consumo humano 227.

También posee una "Ordenanza de Seguridad Alimentaria", que registra la trazabilidad en el origen del producto tanto para los importadores, distribuidores y vendedores. También existe una regulación estricta con respecto a los residuos de pesticidas que define las cantidades permitidas de un listado de químicos determinados por la ordenanza, todo dado a casos polémicos de contaminación de alimentos en China continental en el 2014 , siendo el responsable legal el importador ${ }^{228}$.

Todo alimento que ingresa tiene que estar acompañado por todos los documentos de salud en temas de inocuidad del país de origen ${ }^{229}$, para Chile las entidades a cargo corresponden al Servicio Agrícola Ganadero (SAG) y la Dirección general de relaciones Económicas Internacionales (DIRECON) ${ }^{230}$.

\subsubsection{Certificaciones orgánicas: legislación y requerimientos locales}

Si bien las entidades certificadoras chilenas (Intitute for Marketecology Chile S.A, BCS ÖKO: GARANTIE GmbH, Argencert S.R.L y Ceres-Certification of Enviromental Standards $\mathrm{GmbH}$.) y argentinas (Las certificadoras son Argencert S.R.L, OIA S.A, Letis

\footnotetext{
225 Dirección General de Relaciones Económicas Internacionales. (2016). Tratado de Libre Comercio Chile - Hong Kong SAR. Obtenido de https://www.direcon.gob.cl/2017/06/tratado-de-libre-comercio-chile-hong-kong-sar/. Recuperado: 13 de noviembre del 2017

226 ProChile Oficina Comercial Hong Kong . (2017). INFORME PAÍS - 2017. Obtenido de HONG KONG SAR : https://www.prochile.gob.cl/wp-content/uploads/2017/12/guia_pais_hong_kong_2017.pdf. Recuperado: 13 de noviembre del 2017

227 Lo Coco, M. (21 de agosto de 2015). Importancia de los productos orgánicos en Hong Kong y en Asia. (C. Vivanco, Entrevistador)

228 ProChile Oficina Comercial Hong Kong . (2017). INFORME PAÍS - 2017. Obtenido de HONG KONG SAR : https://www.prochile.gob.cl/wp-content/uploads/2017/12/guia_pais_hong_kong_2017.pdf. Recuperado: 13 de noviembre del 2017

229 Gobierno de Chile, Servicio Agricola Ganadero [SAG]. (2014). Centros de documentación SAG. Obtenido de LINEAMIENTOS PARA EXPORTACIÓN DE ARÁNDANOS A CHINA: http://www.sag.cl/sites/default/files/lineamientos_exportacion_arandanos_a_china.pdf. Recuperado: 25 de mayo del 2015
} 
S.A. y Food Safety S.A) tiene que certificar nuevamente por una entidad china ${ }^{231}$, esta practica no se realiza, dado que el costo es alto y al valor percibido de las certificaciones nacionales tienen reconocimiento mundial, y altamente validada en Hong Kong y en China Continental ${ }^{232}$.

\subsubsection{Reporte estado}

Argentina no tiene presencia al 2016, en ninguna exportación de arándano orgánico en toda Asia, principalmente por los altos aranceles y bajo nivel de competitividad. Los tiempos de traslados desde los puertos de Argentina a los puertos de Hong Kong superan los 30 días $^{233}$, lo que contrasta con los 15 días record que tiene Chile por vía marítima ${ }^{234}$.

Vía área los costos son altos, existiendo además una contradicción misma en el concepto de producto orgánico, dado que la huella de carbono por el consumo de combustible se eleva considerablemente, pero para lograr aumentar su competitividad Argentina habilitó el aeropuerto de Tucumán el cual exporta arándanos las 24 horas del día, especialmente en temporada alta (septiembre, octubre y noviembre), siendo el principal medio de exportación de arándano fresco ${ }^{235}$.

231 Landa, P. (28 de julio de 2015). La importancia de los productos orgánicos en Argentina y el mundo. Certificaciones y procesos. (C. Vivanco, Entrevistador)

232 Catalán, C. C. (10 de agosto de 2015). Situación de la Agricultura Orgánica en Chile, visión desde SAG. (C. Vivanco, Entrevistador)

233 Landa, P. (28 de julio de 2015). La importancia de los productos orgánicos en Argentina y el mundo. Certificaciones y procesos. (C. Vivanco, Entrevistador)

234 Eguillor, P. (7 de septiembre de 2015). Mirada desde el Gobierno Chileno al potencial orgánico del arándano. (C Vivanco, Entrevistador)

235 Ramírez, J. C. (17 de julio de 2015). Situación de la Agricultura Orgánica en la Argentina, visión desde SENASA. (C. Vivanco, Entrevistador) 


\section{CONCLUSIONES}

Los productos orgánicos en el mundo han aumentado su participación, siendo un mercado de nicho con precios más altos, con valor percibido en la inocuidad, sustentabilidad y sostenibilidad de las producciones, para consumidores más informados y conscientes con el medio ambiente.

La situación del arándano orgánico para el mercado de exportación hortofrutícola de Argentina esta en pleno proceso de definición, dado que se cuenta con todos los potenciales para que Argentina sea un referente a nivel mundial, sin dejar de lado que posee una capacidad productiva dormida y un sistema de certificación orgánica con homologación directa al mercado europeo.

La situación del arándano orgánico para el mercado de exportación hortofrutícola de Chile esta consolidado, con una completa armonía entre los sectores publico y privado, con una clara tendencia al uso de tecnologías para reducción de costos, con aumento de productividad sin perder calidad.

La demanda hortofrutícola en Hong Kong, China se proyecta como una de las más importantes en el mundo a corto plazo, desplazando rápidamente a Estados Unidos y al Bloque Europeo, dado que hace puente comercial con China continental, mercado que contiene más población del mundo, casi 4,3 veces más que Estados Unidos y 2,7 veces más que toda la Unión Europea, mercado que se adapta rápidamente, demandando productos de nicho, estimulado por políticas internas de alimentación saludable y a un aumento poblacional proyectado, debido a la regulación del segundo hijo.

Argentina y Chile, poseen una historia en común lo que se refleja en todos los puntos que comparten de los escenarios externos, pero que, divergen principalmente en los aspectos políticos, económicos y tecnológicos, dado que poseen una estrategia diferente, Argentina por su parte tiene una mirada al mercado interno en donde la consigna agroalimentaria es cantidad y extensión de tierras, mientras que para Chile es calidad y con un claro objetivo a la exportación. Otro aspecto diferente tiene que ver con la imagen país, en temas de corrupción, argentina posee una mala imagen mundial cosa que Chile, al contrario, posee la imagen menos corrupta de toda Latino América.

También hay una diferenciación en el tema legislativo, a pesar de que Argentina posee un sistema robusto en contenidos de leyes, normas y certificaciones, en su mercado hortofrutícolas, estas no son implementadas del todo, dado al poco control en supervisión, sanción y a temas socioculturales; situación que en Chile es opuesta, dado que el sistema legal existe y es puesto en marcha de forma íntegra, siendo respetado por 
el mercado, con una supervisión y contraloría exhaustiva por las entidades pertinentes, siendo un sistema muy estricto.

Las relaciones comerciales entre Argentina-Chile son estrechas y generadas de forma natural, con un marco regulatorio establecido y respetado, con una tendencia a beneficiar ambas economías, con una mirada a ser aliados comerciales en conjunto y en conjunto para el mundo.

Las relaciones comerciales entre Argentina-Hong Kong están creciendo, pero no se han afianzado, aun faltando procesos comerciales, políticos y legales por resolver.

Las relaciones comerciales entre Chile-Hong Kong han crecido por más de 30 años de forma constante, consolidando estas en el 2012 con el TLC, posicionando actualmente a Chile como a uno de sus proveedores principales en frutas.

Al analizar las oportunidades de ambos países, en el mercado hortofrutícola orgánico, se observa que son altamente complementarias, por una parte, Argentina es el segundo referente mundial en tener tierras certificadas para producciones orgánicas, con campos extensos y fértiles, con experiencia en producción de volumen, pero con volúmenes exportados no coherentes con su capacidad, en el caso especifico del arándano, Chile exportó aproximadamente 24 veces más fruta en un año que toda Argentina, siendo Chile pequeño y en una posición mundial lejana de los top ten $\left(68^{\circ}\right.$ sexagésima octava) en poseer tierras certificadas para la producción orgánica, basando su éxito en una apertura comercial, a estándares de producción apoyado por la tecnología y un trabajo constante de marca país.

Chile posee experiencia internacional, con tratados de libre comercio con aranceles 0 o preferenciales, con blindajes y barreras de entrada para los competidores, siendo un socio clave para Argentina para consolidar exportaciones en conjunto.

Por otra parte, la demanda de Hong Kong en temas alimentarios es un gran desafío a nivel mundial, dado a que es puerta de entrada a China continental, se resume en mucha población que alimentar, Argentina y Chile aparecen como una respuesta dado a su perfil productivo agroalimentario y a complementar la oferta mundial con productos agrícolas contra estación.

Se concluye por todos los temas antes expuestos que, existe una alta viabilidad de exportación compartida, de pequeñas y medianas empresas de arándanos orgánicos asentadas en los países de Argentina y Chile, hacia el mercado hortofrutícola de la región administrativa especial de Hong Kong, de la República Popular China. 


\section{BRECHAS DETECTADAS}

Durante la elaboración de esta investigación se detectaron brechas que se describen a continuación:

A. Información y datos

Argentina y Chile poseen una dicotomía con respecto a la dificultad para obtener información oficial actualizada y completa, para los temas que se abordaron en esta investigación, en Argentina la información publicada describe el estado de dos años anteriores, obteniendo datos actualizados parciales de fuentes directas de un año atrás; para Chile describe el estado solo con un mes de retardo, estando disponible fácilmente online, paralelamente Chile genera informes semestrales de estado de mercados y proyecciones comerciales los cuales son públicos y sin costo.

\section{B. Burocracia}

Argentina y Chile son países que poseen sistemas burocráticos complejos con un orden jerárquico establecido y rígido, con un nivel de tramitación alto. Para esta investigación, en Argentina el contacto directo con jefaturas y encargados fue más expedita que con los homólogos en Chile, no obstante, para Chile este contacto no depende tanto de la voluntad y buena disposición de estos o sus secretarios/as, sino del estado de sus agendas, existiendo por ley una obligación de atención de audiencias (Ley del Lobby) que esta investigación elevo en dos oportunidades.

C. Capacidad de exportación de las Pymes

Los principales productores orgánicos de Argentina y Chile corresponden a la pequeña agricultura rural, en su mayoría gente adulta sin estudios universitarios con poco acceso a la tecnología y con pocas capacidades técnicas de exportación directa, existiendo empresas intermediarias que se encargan principalmente de packing, los tramites de exportación y las ventas; Chile posee incentivos público y apoyo a la exportación directa de pequeños productores rurales.

D. Análisis y estudio financiero.

El costo de producción del arándano es alto, desde la plantación hasta el año que alcanza el nivel productivo máximo, la mantención posterior y los costos asociados a la exportación y los manejos agronómicos -en especial el riego, control de plagas y fertilidad- son de media dificultad y requieren un nivel técnico alto. 
Determinar los costos y la factibilidad financiera de una exportación compartida entre PyMES productoras de arándano orgánico, de Argentina y Chile, hacia el mercado hortofrutícola de Hong Kong, China, sería la continuidad de esta investigación. 


\section{BIBLIOGRAFIA}

A. Fuentes Bibliográficas

Aparicio, G., \& Gómez, C. (2005). Geografía Argentina - Polimodal. Obtenido de http://bdigital.uncu.edu.ar/objetos_digitales/1385/geografiaapoli.pdf. Recuperado: 22 de mayo del 2015

Araneda, C. (2017). National Innovation System: Reflections and analysis of the Chilean case. Obtenido de https://scielo.conicyt.cl/pdf/idesia/v35n4/0718-3429-idesia-3504-00111.pdf. Recuperado:10 de enero del 2018

Banco Mundial. (2016). Argentina: panorama general. Obtenido de http://www.bancomundial.org/es/country/argentina/overview. Recuperado: 10 de octubre del 2016

Biblioteca del Congreso Nacional. (2012). Relaciones bilaterales Chile-Hong Kong y aspectos relevantes para la firma de un TLC. Obtenido de Relacioneshttps://www.bcn.cl/obtienearchivo?id=repositorio/10221/14579/3/20125 2311628389_201252391732882_201252217476609_201252217313603_GRID_2 2_05_2012_SA_CF_JJ_HONG\%20KONG_.pdfbilaterales Chile-Hong Kong y aspectos relevantes para la firma de un TLC. Recuperado: 21 de octubre del 2016

Brendecke, U. (2014). El mercado frutihortícola argentino y su comercialización. Obtenido de Info Campo: www.infocampo.com.ar/el-mercado-frutihorticola-argentino-y-sucomercializacion/. Recuperado:15 de Octubre del 2015

Cámara de Comercio Argentina. (2015). RELACIONES BILATERALES Argentina y Hong Kong - China . Obtenido de http://www.argentinahk.com/relaciones-bilaterales/. Recuperado: 10 de enero del 2017

Centro de Economía y Política Argentina. (2016). Desigualdad un cambio con ganadores y perdedores. Obtenido de http://eppa.com.ar/wpcontent/uploads/2016/11/Desigualdad-Octubre-2016.pdf. Recuperado:14 de enero del 2017

Consulado General y Centro de Promoción Argentina En Shanghái. (2015). Perfil del mercado de arándano en China. Obtenido de Promoción Comercial: https://www.santanderrio.com.ar/banco/wcm/connect/171b0dda-dc43-4f1d-93041f074ba0fc95/CSHAN+informe+de+mercado+de+arandano.pdf. Recuperado:18 de enero del 2016

Cranberries, O. S., \& EUA, I. L. (2005). Constituyentes fitoquímicos del arándano americano (Vaccinium macrocarpon) y sus beneficios para la salud. Revista de fitoterapia. Revista de fitoterapia, 5(1), 5-16 
Datos Macro. (2016). Comparar economía países: Argentina vs Hong Kong. Obtenido de https://datosmacro.expansion.com/paises/comparar/argentina/hong-kong.

Recuperado: 10 de enero del 2017

Datos Macro. (2017). Hong Kong - Población. Obtenido de

https://datosmacro.expansion.com/demografia/poblacion/hong-kong. Recuperado: 16 de enero del 2017

Defilippi, B., Robledo, P., \& Becerra, C. (2013). Manejo de cosecha y Poscosecha en Arándano. En C. R. Quilamapu, Manual del Arándano (págs. 107-125). Chillán, Chile: Instituto de Investigaciones Agropecuarias. Obtenido de http://biblioteca.inia.cl/medios/biblioteca/boletines/NR39094.pdf. Recuperado: 1 de octubre del 2015

Dirección General de Relaciones Económicas Internacionales. (2016). 20 años del Acuerdo Mercosur. Obtenido de https://www.direcon.gob.cl/wpcontent/uploads/2017/05/20-a\%C3\%B1os-del-Acuerdo-Chile-Mercosur.pdf. Recuperado: 10 de enero del 2017

Dirección General de Relaciones Económicas Internacionales. (2016). ¿Qué es OCDE?. Obtenido de https://www.direcon.gob.cl/ocde/. Recuperado: 10 de noviembre del 2016

Dirección General de Relaciones Económicas Internacionales. (2016). Tratado de Libre Comercio Chile - Hong Kong SAR. Obtenido de https://www.direcon.gob.cl/2017/06/tratado-de-libre-comercio-chile-hong-kongsar/. Recuperado: 13 de noviembre del 2017

Dirección General de Relaciones Económicas Internacionales. (2017). Sistema Armonizado de Designación y Codificación de Mercancías . Obtenido de https://www.direcon.gob.cl/certificacion-de-origen/nomenclatura/. Recuperado: 13 de noviembre del 2017

Dos Manos Travel Agency. (2009). Argentina - Cultura y Sociedad. Obtenido de http://www.dosmanosargentina.com/travelargentina/spanish/cultura-ysociedad.php. Recuperado: 10 de mayo del 2015

Editorial Ecoprensa S.A. (2016). La inflación en Chile cierra el año 2015 en un 4,4\%, bajo las proyecciones. Obtenido de https://www.eleconomistaamerica.cl/economiaeAm-chile/noticias/7265204/01/16/La-inflacion-en-Chile-cierra-el-ano-2015-en-un44-por-ciento.html. Recuperado: 15 de junio del 2016

Embajada de Chile en Argentina. (2016). Relación bilateral. Obtenido de https://chile.gob.cl/argentina/relacion-bilateral. Recuperado: 11 de septiembre del 2016 
Export Entreprises SA. (2016). HONG KONG: POLÍTICA Y ECONOMÍA. Obtenido de Santander Trade: https://es.portal.santandertrade.com/analizar-mercados/hongkong/politica-y-economia. Recuperado: 11 de octubre del 2016

Export Entreprises SA. (2017). CHILE: ENTORNO LEGAL. Obtenido de https://es.portal.santandertrade.com/establecerse-extranjero/chile/entorno-legal. Recuperado: 12 de diciembre del 2017

Ferrada, M. (2002). Agroindustria Hortofrutícola Chilena. Obtenido de https://www.odepa.gob.cl/publicaciones/articulos/agroindustria-hortofruticolachilena-2002. Recuperado: 21 de junio del 2016

Food and Agriculture Organization of the United Nations [FAO]. (1999). Depósito de Documentos de la FAO: Glosario. Obtenido de www.fao.org/docrep/006/y4893s/y4893s0c.htm. Recuperado: 21 de septiembre del 2015

Food and Agriculture Organization of the United Nations [FAO]. (2007). COMITÉ DE AGRICULTURA. Obtenido de EL MEDIO AMBIENTE Y LA AGRICULTURA [PDF]: $\mathrm{ftp}: / / \mathrm{ftp}$.fao.org/docrep/fao/meeting/011/j9289s.pdf. Recuperado:18 de mayo del 2015

Food and Agriculture Organization of the United Nations [FAO]. (2014). POLÍTICAS AGROAMBIENTALES [PDF]. Obtenido de http://www.fao.org/docrep/019/i3523s/i3523s.pdf. Recuperado:14 de septiembre del 2018.

Food and Agriculture Organization of the United Nations [FAO]. (2015). Organic Agriculture. Obtenido de http://www.fao.org/organicag/oa-home/en/. Recuperado:18 de mayo del 2016.

Food and Agriculture Organization of the United Nations [FAO]. (s.f.). Obtenido de Glossary: http://faostat.fao.org/site/379/DesktopDefault.aspx?PagelD=379. Recuperado:18 de junio del 2015.

Fundación Universia. (2016). CULTURA Y TRADICIONES. Obtenido de http://www.universia.es/estudiar-extranjero/chile/vivir/cultura-tradiciones/3194. Recuperado: 10 de diciembre del 2016

Fundación Universia. (2016). ESTUDIAR EN HONG KONG. Obtenido de CULTURA Y TRADICIONES: http://www.universia.es/estudiar-extranjero/hongkong/vivir/cultura-tradiciones/4640. Recuperado: 15 de junio del 2016

Gaete Coddou, G. (2006). MANUAL DE GEOGRAFIA DE CHILE. Obtenido de https://es.scribd.com/doc/286956087/Manual-Geografia-de-Chile. Recuperado: 10 de diciembre del 2016 
García, S. I. (2016). Obtenido de GUÍA DE USO RESPONSABLE DE AGROQUÍMICOS: https://www.toxicologia.org.ar/wpcontent/uploads/2016/03/guia_de_uso_de_agroquimicos.pdf. Recuperado:10 de enero del 2017

Garcia, T. (2005). Hong Kong, Puente de encuentro del Oriente y Occidente. Obtenido de http://catarina.udlap.mx/u_dl_a/tales/documentos/lri/garcia_t_g/capitulo1.pdf. Recuperado: 10 de julio del 2017

Gattavara, F. (2017). Chile: Avances tecnológicos cambiarán los empleos, pero no los harán desaparecer. Obtenido de https://www.america-retail.com/chile/chileavances-tecnologicos-cambiaran-los-empleos-pero-no-los-haran-desaparecer/. Recuperado: 20 de noviembre del 2017

Gobierno de Argentina, Dirección Nacional de Inocuidad y Calidad Agroalimentaria. (2016). Coordinación de productos Ecológicos. Situación de la Producción Orgánica en la Argentina durante el Año 2015. Obtenido de http://www.senasa.gob.ar/sites/default/files/ARBOL_SENASA/INFORMACION/PR OD_ORGANICA/5-17informe_estadstico_2015.pdf. Recuperado: 6 de enero del 2016

Gobierno de Argentina, Instituto Nacional de Tecnología Agropecuaria [INTA]. (2011). Guía práctica para el cultivo de Arándanos en la zona norte de la provincia de Buenos. Obtenido de http://inta.gob.ar/documentos/guia-practica-para-el-cultivode-arandanos-en-la-zona-norte-de-la-provincia-de-buenosaires/at_multi_download/file/mg_0801.pdf. Recuperado: 22 de junio del 2015.

Gobierno de Argentina, Presidencia de la Nación. (2016). Los Tres Poderes. Obtenido de Casa Rosada, Nuestro País: https://www.casarosada.gob.ar/nuestropais/organizacion?id=2722. Recuperado: 12 de septiembre del 2016

Gobierno de Chile, Dirección General de Relaciones Económicas Internacionales. (2009). Chile: 20 Años de Negociaciones Comerciales. Obtenido de http://www.direcon.gob.cl/wp-content/uploads/2013/09/Chile-20-a\%C3\%B1os-denegociaciones-comerciales1.pdf. Recuperado: 25 de mayo del 2015.

Gobierno de Chile, Dirección General de Relaciones Económicas Internacionales. (2014). Chile-Hong Kong SAR. Obtenido de http://www.direcon.gob.cl/wpcontent/uploads/2014/12/Hong-Kong-SARoctubre2014.pdf. Recuperado: 25 de mayo del 2015

Gobierno de Chile, Fundación ProChile. (2015). Estadísticas de Comercio Exterior. Obtenido de Resultado de Búsqueda de Estadísticas de Exportaciones Chilenas: Arándano Orgánico: http://www.prochile.gob.cl/inicio/estadisticas-de-comercioexterior/?buscarpor=producto\&nombre_codigo=ARANDANOS\%20AZULES\%200 
\%20BLUEBERRY\%20ORGANICOS\%20FRESCOS.\&pais=0\&anio=2016\&idprodu cto=8104021. Recuperado: 25 de mayo del 2015

Gobierno de Chile, Ministerio de Agricultura. (2013). Agricultura Orgánica Nacional:

Bases Técnicas y Situación Actual [PDF]. Obtenido de

http://www.sag.cl/sites/default/files/agricultura_org._nacional_bases_tecnicas_y_si tuacion_actual_2013.pdf. Recuperado: 25 de mayo del 2015

Gobierno de Chile, Oficina Comercial de ProChile en R.P. China - Beijing. (2013).

Tendencias del Mercado: Alimentos Orgánicos en la R. P. China. Obtenido de http://www.prochile.gob.cl/wp-

content/blogs.dir/1/files_mf/1367963128China_Tendencias_Organicos_2013_Beiji ng.pdf. Recuperado: 25 de mayo del 2015

Gobierno de Chile, Oficina de Estudio y Políticas Agrarias [ODEPA]. (2015). Producción orgánica nacional: Situación y Perspectivas. Obtenido de http://www.odepa.cl/wpcontent/files_mf/1440087284AgriculturaOrg\%C3\%A1nica2015.pdf. Recuperado: 27 de mayo del 2015

Gobierno de Chile, Servicio Agricola Ganadero [SAG]. (2014). Centros de documentación SAG. Obtenido de LINEAMIENTOS PARA EXPORTACIÓN DE ARÁNDANOS A CHINA:

http://www.sag.cl/sites/default/files/lineamientos_exportacion_arandanos_a_china. pdf. Recuperado: 25 de mayo del 2015

Gobierno de Chile, Servicio Nacional de Adunas. (2012). Tratado de Libre Comercio Chile - Hong Kong. Obtenido de https://www.aduana.cl/aduana/site/artic/20141204/asocfile/20141204120610/o_c_ _n__358_28_11_14_instr_tlc_chile_hong_kong.pdf. Recuperado: 25 de mayo del 2015

Gobierno de Chile. ODEPA. (2014). Chile: comercio exterior de productos orgánicos. Obtenido de http://www.odepa.cl/wpcontent/files_mf/1391441139ChileComercioExteriorProductosOrganicos.pdf. Recuperado:25 de mayo del 2015. Recuperado: 25 de mayo del 2015 Heifetz, J. (2017). Hong Kong se ha quedado casi sin espacio para la basura. Obtenido de https://www.vice.com/es_latam/article/bjz8x3/hong-kong-sin-espacio-parabasura. Recuperado: 15 de octubre del 2017

Infobae. (2017). IPC Congreso: la inflación superó el 40\% en 2016 y fue la más alta en 14 años . Obtenido de https://www.infobae.com/economia/2017/01/10/ipc-congresola-inflacion-supero-el-40-en-2016-y-fue-la-mas-alta-en-14-anos/. Recuperado: 22 de mayo del 2017 
Instituto de Relaciones Internacionales. (2017). El retorno de Hong Kong a China por parte del Reino Unido. Obtenido de http://www.iri.edu.ar/wpcontent/uploads/2017/07/Efemerides_julio_espinoza.pdf. Recuperado: 10 de septiembre del 2017

Instituto Nacional de Estadística y Censos. (2016). Proyecciones nacionales. Obtenido de Estimaciones y proyecciones de población. Total del país 2010-2040: https://www.indec.gob.ar/nivel4_default.asp?id_tema_1=2\&id_tema_2=24\&id_tem a_3=84. Recuperado: 10 de septiembre del 2017

Instituto Nacional de Estadísticas. (2016). DEMOGRÁFICAS Y VITALES. Obtenido de http://www.ine.cl/estadisticas/demograficas-y-vitales. Recuperado: 10 de septiembre del 2017

Instituto Nacional de Tecnología Agropecuaria [INTA]. (2010). ATLAS CLIMÁTICO DIGITAL DE LA REPÚBLICA ARGENTINA. Obtenido de https://inta.gob.ar/sites/default/files/script-tmptexto_atlas_climtico_digital_de_la_argentina_110610_2.pdf. Recuperado: 20 de mayo del 2015

International Organization for Standardization. (2016). Códigos de monedas ISO 4217. Obtenido de Currency codes - ISO 4217: https://www.iso.org/iso-4217-currencycodes.html. Recuperado: 23 de octubre del 2016

Jiménez Bonilla, V.; Abdelnour Esquivel, A. (2011). Identificación y Valor nutricional de algunas especies nativas de arándano (Vaccinium spp)., de Doctoral dissertation, Instituto Tecnológico de Costa Rica. Vicerrectoría de Investigación y Extensión. Obtenido de http://bibliodigital.itcr.ac.cr/handle/2238/2944. Recuperado: 10 de marzo de 2015

Jolias, L. (2016). Hong Kong, nueva expresión del desafío de las ciudades inteligentes. Obtenido de https://politicacomunicada.com/cgi-sys/suspendedpage.cgi. Recuperado: 14 de julio del 2017

Leke I, R. J., Oduma , J. A., Bassol-Mayagoitia, S., \& Bacha, A. M. (1993). Regional and Geographical Variations in and Socioeconomic Factors and Socioeconomic Factors. Environmental Health Perspectives Supplements, 101 (Suppl. 2), 73-80. Obtenido de http://www.ncbi.nlm.nih.gov/pmc/articles/PMC1519926/pdf/envhper003790077.pdf. Recuperado: 15 de octubre del 2015

Lopez, M. (2011). El estatuto jurídico-político de Hong Kong en la República Popular de China. Obtenido de https://revistas.um.es/analesderecho/article/view/118071/111611/. Recuperado: 10 de noviembre del 2016 
Maroni, J. (2010). Las nuevas Tecnologías y su impacto sobre la producción Agrícola. Obtenido de Facultad de Ciencias Agrarias, Universidad Nacional de Rosario: http://www.fcagr.unr.edu.ar/Extension/Agromensajes/14/3AM14.htm. Recuperado: 20 de mayo del 2015

Martínez, M., Balois, R., \& Alia, I. (2013). Postharvest fruits: maturation and biochemical changes. Obtenido de http://www.redalyc.org/pdf/2631/263153823018.pdf. Recuperado: 10 de junio del 2016

Ministerio de Agricultura de Chile. (2013). Mercado y Proyecciones del Cultivo del Arándano. Obtenido de http://www.minagri.gob.cl/wpcontent/uploads/2013/08/Mercado-y-proyecciones-del-cultivo-dear\%C3\%A1ndanos.pdf. Recuperado: 25 de mayo del 2015

Ministerio de Ambiente y Desarrollo Sustentable. (2016). Institucional. Obtenido de www.abiente.gov.ar/institucional. Recuperado: 10 de junio del 2016

Ministerio de Economía, Fomento y Turismo. (2016). EVALUACIÓN DE IMPACTO DEL PROGRAMA START-UP CHILE DE CORFO. Obtenido de http://www.economia.gob.cl/wp-content/uploads/2016/08/Resumen-EjecutivoStart-Up-Chile-Abril-2016.pdf. Recuperado: 10 de septiembre del 2017 Ministerio de Relaciones Exteriores y Culto. (2016). Consulado General de la Republica Argentina en Hong Kong. Obtenido de http://www.chong.mrecic.gov.ar/es/content/consulado-general-de-la-republicaargentina-en-hong-kong. Recuperado: 10 de enero del 2017

Ministerio de Relaciones Exteriores. (2016). Acuerdos y Tratados Bilaterales. Obtenido de https://chile.gob.cl/argentina/relacion-bilateral/acuerdos-y-tratados-bilaterales. Recuperado: 11 de septiembre del 2016

Ministerio de Relaciones Exteriores. (2017). Chile en el Exterior Embajadas, Consulados y Misiones Multilaterales de Chile. Obtenido de Sistema político: https://chile.gob.cl/chile/sistema-politico. Recuperado: 15 de septiembre del 2017 Ministerio de Relaciones Exteriores. (2017). Chile y Hong Kong destacan los 5 años del TLC bilateral. Obtenido de https://www.prochile.gob.cl/noticia/chile-y-hong-kongdestacan-los-5-anos-del-tlc-bilateral/. Recuperado: 13 de noviembre del 2017 Ministerio del Medio Ambiente. (2016). http://portal.mma.gob.cl/estructura/. Obtenido de http://portal.mma.gob.cl/estructura/. Recuperado: 10 de noviembre del 2016 Ministerios de Relaciones Exteriores. (2016). Exportaciones/importaciones. Obtenido de https://chile.gob.cl/argentina/asuntos-comerciales/oficina-comercial/exportacionesimportaciones. Recuperado: 10 de enero del 2017

Morales, P. (2017). El estado de las relaciones de chile con Asia pacífico: obstáculos y desafíos para una estrategia a futuro. Obtenido de 
https://www.bcn.cl/obtienearchivo?id=documentos/10221.1/67263/6/Estado_relaci onesChile_AsiaPacifico-julio2017-1. Recuperado: 13 de noviembre del 2017 Oesterbheld, M. (2008). Impacto de la agricultura sobre los ecosistemas [PDF]. Ecología Austral(18), 337-346. Obtenido de http://www.scielo.org.ar/pdf/ecoaus/v18n3/v18n3a07.pdf. Recuperado: 25 de mayo del 2015

Oficina de Estudios y Políticas Agrarias. (2016). Comisión Nacional de Agricultura Orgánica. Obtenido de https://www.odepa.gob.cl/coordinacion-publicoprivada/comision-nacional-de-agricultura-organica. Recuperado: 15 de junio del 2016

Olfos, M. J. (2013). Obtenido de Proyecciones del mercado internacional del azúcar y cultivo nacional de remolacha: https://www.odepa.gob.cl/odepaweb/publicaciones/doc/9033.pdf. Recuperado: 25 de mayo del 2015

Organisation for Economic Co-operation and Development. (2016). Hong Kong, China. Obtenido de http://www.oecd.org/countries/hongkongchina/. Recuperado: 10 de noviembre del 2016

Organización de los Estados Americanos. (2007). Sistema de administración de justicia Argentino. Obtenido de http://www.oas.org/juridico/MLA/sp/arg/sp_arg-intdescription.html. Recuperado: 20 de mayo del 2015

Oviedo, E. (2015). El ascenso de China y sus efectos en la relación con Argentina. Obtenido de https://scielo.conicyt.cl/pdf/rei/v47n180/art04.pdf. Recuperado: 10 de enero del 2017

ProChile Oficina Comercial Hong Kong . (2017). INFORME PAÍS - 2017. Obtenido de HONG KONG SAR : https://www.prochile.gob.cl/wpcontent/uploads/2017/12/guia_pais_hong_kong_2017.pdf. Recuperado: 13 de noviembre del 2017

Procuración General de la Nación. (2016). Ministerio Público Fiscal. Obtenido de Qué es el MPF: https://www.mpf.gob.ar/que-es-el-mpf/ Recuperado: 15 de octubre del 2017

Programa de las Naciones Unidas Para el Desarrollo. (2017). Orígenes, cambios y desafíos de la brecha social en Chile. Obtenido de http://www.cl.undp.org/content/dam/chile/docs/pobreza/undp_cl_pobreza-LibroDESIGUALES-final.pdf. Recuperado: 20 de septiembre del 2017

Rearch Institute of Organic Agriculture. (2014). Sustainability and quality of organic food [PDF]. Obtenido de https://www.fibl.org/fileadmin/documents/shop/1413-organicproducts.pdf. Recuperado: 25 de mayo del 2015 
Recabarren, P. E. (2015). Certificación de productos orgánicos. Obtenido de Ministerio de Agricultura: http://cnao.odepa.cl/wp-

content/files_mf/1422966075Productos_org\%C3\%A1nicos_certificaci\%C3\%B3n.p df. Recuperado: 20 de enero del 2016

Reinke, M. (2018). Realizan la primera exportación de arándanos a China. Obtenido de Diario la Nación https://www.lanacion.com.ar/2193498-arandanos-china-parteprimer-embarque. Recuperado: 20 de noviembre del 2018

Revill, G. (2015). El mercado de servicios financieros en Hong Kong. Obtenido de https://www.icex.es/icex/es/navegacion-principal/todos-nuestrosservicios/informacion-de-mercados/paises/navegacion-principal/elmercado/estudios-informes/DOC2015600286.html?idPais=HK. Recuperado: 11 de septiembre del 2016

Rivadeneira, M. F. (2001). Instituto Nacional de Tecnología Agropecuaria [INTA]. Obtenido de Comportamiento Fenológico de variedades tradicionales y nuevas de arándano: http://inta.gob.ar/documentos/comportamiento-fenologico-devariedades-tradicionales-y-nuevas-dearandano/at_multi_download/file/fenolog\%C3\%ADa\%20nuevas\%20y\%20tradicion ales\%20arandanos.pdf. Recuperado: 25 de mayo del 2015

Rivas, F. (2017). Argentina profundiza la desigualdad social. Obtenido de El Pais: https://elpais.com/economia/2017/01/06/actualidad/1483732167_789124.html. Recuperado: 20 de enero del 2018

San Martín, D. (2017). LA INICIATIVA “ONE BELT, ONE ROAD” Y SU IMPACTO EN CHILE. Obtenido de http://centroestudiosinternacionales.uc.cl/images/noticias/One_belt_one_road_y_s u_relaci\%C3\%B3n_con_Chile.pdf. Recuperado: 13 de noviembre del 2017

San Martín, J. (2010). SITUACIÓN VARIETAL EN ARÁNDANO. Obtenido de http://biblioteca.inia.cl/medios/biblioteca/boletines/NR39095.pdf. Recuperado: 10 de junio del 2016

Schmidt-Hebbel, H. (1986). Toxicos quimicos en alimentos [PDF] (Fundación Chile ed.). Santiago: Universitaria. Obtenido de http://mazinger.sisib.uchile.cl/repositorio/lb/ciencias_quimicas_y_farmaceuticas/sc hmidth09/schmidth09.pdf. Recuperado: 25 de mayo del 2015

Seghezzo, L. (2013). Ensayo IX.1 Recursos Naturales y sustentabilidad. En L. Malacalza, \& L. Malacalza (Ed.), Ecología y Ambiente. Buenos Aires: LISEA.

Servicio Nacional de Aduana de Chile. (2016). Tratado de Libre Comercio Chile - Hong Kong. Obtenido de https://www.aduana.cl/tratado-de-libre-comercio-chile-hongkong/aduana/2014-12-04/120610.html. Recuperado: 20 de octubre del 2016 
Siekman, D. (2015). Fresh Fruits. Obtenido de: Asia Fruit Logistica 2015:

https://www.producereport.com/article/photos-asia-fruit-logistica-2015.

Recuperado: 10 de diciembre del 2016

Silvia Nuñez, E. M. (2015). Actividad antioxidante del arándano (vaccinium corymbosum

I.) Y sus propiedades para prevenir enfermedades neurodegenerativas. Obtenido de http://152.74.96.159:8080/jspui/handle/123456789/295. Recuperado: 25 de noviembre del 2015

Souza Brito, P. (2014). Exitosas políticas públicas reducen el impacto de la agricultura sobre el medio ambiente. Obtenido de http://www.fao.org/americas/noticias/ver/es/c/230491/. Recuperado: 25 de mayo del 2015

The Observatory of Economic Complexit. (2016). Hong Kong. Obtenido de https://atlas.media.mit.edu/en/profile/country/hkg/. Recuperado: 10 de enero del 2017

Thomson Reuters. (2015). DATOS-¿Qué es el "cepo" cambiario de Argentina? Obtenido de https://ar.reuters.com/article/topNews/idARL1N1451XY20151216. Recuperado: 10 de enero del 2016

Transparency International. (2017). CORRUPTION PERCEPTIONS INDEX 2016. Obtenido de https://www.transparency.org/news/feature/corruption_perceptions_index_2016. Recuperado: 10 de enero del 2018

U.S. Food and Drug Administration [FDA]. (2013). COMUNICADO DE PRENSA DE LA FDA. Obtenido de La FDA propone nuevas normas de seguridad alimentaria para la prevención de enfermedades transmitidas por alimentos y la inocuidad de los productos agrícolas:

http://www.fda.gov/newsevents/newsroom/pressannouncements/ucm334188.htm. Recuperado: 28 de mayo del 2015

Undurraga, P., \& Vargas, S. (2013). Boletín INIA N²63. Obtenido de Manual del Arándano: http://biblioteca.inia.cl/medios/biblioteca/boletines/NR39094.pdf. Recuperado: 10 de junio del 2016

Unidad Editorial Información Económica S.L. (2016). Chile: EI PIB ascendió un 2,3\%.

Obtenido de https://datosmacro.expansion.com/pib/chile?anio=2015. Recuperado: 10 de junio del 2016

Willer, H., \& Lernoud, J. (2015). Current Statistics on Organic Agriculture Worldwide: Organic Area, Producer, Markets and Selected Crops. En FiBL \& IFOAM, The World of Organic Agriculture Stadistics \& Emerging Trends 2015 (págs. 32-118). Switzerland: FiBL \& IFOAM. 
Willer, H., \& Lernoud, J. (2015). The World of Organic Agriculture 2015: Summary. En FiBL \& IFOAM, The World of Organic Agriculture Statistics \& Emerging Trends 2015 (págs. 24-31). Switzerland: FiBL \& IFOAM.

Zheng, P. (2006). Geografía China. Shanghái: China Intercotineal Press.

\section{B. Entrevistas verbales}

Bacco, A. (23 de julio de 2015). Mirada de la exportación desde Argentina de Productos orgánicos. (C. Vivanco, Entrevistador)

Catalán, C. C. (10 de agosto de 2015). Situación de la Agricultura Orgánica en Chile, visión desde SAG. (C. Vivanco, Entrevistador)

Eguillor, P. (7 de septiembre de 2015). Mirada desde el Gobierno Chileno al potencial orgánico del arándano. (C. Vivanco, Entrevistador)

Fischer, S. (15 de octubre de 2015). Producciones orgánicas en Chile, potencial e importancia mirada desde la academia. (C. Vivanco, Entrevistador)

Hang, G. (17 de junio de 2015). Desarrollo rural de los productos orgánicos en Argentina. (C. Vivanco, Entrevistador)

Landa, P. (28 de julio de 2015). La importancia de los productos orgánicos en Argentina y el mundo. Certificaciones y procesos. (C. Vivanco, Entrevistador)

Ferrera, M. (4 de diciembre de 2015). Realidad de exportación de Arándanos Orgánicos en Chile. (C. Vivanco, Entrevistador)

Lo Coco, M. (21 de agosto de 2015). Importancia de los productos orgánicos en Hong Kong y en Asia. (C. Vivanco, Entrevistador)

Montes, L. (31 de julio de 2015). Realidad de Exportación de arándanos orgánicos en Argentina. (C. Vivanco, Entrevistador)

Montenegro, L. (23 de noviembre de 2015). Certificaciones de arándanos orgánicos producidos en Argentina y en Chile. (C. Vivanco, Entrevistador)

Morelli, G. (20 de marzo de 2015). Mirada desde la academia del potencial del arándano orgánico de la Argentina. (C. Vivanco, Entrevistador)

Ramírez, J. C. (17 de julio de 2015). Situación de la Agricultura Orgánica en la Argentina, visión desde SENASA. (C. Vivanco, Entrevistador)

Serri, H. (8 de diciembre de 2015). Arándano orgánico en Chille, plagas y enfermedades. (C. Vivanco, Entrevistador)

Vargas, S. (23 de junio de 2016). El arándano orgánico en Chile, avances en tecnología, producción y calidad. (C. Vivanco, Entrevistador) 


\section{ACLARACIÓN}

Declaro bajo juramento que esta tesis fue elaborada por mí, que no utilicé ningún otro material que no haya dado a conocer en las referencias y que no utilicé frases o párrafos de otros autores y que este trabajo de tesis nunca ha sido presentado ante un comité de evaluación de tesis y que no transgrede derechos de terceros.

Christopher Andrés Vivanco Barra

Ingeniero Agrónomo, Enólogo. 